\title{
AN EYE-TRACKING EVALUATION OF DRIVER DISTRACTION AND ROAD SIGNS
}

\author{
by \\ Stephanie Hurtado \\ A thesis submitted to \\ the Faculty of Graduate and Postdoctoral Affairs \\ in partial fulfillment of \\ the requirements for the degree of \\ MASTER OF SCIENCE \\ School of Computer Science \\ at \\ CARLETON UNIVERSITY
}

Ottawa, Ontario

September, 2015

(C) Copyright by Stephanie Hurtado, 2015 


\begin{abstract}
Driving is a complex task that requires auditory, visual, and tactile attention. It is difficult enough for drivers to handle the increasing number of distractions when they are in a familiar environment, but what happens when drivers are placed in a new environment? If we understood this issue, we could design tools to reduce driving hazards and minimize distractions.

We address this gap by exploring drivers' behaviour when they encounter road signs from different countries. We conducted two eye-tracking studies with 50 participants. Participants' spent increased time looking at unfamiliar road signs. Misinterpretation occurred due to the influence of previous experience and many drivers drove at reduced speeds throughout to compensate for the anticipated cognitive load. We suggest developing context-aware in-vehicle systems that use web mapping services to present drivers with road signage information. Based on our results, we also provide four recommendations to improve driver safety.
\end{abstract}




\section{Acknowledgements}

First and foremost, I would like to thank my supervisor Sonia Chiasson, without whom this thesis would not be what it is today. Your guidance, feedback, and continuous support, has helped me immensely on my journey. For all of this, I am extremely grateful and proud to be your student.

Many thanks to the members of my committee, Audrey Girouard, Hussein Al Osman, and Olga Baysal, for your time and constructive feedback.

To David, for his unwavering love and encouragement throughout my graduate studies. Thank you for believing in me.

Lastly, I would like to thank my family for all their love, enthusiasm, and support. There aren't enough words to describe how much it means to me. A special thanks to my parents, who taught me that I could accomplish anything I set my mind to. 


\section{Table of Contents}

Abstract $\quad$ ii

Acknowledgements $\quad$ iii

List of Tables viii

List of Figures $\quad$ X

$\begin{array}{lll}\text { Chapter } 1 & \text { Introduction } & 1\end{array}$

1.1 Motivation .......................... 1

1.2 Research Question . . . . . . . . . . . . . . . . . 2

1.3 Contribution . . . . . . . . . . . . . . . . . 2

1.3.1 An empirical examination of unfamiliar road signs using a driving simulator and eye tracking software . . . . . . . . . 2

1.3.2 Design recommendations for in-vehicle systems . . . . . . . . . 3

1.4 Thesis Outline . . . . . . . . . . . . . . . . . . . . 3

$\begin{array}{lll}\text { Chapter } 2 & \text { Background } & 4\end{array}$

2.1 Ergonomics . . . . . . . . . . . . . . . . 4

2.2 Human Factors . . . . . . . . . . . . . . . . . . . . . . . . . . . 7

2.3 Driving Distractions . . . . . . . . . . . . . . . . . . . 10

2.4 In-vehicle Interface Systems . . . . . . . . . . . . . . . . 13

2.5 Summary . . . . . . . . . . . . . . . . . 17

$\begin{array}{lll}\text { Chapter } 3 & \text { Prototypes } & 18\end{array}$

3.1 Overview of OpenDS . . . . . . . . . . . . . . . . . 18

3.2 Highway simulation . . . . . . . . . . . . . . . . . 19

3.3 City simulation . . . . . . . . . . . . . . . . 20

3.4 Practice Tracks . . . . . . . . . . . . . . . . . . . . 21 
3.5 Experimental Set-up . . . . . . . . . . . . . . . . . . . . . . . 21

3.6 Road Signs . . . . . . . . . . . . . . . . . . . . . . . 23

$\begin{array}{lll}\text { Chapter } 4 \quad \text { Methodology } & 24\end{array}$

4.1 Goal of the studies . . . . . . . . . . . . . . . . 24

4.2 Study Design . . . . . . . . . . . . . . . . . . . . . 24

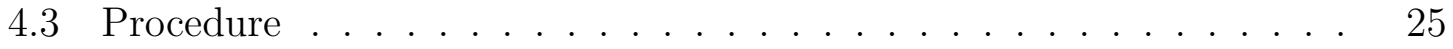

4.4 Data Collection . . . . . . . . . . . . . . . . . . . 27

4.4 .1 Software $\operatorname{Logs} \ldots \ldots \ldots \ldots$. . . . . . . . . . . 27

4.4 .2 Eye Tracking . . . . . . . . . . . . . . . . . . . . 29

4.4 .3 Audio Capture . . . . . . . . . . . . . . . . . . . . . . 29

4.4.4 Questionnaires . . . . . . . . . . . . . 30

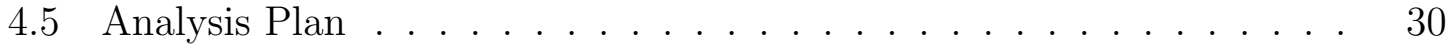

4.6 Participants . . . . . . . . . . . . . . . . . . . . 30

4.6 .1 Highway Study . . . . . . . . . . . . . . . . . . 31

4.6 .2 City Study . . . . . . . . . . . . . . . . . . 31

$\begin{array}{lll}\text { Chapter } 5 & \text { Results } & 35\end{array}$

5.1 Hypotheses . . . . . . . . . . . . . . . . . 35

5.2 Gaze Fixation . . . . . . . . . . . . . . . . . . . . 35

5.2 .1 Highway Study . . . . . . . . . . . . . . . 36

5.2 .2 City Study . . . . . . . . . . . . . . . . . . . . 37

5.2 .3 Summary of Gaze Fixations _ . . . . . . . . . . . . . 39

5.3 Road Sign Identification $\ldots \ldots \ldots$

5.3 .1 Highway Study . . . . . . . . . . . . . . . . . . . . 39

5.3 .2 City Study . . . . . . . . . . . . . . . . . . . . 40

5.3 .3 Summary of Road Sign Identification . . . . . . . . . . . 41

5.4 Lane Deviation . . . . . . . . . . . . . . . . . . . . . . 41

5.4 .1 Highway Study . . . . . . . . . . . . . . . . . . . 42

5.4 .2 City Study . . . . . . . . . . . . . . . . . . . . 44

5.4 .3 Summary of Lane Deviation . . . . . . . . . . . . . 45 


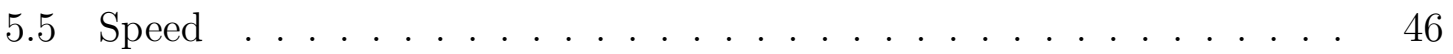

5.5 .1 Highway Study . . . . . . . . . . . . . . . . . . 46

5.5 .2 City Study . . . . . . . . . . . . . . . . . . . . 47

5.5 .3 Summary of Speed . . . . . . . . . . . . . . . . 47

5.6 Perception Questionnaire . . . . . . . . . . . . . . . . . . . . 47

5.6 .1 Highway Study . . . . . . . . . . . . . . . . . . . 48

5.6 .2 City Study . . . . . . . . . . . . . . . . . . . . 51

5.6.3 Summary of Perception Questionnaire . . . . . . . . . 54

5.7 Recognition and Interpretation Questionnaire . . . . . . . . . 54

5.7 .1 Highway Study . . . . . . . . . . . . . . . . . . . . . 54

5.7 .2 City Study . . . . . . . . . . . . . . . . . . 57

5.7.3 Summary of Recognition and Interpretation Questionnaire . . 58

5.8 Effects of unfamiliar road signs on driving performance . . . . . . 58

5.8 .1 Highway Study . . . . . . . . . . . . . . . . . 58

5.8 .2 City Study . . . . . . . . . . . . . . . . . . . . 59

5.8.3 Summary of Effects of unfamiliar road signs on driving performance . . . . . . . . . . . . . . . . . . . 60

5.9 Effects of unfamiliar road signs on gaze fixation $\ldots \ldots \ldots \ldots$

5.9 .1 Highway Study . . . . . . . . . . . . . . . . . . 61

5.9 .2 City Study . . . . . . . . . . . . . . . . . . . . . . . 62

5.9.3 Summary of Effects of unfamiliar road signs on gaze fixation . 62

5.10 Support for Hypotheses . . . . . . . . . . . . . . . . . . . . . 62

$\begin{array}{lll}\text { Chapter } 6 & \text { Discussion and Conclusion } & 64\end{array}$

6.1 Summary of Results . . . . . . . . . . . . . . . . . . . 64

6.2 Recommendations . . . . . . . . . . . . . . . . . . . . . 68

6.2 .1 Design of Road signs . . . . . . . . . . . . . . . . . 68

6.2 .2 Design of In-vehicle Systems … . . . . . . . . . . . . 69

6.3 Limitations . . . . . . . . . . . . . . . . . 70

6.4 Future Work . . . . . . . . . . . . . . . . . . . . . . 71 


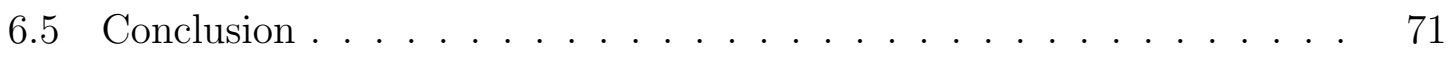

$\begin{array}{ll}\text { Bibliography } & 73\end{array}$

Appendix A Road Signs used for Highway and City studies $\quad 80$

Appendix B $\quad$ Longest Consecutive Gaze Fixation Time Per Sign $\quad 91$

Appendix C Road Sign Recognition Scores $\quad 95$

C.1 Highway Study . . . . . . . . . . . . . . . . . . . . . . . 95

C.2 City Study . . . . . . . . . . . . . . . . . . . . . . . 95

Appendix D Effects of Unfamiliar road signs on speed - Tables 98

Appendix E Effects of Unfamiliar road signs on gaze - Tables 104

$\begin{array}{lll}\text { Appendix F } & \text { Questionnaires } & 109\end{array}$

F.1 Pre-test questionnaire . . . . . . . . . . . . . . . . . . . . . . . . . 109

F.2 Post-test questionnaire . . . . . . . . . . . . . . . . . . . . 113

F.2.1 Highway Study . . . . . . . . . . . . . . . . . . . 113

F.2.2 City Study. . . . . . . . . . . . . . . . . . . . . . 127 


\section{List of Tables}

$3.1 \quad$ Number of road signs per track . . . . . . . . . . . . . 23

$4.1 \quad$ Study Design . . . . . . . . . . . . . . . . . . 25

$4.2 \quad$ Distance $(\mathrm{cm})$ from ideal path $\ldots \ldots \ldots \ldots . \ldots 28$

$4.3 \quad$ Summary of statistical tests conducted . . . . . . . . . 31

5.1 Total gaze fixation time statistics per sign (Highway Study) . . 36

5.2 Total gaze fixation time statistics per sign (City Study) . . . 37

$5.3 \quad$ Zone statistics for each track (Highway Study) . . . . . . . 42

$5.4 \quad$ Zone statistics for each track (City Study) . . . . . . . . . 44

$5.5 \quad$ Summary of average speed (Highway Study) . . . . . . . . 46

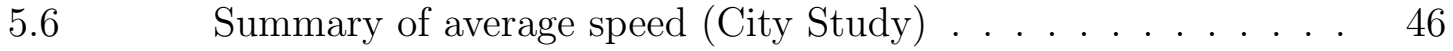

5.7 Likert scale questionnaire responses (Highway Study) . . . . . 48

$5.8 \quad$ Likert scale questionnaire responses (City Study) . . . . . . 51

5.9 Recognition and Identification of signs (Highway Study) . . . 56

$5.10 \quad$ Recognition and Identification of signs (City Study) . . . . 56

B.1 Longest Consecutive Gaze Fixation Time per sign (German Track) 92

B.2 Longest Consecutive Gaze Fixation Time per sign (Canadian

Track) . . . . . . . . . . . . . . . . . . 92

B.3 Longest Consecutive Gaze Fixation Time per sign (Chinese Track) 93

B.4 Longest Consecutive Gaze Fixation Time per sign (German Track) 93

B.5 Longest Consecutive Gaze Fixation Time per sign (Canadian Track) . . . . . . . . . . . . . . . . . . . . 94

B.6 Longest Consecutive Gaze Fixation Time per sign (Chinese Track) 94

D.1 Unfamiliar German road signs (Highway Study) . . . . . . 99

D.2 Unfamiliar Canadian road signs (Highway Study) . . . . . 100

D.3 Unfamiliar Chinese road signs (Highway Study) . . . . . . . 101

D.4 Unfamiliar German road signs (City Study) . . . . . . . . 102 
D.5 Unfamiliar Canadian road signs (City Study) . . . . . . . 102

D.6 Unfamiliar Chinese road signs (City Study) . . . . . . . 103

E.1 Average gazing time for unfamiliar German signs (Highway Study) 105

E.2 Average gazing time for unfamiliar Canadian signs (Highway Study ～. . . . . . . . . . . . . . . . . 105

E.3 Average gazing time for unfamiliar Chinese signs (Highway Study)106 E.4 Average gazing time for unfamiliar German signs (City Study) 107 E.5 Average gazing time for unfamiliar Canadian signs (City Study) 107 E.6 Average gazing time for unfamiliar Chinese signs (City Study) . 108 


\section{List of Figures}

2.1 Stop signs from different countries . . . . . . . . . . . . 10

$2.2 \quad$ Zhang et al.'s nine-panel road $\operatorname{sign} \ldots \ldots \ldots$. . . . . . . . 13

3.1 OpenDS Architecture . . . . . . . . . . . . . . 19

3.2 Driver's seat view of the Highway track . . . . . . . . . 20

3.3 Driver's seat view of the City track . . . . . . . . . . 21

3.4 Driving simulator lab set-up . . . . . . . . . . . . . 22

4.1 First lane demarcation . . . . . . . . . . . . . 27

$4.2 \quad$ Second lane demarcation . . . . . . . . . . . . . . . 27

4.3 Lane deviation example . . . . . . . . . . . . . . . . 29

$4.4 \quad$ Hours Spent Driving per week . . . . . . . . . . . . 32

4.5 Participants' driving habits . . . . . . . . . . . 33

4.6 Driving outside of regular route (pre-test questionnaire responses) 34

5.1 Gaze fixation box plots (Highway Study) . . . . . . . . 36

5.2 Gaze fixation box plots (City Study) . . . . . . . . . . 38

5.3 Results from verbal road sign identification by study . . . . . 40

5.4 Distribution of distance travelled by Zones (Highway Study) . 43

5.5 Distribution of distance travelled by Zones (City Study) . . . 45

5.6 Likert scale responses to perceived track difficulty (Highway Study) . . . . . . . . . . . . . . . . . 49

$5.7 \quad$ Perceived level of road sign distraction (Highway Study) . . . 49

$5.8 \quad$ Perceived ability to obey road signs (Highway Study) . . . . . 50

$5.9 \quad$ Perceived ability to stay in proper lane (Highway Study) . . . 50

$5.10 \quad$ Likert scale responses to perceived track difficulty (City Study) 52

$5.11 \quad$ Perceived level of road sign distraction (City Study) . . . . . . 52

5.12 Perceived ability to obey road signs (City Study) . . . . . . 53

$5.13 \quad$ Perceived ability to stay in proper lane (City Study) . . . . . 53 
$5.14 \quad$ Overall Sign Recognition Scores (Highway Study) . . . . . . . 55

5.15 Overall Sign Recognition Scores (City Study) . . . . . . . 57

C.1 Individual Recognition Scores per track (Highway Study) . . . 96

C.2 Individual Recognition Scores per track (City Study) . . . . . 97 


\section{Chapter 1}

\section{Introduction}

\subsection{Motivation}

Driving is a complex task that requires auditory, visual, and tactile attention from drivers. Since a drivers' environment is constantly changing, it is important for them to use their sensory resources to maintain a good understanding of their immediate environment. The Canadian Automobile Association (CAA) [4] regards distracted driving as anything that takes your attention away from the primary task of driving. With new entertainment features being integrated into vehicles, and a growing use of hand-held devices, drivers are becoming more susceptible to distraction. Reports indicate that use of hand-held devices while driving increases probability of being involved in an accident by a fourfold [65]. Additionally, 29.9\% of the top distractions [3] are external to the vehicle. It is difficult enough for drivers to handle the increasing number of distractions when they are in a familiar environment, but what happens when drivers are placed in a new environment?

The United Nations World Tourism Organization recorded 1087 million international tourist arrivals in 2013 [55], a large number will rent vehicles during their stay. Aty and Radwin [5] found foreign drivers have higher accident rates at intersections with turning manoeuvres. Likewise, a study showed tourists visiting the Greek Island of Crete were 2.5 times more vulnerable to accidents [58].

Road signs are designed to provide critical cues for drivers, regardless of where drivers are from. Consequences of ignoring or misunderstanding these cues can cause drivers to make errors in judgement and increase their risk of accidents. Surprisingly, there is no universally accepted standard for road signs, rather there exists a variety of guidelines set at provincial or state levels. As such, one does not even need to travel overseas to encounter unfamiliar road signs. A recent article published by the Boston Globe [15] showed how confusing some Canadian road signs can be for an 
American driving along the New Brunswick coast.

There is little research looking at drivers in unfamiliar environments. Therefore, we have minimal data to understand drivers' behaviour when they encounter an unfamiliar situation, and how this may contribute to driving distraction. If we understood this issue, then we could design tools to reduce hazards while driving, and minimize distractions such as those external to the vehicle. Therefore, in this thesis, we address this gap by exploring drivers' behaviour when they encounter road signs from different countries.

\subsection{Research Question}

Our main research question for this thesis is:

How do unfamiliar road signs affect drivers' behaviour?

We addressed our research question by developing a driving simulation for two different driving scenarios and road signs from three different countries. We explored the effect of road sign familiarity on other driving attributes such as lane keeping and speed. We also compared drivers' ability to interpret the road signs and how long drivers gazed at the signs as a measure of the level of distraction.

\subsection{Contribution}

The two main contributions of this thesis are summarized in the following sections.

\subsubsection{An empirical examination of unfamiliar road signs using a driving simulator and eye tracking software}

We conducted two user studies, using an open source driving simulator and eye track-

ing software. We provide empirical results from 50 participants, in which we tested their driving performance to evaluate their reaction when encountering unfamiliar road signs. We found that unfamiliar road signs result in longer gaze fixation times. Furthermore, misinterpretation of signs can occur due to the influence of previous 
driving experience and local driving practices. This can lead to drivers making errors in judgement, putting them at risk for accidents. Complex road sign symbols contribute to longer gaze fixation times and poor sign recognition accuracy.

\subsubsection{Design recommendations for in-vehicle systems}

From our findings, we propose four recommendations: the design of road signs should be simplistic, road signs should be internationally standardized; in-vehicle systems should be used as context-aware interpreters and in-vehicle systems should leverage web mapping services. These recommendations are based on our findings and previous literature.

\subsection{Thesis Outline}

This thesis consists of six chapters. In the second chapter, we provide a literature review of road sign design and in-vehicle computer interfaces, with a focus on driving distraction. In chapter three, we present the design of our driving simulator and experimental set-up. In chapter four, we describe the methodology used for the studies, including data collection tools, and participants. In chapter five, we present the results of each study. Finally in chapter six, we present a discussion of the results from our studies and our recommendations. We also present future work and the conclusion of the thesis. 


\section{Chapter 2}

\section{Background}

Drivers dynamically maintain an understanding of their immediate environment. This includes vehicle speed, neighbouring vehicles, pedestrians, landmarks, GPS/consoles and road signs. All of these items contribute to a driver's situation awareness (SA) which facilitates decision making. Previous researchers have focused on developing models to understand how dynamic decisions are made in high-complex situations such as driving [23]. Likewise, there have been many investigations into the consequences and failures that arise from an incorrectly formed situation awareness model $[24,29]$. In this chapter, we examine how road signs and driver behaviour contribute to a situation awareness model. We describe related concepts and literature. We investigate the challenges ergonomic design experts face when developing road signs. We consider the Human Factors perspective on the understanding of road signs, and the implications of driver distractions.

\section{$2.1 \quad$ Ergonomics}

Drivers need an understanding of the upcoming changes to their immediate environment and road signs provide a visual way to communicate such changes to drivers. When understood properly, road signs allow for effective decision making. A sub-field of Ergonomics considers the design of signs highly important and has extensively studied sign design features $[11,22,56]$ such as colour, size, and placement. Ng and Chan [52] categorized these features as "visual" and included cognitive features to improve the development of user friendly icons. Cognitive features include: familiarity, concreteness, complexity, meaningfulness, and semantic distance. Both visual and cognitive features must be considered in road sign design.

A variety of organizations, such as the American National Standard Institute (ANSI) [34], define road sign standards. For example, standards define that particular 
colours are associated with specific warnings; Red is used to convey danger, Orange for warning, and Yellow for caution. Leonard [41] conducted four experiments to investigate whether the standard warning colours are effective in capturing people's attention and conveying the correct level of risk. Participants were asked to rate either colours, words, or a combination of both in terms of severity. Results revealed that while red was consistently ranked as most severe. Orange was ranked less than yellow which does not align with ANSI standards. Ng and Chan [52] also found red conveys the most serious warnings in other cultures (e.g., Chinese, Spanish). In road traffic, we see the use of these colours, but at times they may communicate different meanings. For example, red may tell the driver to stop (e.g., traffic light or stop sign), that an action is prohibited, or to alert the driver (e.g., yield). Therefore relying on colours alone is insufficient enough to convey risk.

Dewar [18] stresses the importance of proper placement and legibility distance of road signs as a criteria for traffic safety. He states that unsatisfactory signage to inform drivers of a hazard leads to the most common type of highway accident litigation cases. According to the Canadian Ministry of Transportation [69], the distance between a road sign and the point in which it applies depends on the posted speed limit. Additionally, approximately 2.5 seconds is sufficient time for perceptionreaction time [31]. Dewar argues against this by pointing out that previous studies, such as Hooper and McGee [33], have shown that a minimum of 3.5 seconds is needed for a proper reaction-time, suggesting a discord within the risk and safety community.

Even though traffic design manuals provide requirements for road sign design and placement the design criteria remains vague. Take as an example the road sign requirements outlined by British Colombia's Ministry of Transportation [69]:

To be effective a sign should:

- Fulfill a need

- Command attention and respect

- Convey a clear and simple message

- Allow adequate time for a proper response

This definition is rather vague; for example, it does not specify that a road sign's 
message must be understood by everyone. The ambiguity allows for inconsistencies to occur when designing a sign.

Although there have been international attempts to standardize traffic signs and regulations. Many studies have found that a large portion of drivers have no understanding of road signs' meaning. For example, David Shinar et al. [63] conducted an investigation to see how well traffic signs were understood cross-culturally. This included showing participants road signs from their country (i.e., where their driving license was issued) and internationally. Unsurprisingly, comprehension scores for nonlocal signs were low. Furthermore, a significant percentage of drivers interpreted road signs to mean the complete opposite of their actual meaning. This could lead to a potential driving accident as drivers will fail to react properly if a decision needs to be made. This study did not reveal a difference between the level of driving experience and road sign comprehension.

To improve the usability of road signs, Shinar recommends ensuring: spatial compatibility, conceptual compatibility, physical representation, familiarity, and standardization. If we recall, $\mathrm{Ng}$ and Chan [16] suggested a similar criteria, defined as cognitive features. Other studies have also suggested incorporating similar features, however, including familiarity is difficult because it can vary greatly between people.

In cases where a good symbolic representation cannot be found, Shinar suggests using a textual representation, although other studies have argued against this [56,71]. Viaganò and Rovida [71] argue that text added below a pictorial based road sign is not effective because it takes longer to read and most often cannot be understood by foreigners. They propose replacing text with semantic symbols as a way to improve cross-cultural comprehension. Text on road signs uses common prepositions and complements symbols to convey meaning. Therefore reducing it to a verb or object could allow for a uniform pictorial representation. Whether this can be considered a valid alternative has yet to be determined as no user studies have been conducted to test this method.

While the majority of studies measure participants' comprehension by rating their interpretation of road signs, Shinar [64] goes further, by measuring participants' speed 
of comprehension in addition to accuracy. His within-subject design presents participants with either a symbol sign, a text sign, or a symbol-text sign. Results revealed that text signs yielded quicker reaction times and better comprehension, whereas symbolic signs were better understood only if it was familiar to the driver. The author highlights the advantages of combining symbol and text signs. For one, they can be seen from further away, and drivers can learn to associate the symbol with the text. Lastly, the use of symbol-text signs does not increase comprehension time according to the results from the author's study.

A consensus among these studies indicates that road signs are better understood the more they follow the ergonomic principles identified by experts such as $\mathrm{Ng}$ and Chin and Shinar. This is made further evident in Ben-Bassat's [8] study where drivers and ergonomic experts were asked to explain the meaning of signs in terms of ergonomic principles: sign-content compatibility, familiarity, and standardization. Responses from both groups were compared in an attempt to find a correlation between sign comprehension and adherence to ergonomic principles. Results showed that familiarity had a significant influence on comprehension. Furthermore, the author found evaluations from drivers and experts lead to the same conclusions, subsequently confirming that a road signs with higher comprehension scores adhered closer to ergonomic principles.

\subsection{Human Factors}

While Human Factors and Ergonomics are often defined synonymously [25], we have intentionally focused on the Ergonomics literature concerned with the design of functional and user-friendly systems. We move forward with addressing the Human Factors side which accounts for understanding the behaviour within interactions. Specifically, we focus on how road signs and regulations affect drivers' behaviour.

Al-Madani et al. [1] investigated the influence of drivers' personal characteristics on their understanding of road signs. Questionnaires were distributed among different occupation sectors based on the percentage of people employed in each sector. The questions were divided into two sections, the first identified personal and socioeconomical characteristics, and the second tested drivers' understanding of traffic 
signs. Results showed that male drivers comprehend traffic signs better than females. However, this finding may not be generalizable since samples were taken from the Arab states of the Persian Gulf which have a low percentage of female drivers due to social constraints. Marital status did not influence traffic sign comprehension and, in general, a higher education and income resulted in better sign comprehension. Furthermore, it was found that novice drivers understand signs less than experienced drivers which confirms the author's initial assumption, although driving experience had no influence on comprehension for people who first received their license at the age of 45 or older.

Driving practices also influence how drivers comprehend traffic signs. Summala [67] looked at how American drivers without European driving experience interpreted uncontrolled intersections. Although this study observed only 3 subjects, the findings highlight an important observation: driving behaviour is influenced by local driving practices, immediate surroundings, and general rules. These factors can, at times, conflict with each other, like drivers' adopted practices and local traffic rules, which may leave drivers susceptible to greater driving risks. Informing drivers of local rules can change their adopted practices and thus the way they observe their surroundings. As Summala noticed, after subjects were told the rules for uncontrolled intersections, subjects changed their visual scanning pattern and decreased their speed when approaching subsequent intersections. Borowsky [10] reported a similar finding, where experienced drivers were less likely to notice important road signs when in an unfamiliar place; this "selective looking" behaviour is influenced once again by adopted practices.

Opposite to Summala, Dissanayake et al. [19] investigated transportation needs and highway safety issues of tourists driving in the United States as compared to local U.S. drivers. Findings from their survey show the understanding of traffic signs, pavement markings, and traffic signals were significantly lower for tourists. Certain symbol-only road signs were found to be difficult to interpret by tourists. A common concerned raised by tourists was the lack of advance notice signs about upcoming traffic events. Ward et al. [72] conducted a study to test American drivers' comprehension of international road signs before and after a training session. The study 
used a between-subject design that presented two participant groups with 50 road signs each. Comprehension levels were evaluated based on the American National Standard Institute (ANSI) Z535.3¹ guidelines. Results showed that prior to training, $60 \%$ of U.S drivers provided incorrect responses to signs, and only 17 signs met ANSI standards. It was found that many participants thought an open red circle road sign meant an action was permitted (with respect to the symbol displayed within the red circle), however, a red circle actually prohibits an action. This highlights differences in road sign design, where in the United States and Canada, prohibited actions are denoted with a slash. Ward's study re-tested participants after training and found that $85 \%$ of participants correctly comprehended the road signs presented. Ward recommends a design improvement for road signs or educational training where there is a lack of design. To address the latter recommendation, Dissanayke [19] suggests rental car locations and hotels would be ideal places for educating foreign drivers about local road signs and traffic regulations.

Educating every tourist when they arrive to a different country is not a realistic option. Road signs need to be designed in a clear and accurate manner, which should be understood by every driver, foreign or local. A well designed road sign should be able to trigger a person's recollection from previous driving experiences such that they will carry out actions conditioned by previous experiences. Bazire [6] refers to this as tactile mental representations. Brézillon et al. [12] discuss how a user-friendly road sign can prompt the appropriate behaviour when perceived by drivers. They claim that the meaning of road signs is interpreted from the environmental context of the driving task, and the context of the current situation. More driving experience leads to more practical knowledge of road signs rather than relying only on theoretical knowledge; after years of driving, the legal meaning of a road sign is lost to practical experience.

To reduce the risk of driving in an unfamiliar environment, we should design traffic signs in a manner that invokes the correct driving practices gained throughout drivers' years of experience. This tactile mental representation will be accompanied by conditioned actions that allow drivers to react appropriately to the task at hand.

\footnotetext{
${ }^{1}$ ANSI standard considers symbols with a $5 \%$ or greater confusion rate, an unacceptable standalone safety sign.
} 


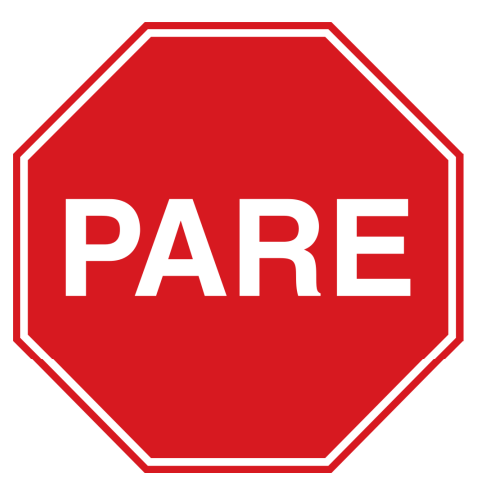

(a) Argentina

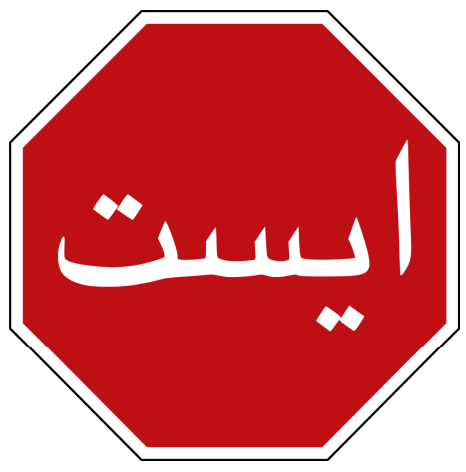

(b) Iran

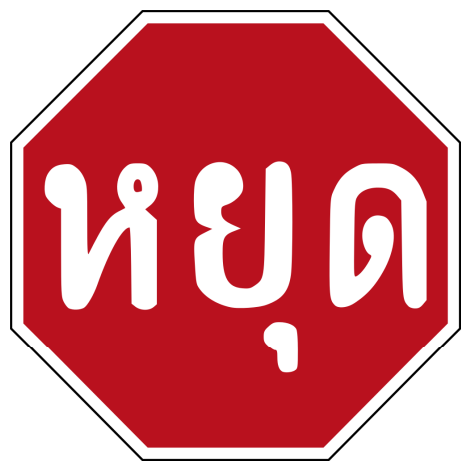

(c) Thailand

Figure 2.1: Stop signs from different countries

An excellent representation of this is the design of a red octagon to denote a stop sign. While the word 'Stop' may differ among countries, the shape and colour remain the same ${ }^{2}$ (See figure 2.1). With this road sign, foreign drivers may not recognize the words within the sign but with the aid of environmental context and driving experience, they will recognize the road sign by its colour and shape, thus their driving behaviour will be to bring their vehicle come to a complete stop (a conditioned action). In the same manner, this design method can be extended to vehicle user interfaces, or advanced driver assistance systems.

\subsection{Driving Distractions}

Driving distraction is characterized by any secondary activity that takes attention away from the primary task of driving. The U.S National Highway Traffic Safety Administration (NHTSA) [53] reported that in 2013 alone, 3154 people were killed in distracted driving accidents. The increase in numbers have been attributed (in-part) to an increasing use of mobile phones and growing number of in-car entertainment features. This risk to road safety has been studied by different organizations (e.g., academia, industry, government) which aim to understand drivers' susceptibility, the level of risk, and countermeasures to the problem.

In understanding why distraction occurs, studies have identified Change Blindness and Inattentional blindness as two major perceptual errors affecting driver distraction

\footnotetext{
${ }^{2}$ Exceptions include Japan, and Zimbabwe.
} 
$[17,27,39]$. Change blindness is a failure to see events such as when a driver fails to check their blind spot [60]. Inattentional blindness occurs when an event was observed but the driver failed to process its significance [42]. Habituation is an example of inattentional blindness, where a new road sign added to a driver's regular route may cause them to completely miss the sign. Given that a driver's surroundings are constantly changing as they are in movement, they can be especially susceptible to these perceptual errors.

Mancero et al. [44] highlighted similarities among studies that examined perceptual errors. They noted that the more relevant and meaningful a change was, the more likely participants would notice. They stress the importance of exploring different mediums to alert drivers of changes, especially the often-missed changes situated outside a driver's central line of vision. Wikens and Horrey [73] considered how drivers visually scan their environment, and the type of perceptual error that results from the location of an event change in relation to the driver's line of sight. They categorize events that occur outside of the driver's line of sight as change blindness errors.

With the understanding of perceptual errors that occur when a driver becomes distracted and events they are likely to miss, we can now examine the sort of activities that drivers choose to engage in, and the level of distraction it can cause. Stutts et al. [66] investigated the frequency of drivers engaging in distracting behaviours. During a three-hour session, 70 subjects were recorded using a video camera mounted on the driver's dashboard. Results from this study showed drivers spent $16.1 \%$ of their time (total driving time) engaging in some type of potentially distracting activity (e.g., manipulating vehicle controls, eating/drinking, grooming, reading/writing, using a cell phone, smoking). Engaging in an activity also resulted in an higher tendency to direct their eyes towards the inside of their vehicle, and a higher percentage of drivers having no hands on the steering wheel (while vehicle was in movement). It is important to note that the paper evaluates activities when the drivers' vehicle was moving and when it was stopped. The results show that drivers choose to engage in certain activities when they were stopped. This suggests that drivers in some manner assess the level of risk that engaging in certain activities might have on their driving performance. 
This issue was considered by Titchener et al. [68] who attempted to understand the judgement of risk that drivers make about deciding to engage in distracting activities. In terms of driving habits, distraction affected drivers' visual scanning pattern, with less time spent looking in their peripheral view. Checking in-car instruments (e.g., speedometer) occurred significantly less, with some subjects not checking at all. These changes were also evident during hands-free tasks. The study also showed that when deciding to engage in an activity, the following factors significantly affected drivers' perception of risk judgement: the probability of a crash, the nature of the distraction, the mental concentration required, the location of the distraction (internal or external to the vehicle), and the physical demands of the distraction.

Although the studies examined thus far have focus primarily on internal distractions, drivers may also become distracted by events external to their vehicle. Metz and Krüger [50] conducted a study to test German regulations which allowed the use of supplementary signs ${ }^{3}$. The goal of this study was to see if supplementary signs caused a distraction for drivers looking for directional information. Their assumption was that it makes it harder for drivers to read directional signs properly since they require more time to look at the sign thus increasing their reaction time. The results contradicted the paper's assumption. It showed that participants who looked for a specific destination did not pay attention to the supplementary information thus it was concluded that supplementary signs do not cause distraction on drivers searching for directional information. Similarly, Dukic et al. [21] measured the effects of electronic billboards on driver attention and found that although subjects had gazed at electronic billboards longer, results were inconclusive.

Zhang et al. [74] used a different approach to examine the implications of new roadside signage. Their concern was that signs with more information might increase visual distraction. To test this, they used a high fidelity driving simulator and headmounted eye tracker to compare driving performance and driver gaze fixation. Zhang et al. [74] tested highway road signs with varying number of logo panels (see Figure 2.2). Results revealed that while the nine-panel signs captured participants' attention longer and resulted in a slower average speed, the changes were small and statistically

\footnotetext{
${ }^{3}$ Installed below direction signs to indicate services offered at rest stops.
} 


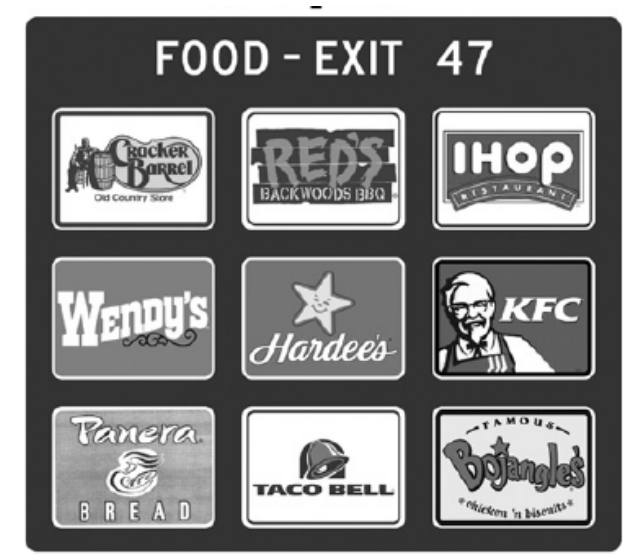

Figure 2.2: Zhang et al.'s [74] nine-panel road sign

insignificant. Their findings align with those of Metz and Krüger [50] and Dukic et al. [21]. Driving distraction is a major concern affecting road safety.

Studies have shown that distractions can occur internally and externally to a driver's vehicle. While external factors cause a distraction, road signs and roadside advertisements may not affect drivers' attention enough to become hazardous. If placed in a visually cluttered environment or if they are highly salient, drivers may pay attention to the signs for a longer period of time which can take focus away from important relevant stimuli and possibly contribute to an increase in road risk when a hazard event is present.

\subsection{In-vehicle Interface Systems}

To help address and minimize drivers' susceptibility to distractions, recent work has looked to new and existing car technology to deliver information safely to drivers $[28$, 57,70]. Advanced Driver Assistance Systems (ADAS) are designed with the intention to automate and enhance safety while driving. Concepts include: adaptive cruise control, pedestrian detection, vehicular communication, and blind spot detectors. Brookhuis et al. [13] review the benefits and challenges of ADAS. They state that implementations of ADAS can enhance drivers' safety and efficiency by providing real-time warnings, alerts, and instructions to drivers. Heinzman et al. [32] present a 
case study to help recognize fatigue and distraction ${ }^{4}$ using video and image processing. The ADAS would send alerts to drivers using audio and vibration. ADAS can either act as a support for drivers, or it could act autonomously.

Brookhuis et al. point out that although these systems are meant to aid drivers they, it can also leave drivers vulnerable to more distraction and safety risks. They advise that complexity can increase the likelihood of failure either from the systems' components, or from the driver. The latter failure can be caused by an overcrowded interface that requires drivers to place more attention on the interface in order to execute an ADAS feature. Likewise, Brooks and Rakotonirainy [14] examine current literature on the effects of ADAS and in-vehicle technologies on driver distraction. They claim that these technologies require manual data entry or visual attention from the driver which can cause them to take their attention away from driving. Speechbased interfaces are a suggested alternative because they do not interfere with drivers' visual or tactile senses. However speech-based interfaces can still cause distraction at the cognitive level. A study by Lee et al. [40] show how the demands of speech-based interfaces on cognitive resources can increase reaction time by $30 \%$.

Further research has examined the implementation of multimodal interfaces as a way to minimize risk. Politis et al. [59] use three sets of modalities; audio, visual, and tactile to convey different levels of urgency to drivers. Their intention was to determine whether these modalities could be recognized accurately by drivers, consequently improving their reaction to different driving scenarios. Their within-subject study consisted of two experiments. The first, obtained participants' initial perception of the level of urgency and annoyance for each of the signals presented. The signals were combinations of the three modalities. Results showed that participants were able to correctly correspond the signals with their proper level of urgency without previous knowledge of the criteria for each level. The second experiment expanded on the first by having participants identify the level of urgency while in a driving simulation. Results concluded that using a combination of all three modalities was perceived as most urgent, while the tactile-visual signal was rated second. High urgency signals produced quicker response rates in comparison to lower urgency levels.

\footnotetext{
${ }^{4}$ The study focused on truck drivers as case subjects
} 
The authors stress the importance of not overloading drivers with warning signals, especially for low urgency situations as they can cause annoyance in drivers. If this occurs, drivers are more likely to ignore or disable this feature entirely.

To gain a better understanding of the usability of in-vehicle warning systems, Maltz and Shinar [43] conducted a study that alerted drivers if they were driving too close to a lead vehicle. Five alert types were used: visual, auditory tone, auditory speech, visual and tone, visual and speech. The study also included false alerts given to represent a system malfunction and to compare driving performance between both types of alerts. Results showed that prior to being exposed to alerts, $12 \%$ of drivers had less than a 2-second headway from the lead vehicle. When alerted, $5 \%$ of drivers decreased their speed providing a larger headway space. Findings show that the auditory speech interface was relied on most by participants compared to the multimodal interfaces. Interestingly, women heeded the warning by slowing down more often than men although no explanation was provided for this finding. Results also showed that drivers were able to accurately distinguish between valid and false alerts $86 \%$ of the time. However, drivers made more errors when receiving a large number of false alerts. This study states that over-reliance on alerts can cause complacency, which they deem not to be hazardous if drivers lightly decelerate. However, it cannot be entirely overlooked. Since drivers were not given the option to disable alerts, their effect between false alerts and driver acceptance was not measured.

Donmez et al. [20] discuss different types of feedback and their advantages for improving drivers' behaviour. They are specifically looking at distracting behaviour. They introduce a timescale feedback taxonomy for mitigating distractions where feedback is given at different times. For example, they discuss when to provide drivers with immediate, delayed, retrospective, and cumulative feedback to improve both long and short term behaviour. A possible problem with this method is that drivers could become habituated to certain feedback which they may later ignore, or as seen Maltz and Shinar [43], drivers may become over-reliant. Feedback reliability could also influence a drivers' behaviour because they may not be willing to accept or trust the feedback provided. This insight further supports the importance of not overwhelming drivers with warnings or alerts. It is clear that this can create opposite intentions 
by reducing driver acceptance, and, at worst, annoyed drivers will be more likely to disable the feedback, rendering the ADAS completely ineffective. With this in mind, developing context-aware systems that can provide warnings or alerts to drivers at high-risk or high-critical times would minimize the number of warnings necessary.

Kennington et al. [36] developed a speech generation system which mimics human passenger conversations. The idea is for this system to recognize situations that require a driver's complete attention. When this occurs, the system will stop its speech delivery and allow drivers to be fully attentive to the driving task, similar to how human passengers choose to interrupt conversation when they deem a situation requires more attention from the driver. The system was tested using a driving simulator with defined "dangerous situations" (e.g., changing lanes). Drivers' attention to the speech system was measured with a short memory-task. Results indicate an improvement in primary driving task, and memory recall tasks. This strategy can be considered when designing navigation systems and in-vehicle infotainment features.

Continuing with context-aware navigation systems, Münter et al. [51] conducted a study to understand what situation-aware support features are considered important to drivers. Results show that $73 \%$ of participants consider traffic conditions, and $63 \%$ consider spatial knowledge, as the top two necessary features for context-aware systems. Weather and sense of direction were also considered important. This study suggests that navigation systems be implemented using a rule-based approach. For example, in familiar environments, support should be minimized and present drivers only with main road sections. Drivers who identify as having a poor sense of direction will require additional support on unfamiliar routes.

ADAS with context-aware functionality can cater to participants' driving situation by providing support in terms of presenting information, sending sensory alerts, or interrupting data presentation at critical times for drivers. This flexibility should not only improve usability, but also improve driver acceptability and reliance. 


\subsection{Summary}

The literature suggests that the design of systems, whether it be road signs or invehicle systems, requires a minimalistic approach. Road sign symbols should not be complex, but rather clear enough to be understood universally among all drivers. This includes foreign, local, novice, and experienced drivers. Likewise, Advanced Driver Assisted Systems should be designed in a way that adapts to the needs of all drivers. Providing support, through information, or warnings, helps to minimize driving risk. When a design fails, such as with a complex road sign symbol or an overcrowded interface, it can draw drivers' attention away from the main driving task. This can decrease drivers' situational awareness, which hinders their abilities to react and make efficient decisions while driving. Likewise, overwhelming a driver with information can have similar effects and reduce not only the usability of the system, but user acceptance as well. While we recognize that drivers may intentionally engage in distracting behaviour, we can use in-vehicle systems and feedback to help them drive safely.

With this awareness, we look to improve on context-aware systems by understanding how drivers behave in unfamiliar situations. Specifically, we examine road signs which can be used by Advanced Driver Assistance Systems to provide informational support for drivers. To our knowledge, using a driving simulator to assess driver distraction when faced with unfamiliar road signs has not been tested. Therefore, we use this approach as a starting point for our investigation. 


\section{Chapter 3}

\section{Prototypes}

To investigate driver distraction and road sign identification, we designed a highway driving simulated track and a city driving simulated track. In this section, we describe these prototypes.

\subsection{Overview of OpenDS}

We designed the driving tracks using OpenDS version 2.5 [45]. OpenDS is a Java-

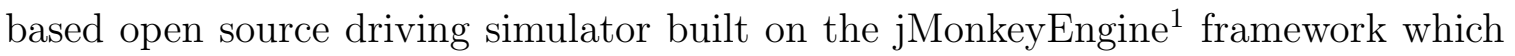
simulates realistic acceleration, friction forces, and audio (i.e., horn, engine noise, collision sounds). Figure 3.1 illustrates the different modules of OpenDS [62]. The integration of the Nifty GUI ${ }^{2}$ toolkit facilitates the development of independent graphical user interfaces which can be rendered within the simulator.

OpenDS allows for the configuration of car properties and events which are simulated as the car drives within the map model. Events can be triggered under conditions (e.g., vehicle position, reaction measurements, visibility of triggers, or weather events) specified in the driving task configuration files. Triggers are objects (visible or invisible) that can be placed at any position on the model map. When a car collides with the trigger, it will cause the event defined in the configuration files to execute. Moreover, multiple camera views can be enabled, such as: top-down view, driver's seat view, or follower view. OpenDS also allows for configuration of engine and transmission types. For example, we can define the maximum and minimum speed, RPM when idle, cruise control, and automatic or standard transmission. 3D map models can be imported into OpenDS to use as custom sceneries. Currently, OpenDS uses

\footnotetext{
${ }^{1}$ http://jmonkeyengine.org/

${ }^{2}$ http://void256.github.io/nifty-gui/
} 


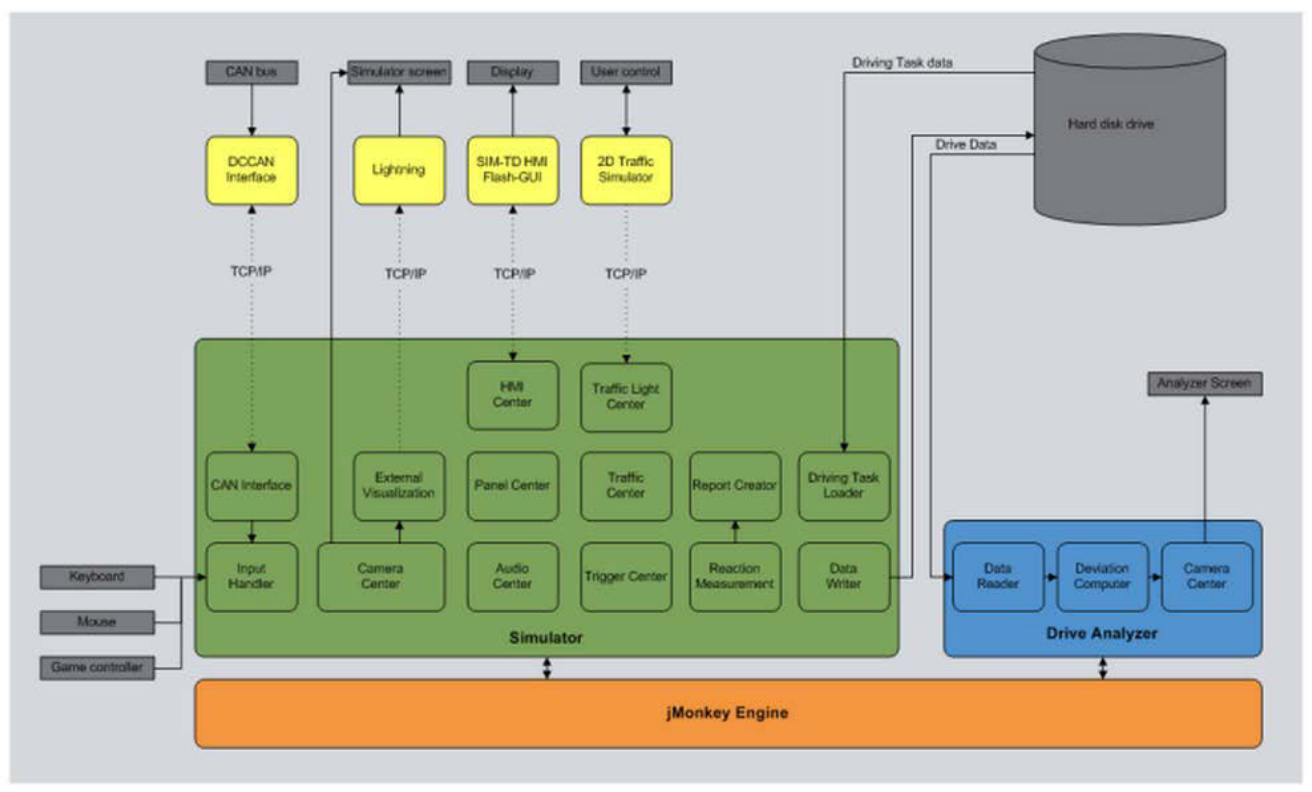

Figure 3.1: Overview of the OpenDS Architecture 3.1

CityEngine $^{3}$ and OpenStreetMap ${ }^{4}$ to generate their map models.

Vehicle data can be recorded (e.g., speed, direction, or pedal state) for analysis with the OpenDS "driver analyzer" tool. This enables experimenters to visualize data from a previous driving experiment and calculate driving deviation. OpenDS has been commonly used to measure drivers' reaction-times and behaviour (e.g., attention, workload) $[30,38,61]$. It has been used as an effective tool to measure the usability of different multi-modal interfaces $[37,47]$, and to evaluate collaborative driving $[7,46]$.

\subsection{Highway simulation}

We used a pre-configured map which modelled roads on an open hilly terrain. This was chosen as a basis for our highway simulation because of its wide road design and closed circuit track which allows users to drive at higher speeds for longer durations. Furthermore, a driver would encounter other vehicles as traffic on the road. Each of these traffic vehicle's route was specified as a list of waypoints. Speed and distance between two traffic vehicles were also defined. This allows for typical traffic related

\footnotetext{
${ }^{3}$ http://www.esri.com/software/cityengine

${ }^{4}$ http://www.openstreetmap.org/
} 




Figure 3.2: Driver's seat view of the Highway track

driving situations (e.g., passing cars, following) which increases realism and means drivers must also avoid collisions. Figure 3.2 shows a driver's seat view of the track. This simulation model was used for the three highway tracks tested in the first user study. The property files were modified to include road sign models that appear alongside the road. Each road sign model was added as an XML attribute within the property files. The attributes specified the repository of the road sign texture, rotation, translation, and entry position of the image. Furthermore, we mapped key functionality between the simulator and driver interface (i.e., brake pedal, accelerator pedal, steering wheel, horn, signal lights), and adjusted pedal and steering sensitivity settings for each track.

\subsection{City simulation}

We used a pre-configured map which modelled European-like roads within a city. This was chosen as a basis for our city simulation because it contained cross walk markers and a roundabout road. The urban layout would require drivers to make more turns and stops, as well as navigate road traffic. This creates a greater cognitive workload than on the highway track. This simulation model was used for the three tracks tested in the second user study. Figure 3.3 shows a driver's seat view of the track. The property files were modified to include road sign models that appear alongside the road. Pedal and steering sensitivity was adjusted for this study. 


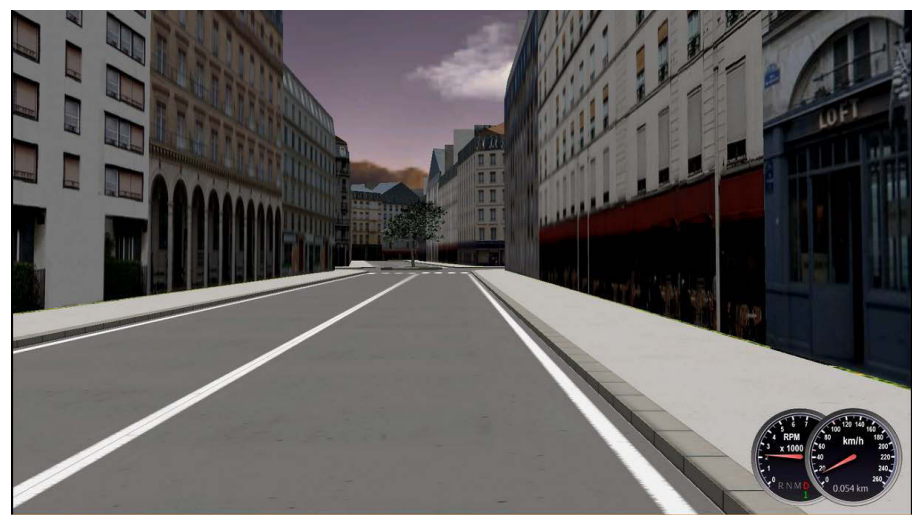

Figure 3.3: Driver's seat view of the City track

\subsection{Practice Tracks}

We used two separate tracks as driving practice for participants before they were introduced to either the Highway or City simulation. Participants were not given navigational directions but were allowed to drive freely around the practice tracks.

The highway practice track was a pre-configured map which modelled dirt roads on an open hilly terrain. We chose to have participants practice on this track since it resembled the same terrain as that in the Highway simulation but did not expose them to the exact tracks that participants would have to drive. This also prevented participants from becoming habituated to the tracks.

The city practice track used the same pre-configured map as the City simulation, however, no modifications were made to this track (i.e., no traffic, no road signs). This track allowed drivers to practice on European-like roads they would encounter in the City simulation.

\subsection{Experimental Set-up}

Participants used a Logitech G27 steering wheel and foot pedals to control their vehicle. The driver interface was connected to a laptop running OpenDS software. For the simulator to recognize the driver interface, controls were assigned to OpenDS's driving functionality. Control of the steering wheel and the pedal sensitivity were adjusted during pilot testing to provide more realistic feedback to drivers. The laptop was a MacBook Pro running OS X Yosemite with Intel Iris Graphics 6100. A 55-inch 


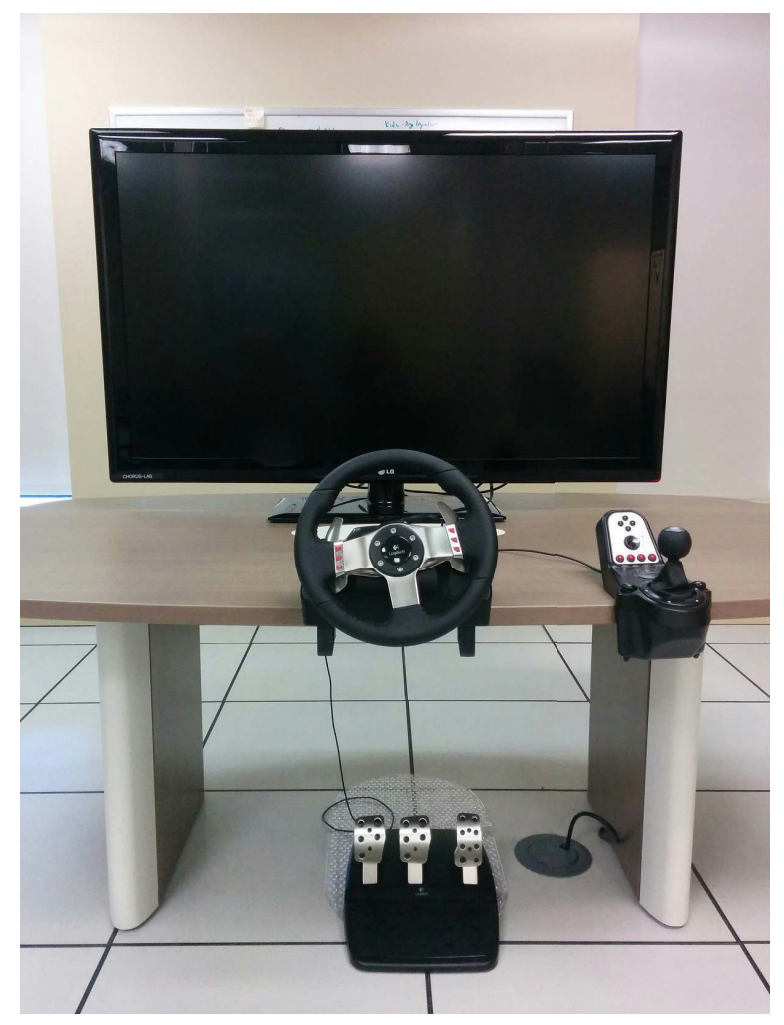

Figure 3.4: Driving simulator lab set-up

monitor centred with the driver interface was used to display the simulation, as shown in Figure 3.4. Participants sat approximately $70 \mathrm{~cm}$ from the monitor. To capture eye gaze movements, we used SMI's iViewETG [35] system, a glasses-type eye tracker device with integrated audio recording. To get an accurate eye gaze reading, the SMI device required a 3-point calibration for every participant. This allowed the system to create an internal eye model that best fit participants' eye physiognomy.

The source code for each track was modified to have road signs placed along the side of the road. Distance between road signs was calculated based on Ontario's Traffic Sign Design Principles [31], where spacing for signs is derived from the driving speed. In our tracks, we considered the maximum speed limit as our base speed therefore signs were placed approximately 50 metres apart for speeds of $60 \mathrm{~km} / \mathrm{h}$ or less, and 75 metres for speeds greater than $70 \mathrm{~km} / \mathrm{h}$. Both layouts were encountered in the Highway study whereas spacing was kept at 50 metres in the City study because of the fixed $50 \mathrm{~km} / \mathrm{h}$ speed limit throughout the track. The number of road signs found on each track is specified in Table 3.1. 


\begin{tabular}{|l|l|l|l|}
\hline \multicolumn{4}{|c|}{ Number of road signs per track } \\
\hline & Canada & China & Germany \\
\hline Highway study & 25 & 25 & 25 \\
\hline City study & 19 & 19 & 19 \\
\hline
\end{tabular}

Table 3.1: Number of road signs per track

For the highway study, each track was $1.6 \mathrm{~km}$ long, had a maximum of two intersections, and took approximately five minutes to complete. In the City study, each track was $1.0 \mathrm{~km}$ long, had a maximum of seven intersections (including a roundabout), and took approximately five minutes to complete. In both studies, the starting position of each of the three tracks was changed to minimize user habituation. An ideal driving path was defined in the simulator's schema files which was used for analysis (see Data Collection, Section 4.5).

\subsection{Road Signs}

The signs placed along each track can be found in Appendix A. The majority of the road signs were used in both studies in order to see differences in sign recognition accuracy between highway and city conditions. Some variation was necessary based on their pertinence to each track. For example, participants encountered a pedestrian cross-walk sign on the city track but not on the highway track. Text-only signs were avoided to ensure participants who were familiar with the language of the sign did not have a significant advantage over other participants however, 2 text signs on the Chinese track (stop, and slow down sign) were used because there was no symbol based alternative. The Chinese stop sign followed the same shape and colour conventions as its equivalent Canadian and German sign, so we felt that participants could recognize and interpret its meaning despite the Chinese symbol being used. This also applied to the Chinese slow down road sign.

The dimensions of the road signs were 1024 x 1024 pixels. The signs were located along the roadside of each track, in positions normally encountered in real life. 


\section{Chapter 4}

\section{Methodology}

\subsection{Goal of the studies}

The goal of our user studies was to assess driver distraction as evidenced by driving performance when faced with road signs from different countries. We conducted two studies, one in a highway setting and the other simulating city driving. The following sections describe the methodology followed in both studies. The study design, including participants, procedure, and data collection tools are discussed.

\subsection{Study Design}

As illustrated in Table 4.1, each participant completed either the Highway or City study. For each study, we used a within-subjects design where each participant drove three tracks. Presentation order of the tracks was determined with a Latin square ${ }^{1}$. Each track contained road signs from one of three countries: Canada, China, and Germany. We chose these countries for both studies because according to the United Nations World Tourism Organization, they represent the top three regions of the world with the highest number of tourists per year [54]. Since participants were recruited from within Canada, they would be most familiar with Canadian road signs, thus Canada was chosen to represent North American road signs. Germany was chosen as the European representative, because of its participation in the 1968 Vienna Convention [26] where European countries signed a treaty that standardized traffic regulations. Lastly, China was chosen because it was the highest ranked tourist destination in the Asia and Pacific region with 55.7 million tourists in 2013 [55].

Participants drove all three tracks then answered a questionnaire corresponding to

\footnotetext{
${ }^{1}$ The order of the tracks is assigned randomly using a $3 \times 3$ table. Each track appears once per row and once per column, ensuring that no ordering effects impact the outcome of the studies. Participants are sequentially assigned a presentation order from one row in the table
} 


\begin{tabular}{|c|c|c|}
\hline Study & Tracks & Number of Participants \\
\hline Highway study & Canada China Germany & 25 \\
\hline City study & Canada China Germany & 25 \\
\hline
\end{tabular}

Table 4.1: Study Design

the road signs found on all three tracks. Participants were told the aim of the study was to recognize the road signs present while driving. The terms driving performance and cognitive workload can encompass a variety of measures and we focus on a subset. In our hypotheses, we outline what specific measures define driving performance and cognitive workload for this thesis. Our hypotheses are as follows:

- H1: If participants face unfamiliar road signs, their driving performance will decrease. Performance will show a decrease in driving speed, and lane keeping.

- H2: Drivers will experience a higher cognitive workload with unfamiliar road signs. A higher workload will increase the visual time needed to identify a sign, and will result in low sign recognition accuracy.

For the first hypothesis, we specifically look at driving performance in terms of speed and lane keeping to identify if unfamiliar road signs contribute to drivers' distraction. We are particularly interested in these measures because both unsafe driving speed and lane drifting can increase driving risk.

For the second hypothesis, we measure specific aspects of cognitive workload. The cognitive workload is affected by every environmental element a driver needs to be aware of when driving. This can include elements such as traffic, pedestrians, and road signs which each attract some of the driver's attention. A higher overall workload therefore may affect drivers' ability to keep track of these elements by splitting their attention and unfamiliar elements may require more attention to process. In our work, we focus on the ability to handle familiar versus unfamiliar road signs.

\subsection{Procedure}

This study was cleared by the Carleton University Research Ethics Board. The sessions lasted 45 minutes on average and unfolded according to the following steps: 
1. Consent form: Participants were asked to consent to the study and to being audio recorded during the session.

2. Pre-test questionnaire: Participants filled out an online questionnaire designed to gather information about participants' previous driving experience, current driving license level, experience driving in foreign countries (outside of Canada), and general demographic questions.

3. Introduction to driving simulator: The experimenter demonstrated the functionality of the wheel and pedal set.

4. Practice track: Participants drove a practice track for approximately one minute. This allowed them to familiarize themselves with the sensitivity of the wheel and pedals. It was also an indication that they could successfully control their on-screen vehicle.

5. Driving instructions: The experimenter instructed participants to

(a) obey posted speed signs, stop signs, and yield signs.

(b) not pass vehicles unless road signs allow it.

(c) avoid collisions with surrounding traffic.

(d) maintain vehicle in the proper lane. For the Highway study, the OpenDS model used two different types of lane demarcations along the track and these were not easily reconfigurable. To alleviate confusion, participants were shown a screen shot of the changes in road markings they would encounter on the tracks (Figure 4.1 and Figure 4.2) and were shown how to maintain their vehicle in the correct lane when they encountered these markings.

6. Task introduction: The experimenter instructed participants to verbally identify road signs as they appeared along the track. The explanation required was twofold: first, explain the symbol/text on the road sign. Second, explain the rule/warning being conveyed. 




Figure 4.1: First lane demarcation found on the Highway track. Proper lane is identified by green check mark

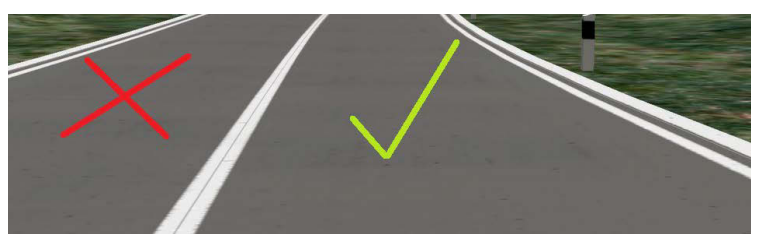

Figure 4.2: Second lane demarcation on the Highway track. Proper lane is identified by green check mark

7. Eye tracker: The SMI eye tracker glasses were adjusted to fit participants and then calibrated using three-point calibration.

8. Track presentation: A Latin square determined the order of presentation for each track. Participants received navigational directions from the experimenter when necessary and were given a few minutes break between tracks.

9. Post-test questionnaire: Once all three tracks were completed, participants completed an online questionnaire. This questionnaire measured participants' recognition and interpretation skills, as well as their opinions and perceptions of each track.

10. Conclusion of session: Participants were thanked and given $\$ 10$ as compensation for their time.

\subsection{Data Collection}

Data was collected using several methods to provide an overall understanding of drivers' behaviour and to measure driving performance. In addition to the methods presented below, the experimenter noted any relevant comments made by participants during the study session.

\subsubsection{Software Logs}

OpenDS can collect driving data from their pre-defined tracks. We used this functionality to collect participant driving data from each of our tracks. The data is collected as plain text files with semicolon delimiters. The logs store information about the 


\begin{tabular}{|c|c|}
\hline Zones & Deviation Distance $\mathbf{( c m )}$ \\
\hline Zone 0 & $|d|<25$ \\
\hline Zone 1 & $25 \leq|d|<50$ \\
\hline Zone 2 & $50 \leq|d|<100$ \\
\hline Zone 3 & $100 \leq|d|<150$ \\
\hline Zone 4 & $|d| \geq 150$ \\
\hline
\end{tabular}

Table 4.2: Distance $(\mathrm{cm})$ from ideal path

vehicle's absolute position, speed $(\mathrm{km} / \mathrm{h})$, steering wheel position, and pedal position. Each data point was timestamped for post study analysis. We wrote a Python script to parse through all of the driving data files. Once the data was parsed, it could be filtered based on any defined key value. For example, data could be filtered for a specific participant or by track. Separate Python modules were written based on the type of analytics required. An example would be the maxSpeed module which is loaded with the main parser script. This module outputs the maximum speed of the data from the specified filter. This allows for quick retrieval of participants' driving data during the analysis part of this experiment. Furthermore, we defined an ideal driving path within each track's property files. This path reflects a vehicle that stays centred in their lane throughout the track. Using the OpenDS Analyzer tool, we can load specific driving sessions and visually compare an individual's actual driven path and the ideal path. Figure 4.3 shows the ideal path (marked in blue) and the actual driven path (marked in yellow). The Analyzer tool calculates the total mean deviation from the ideal path (marked in red). From this, we modified the Analyzer tool's existing code such that it returns the distance $(\mathrm{cm})$ between a point on the ideal path and the direct opposite point on the driven path. We wrote a Python script to categorize the results of the area of deviation into four zones. Table 4.2 shows the boundaries of each zone.

The script aggregates the time participants spent in each zone. Cases where a participant decided to pass a leading vehicle were marked as a controlled pass and were not counted against the final Zone scores. If participants went too far off the track, they were reset back to start of the track. This was counted as a reset in the analysis; data on distance, zones, and road sign identification were not counted until the participant returned to the original position where they went off the track. 


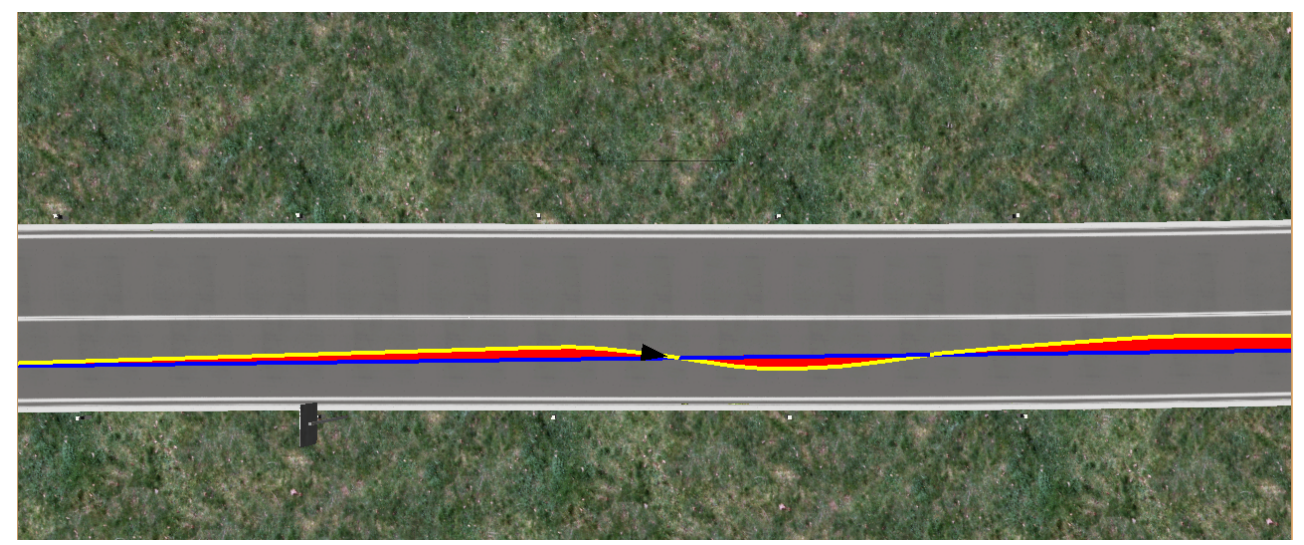

Figure 4.3: Lane deviation example [45]

The Python script sums the distance $(\mathrm{m})$ travelled in each zone, the total number of cars passed, the total number of resets that occurred. It additionally calculates the percentage spent in each zone over the total distance $(\mathrm{m})$ travelled. This data is used to determine if there is a relationship between lane deviation and sign recognition.

\subsubsection{Eye Tracking}

Using SMI's analysis software, we captured video of participants' gaze fixation points. Formatted as a .csv file, the data for each participant was manually tagged to include the point where a road sign came into gaze view, point where the road sign was in plain sight, participant's gaze fixation on the road sign, and the duration of their gaze fixation (ms). This information was then processed in Python for further analysis.

\subsubsection{Audio Capture}

Verbal responses from participants identifying road signs were recorded using SMI's eye-tracking device. During the session, the experimenter scored participants' verbal responses using a modified version of Shinar et. al's road sign guessability score [63]: Correct and complete (coded as +2$)$, correct and complete with repeated tries $(+1.5)$, partially correct (e.g., turn instead of right turn, coded as +1 ), partially correct with repeated tries $(+0.5)$, incorrect $(0)$, or opposite of actual road sign meaning (e.g., pedestrians allowed instead of pedestrians prohibited, coded as -2). The audio captured was used to verify scores assigned during the session. 


\subsubsection{Questionnaires}

The pre-test questionnaires gave us an understanding of participants' previous driving experience. Post-test questionnaires measured the perceived difficulty of each track using a 3-point Likert scale: hard, moderate, easy. Perceived distraction for each track was evaluated using a 5-point Likert scale where "1" was "Not distracting" and "5" was "Very distracting". Participants were also asked to rate their perceived ability to keep in their proper lane, and obey posted speed limits, on a 3-point scale from Poor to Excellent. The post-test questionnaire also examined participants' ability to recognize and interpret road signs that appeared on each track. They were shown road sign images and were asked to identify whether each appeared on the track and explain the rule conveyed by each sign. The Highway study questionnaire had 11 signs that were included in the tracks and 4 decoys. The City study questionnaire had 10 valid signs and 5 decoys. The questionnaires are included in Appendix F.

\subsection{Analysis Plan}

In this thesis, we use two statistical tests to analyze the data gathered from our user studies. In particular, we examined participants' driving data and data from the Analyzer tool to validate our first hypothesis. Data from eye gaze fixations, road sign recognition scores, and questionnaires helped us answer our second hypothesis. Road signs and tracks represent our independent variables, whereas, our dependent variables are speed, lane keeping, gaze fixation, and sign recognition scores. Table 4.3 outlines the tests used. Non-parametric tests were used in cases where data did not follow a normal distribution. A Shapiro-Wilk test was used to check normality. In all cases, $\mathrm{p}<0.05$ is taken as statistically significant.

\subsection{Participants}

Both driving studies required participants to have a valid driver's license from any country. This ensured they minimally had an understanding of the basic road regulations. The following section describes the participants recruited for each study, their driving habits, and driving experience. 


\begin{tabular}{|c|c|c|}
\hline Name & Description & Example \\
\hline Friedman test & $\begin{array}{l}\text { A non-parametric test used to test for differences } \\
\text { between two or more paired groups. } \\
\text { A normal distribution is not assumed. }\end{array}$ & $\begin{array}{l}\chi^{2}=n, d f=k-1, p<0.05 \\
\mathrm{n}=\text { value of test statistic } \chi^{2} \\
k=\text { number of groups } \\
\mathrm{p}=\text { significance level }\end{array}$ \\
\hline One-way repeated measure ANOVA & $\begin{array}{l}\text { Test used to identify differences between } \\
\text { related means by comparing within-subject groups } \\
\text { under three or more conditions. } \\
\text { Normality is assumed. }\end{array}$ & $\begin{array}{l}F(z, n), p<0.05, \eta^{2} \\
F(z, n)=\text { effect of group on value } \\
\mathrm{p}=\text { significance level } \\
\eta^{2}=\text { effect size }\end{array}$ \\
\hline Wilcoxon Signed-rank test & $\begin{array}{l}\text { A non-parametric test that compares } \\
\text { the differences between two matched groups. }\end{array}$ & $\begin{array}{l}Z=n, p<0.05 \\
\mathrm{n}=\text { value of test statistic } \mathrm{Z} \\
\mathrm{p}=\text { significance level }\end{array}$ \\
\hline Pairwise t-test & Tests the differences between two paired groups. & $\begin{array}{l}t=n, p<0.05 \\
\mathrm{n}=\text { value of test statistic } \mathrm{t} \\
\mathrm{p}=\text { significance level }\end{array}$ \\
\hline
\end{tabular}

Table 4.3: Summary of statistical tests conducted

\subsubsection{Highway Study}

We recruited 25 participants, 12 female and 13 male with an average age of 31.7 years $($ S.D.=12.94). Sixteen participants had a full driver's license (i.e., G-level, M-level). One participant had a learner's permit (i.e., G1, M1). Six had graduated learners' permits (i.e., G2, M2). Two participants had enhanced drivers' licenses that allowed them to drive school buses and trucks in addition to regular motor vehicles. Of these participants, 5 reported having had a driving license issued by another country with 3 being from Iran, 1 from El Salvador, and 1 from the United States. The average driving experience was 13.8 years (S.D.=12.59), with the highest being 46 years and the lowest being 1 year. Fifteen participants reported having experience driving in a foreign country (U.S was considered as a foreign country). Figure 4.4a shows the distribution of hours spent driving. Figure $4.5 \mathrm{a}$ provides additional details of how participants spend their driving time (multiple responses were accepted). Results from the demographics questionnaire showed that $80 \%$ of participants drive mostly in the city rather than on a highway, and only $24 \%$ frequently drive outside of their regular routes (see Figure 4.6a). 20\% of participants admitted to having had at-fault car accidents.

\subsubsection{City Study}

Twenty-five participants, 11 female and 14 male with an average age of 32.52 years (S.D.=14.65) were recruited for this study. Eighteen participants had a full driver's 


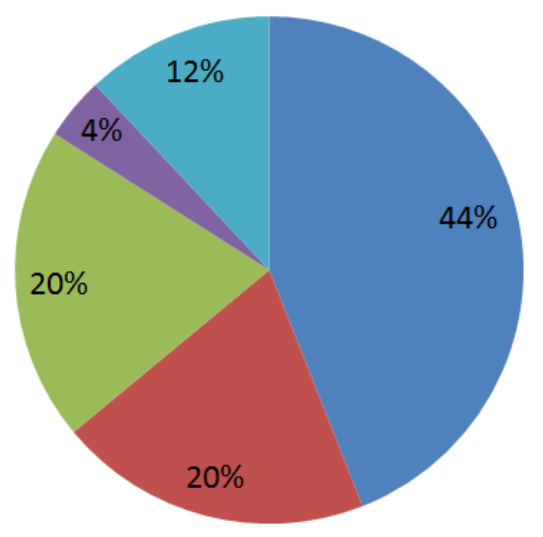

$$
\begin{aligned}
& \square 0-2 \text { hours } \\
& \square \text { 3-5 hours } \\
& \square-8 \text { hours } \\
& \square \text { 9-11 hours } \\
& \square 12+\text { hours }
\end{aligned}
$$

(a) Highway Study

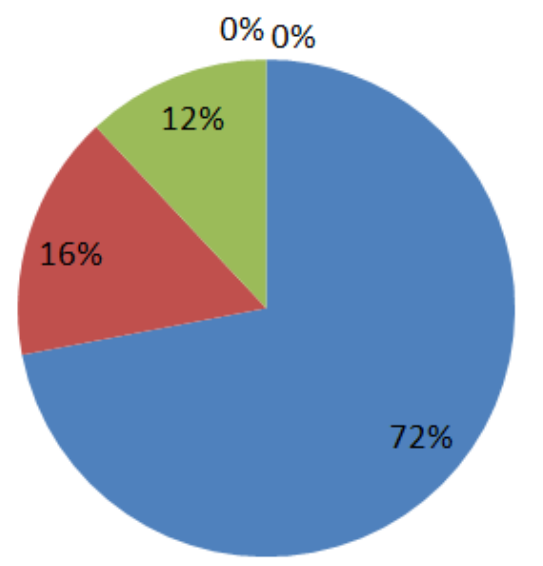

$0-2$ hours

- 3-5 hours

6-8 hours

9-11 hours

$12+$ hours

(b) City Study

Figure 4.4: Hours Spent Driving per week

license (i.e., G-level, M-level). Two participants had their learner's permit (i.e., G1, M1). 5 had a graduated learner's permit (i.e., G2, M2). Of these participants, 8 reported having had a driver's license issued by another country with 4 from Iran, 2 from the United States, 1 from Bangladesh, and 1 from China. The average driving experience was 13.08 years $($ S.D.=13.32), with the highest being 47 years and the lowest being 1 year. Ten participants reported having experience driving in a foreign country. Figure $4.4 \mathrm{~b}$ shows the distribution of hours spent driving. Figure 4.5b provides additional details of how participants spend their driving time (multiple responses were accepted). Results show that $60 \%$ of participants drive mostly in the city rather than on a highway. Only $24 \%$ often drive outside of their regular route 




(a) Highway Study

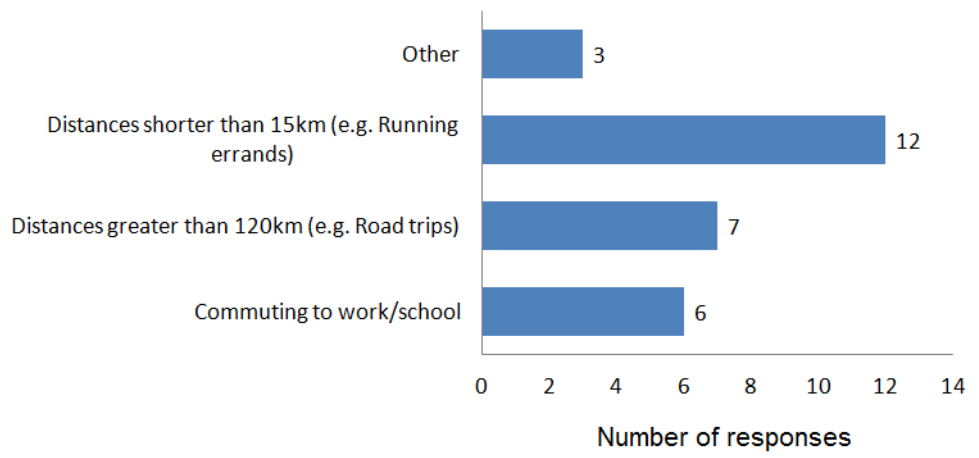

(b) City Study

Figure 4.5: Participants' driving habits

(see Figure 4.6b). 24\% of participants reported having had an at-fault car accident. 


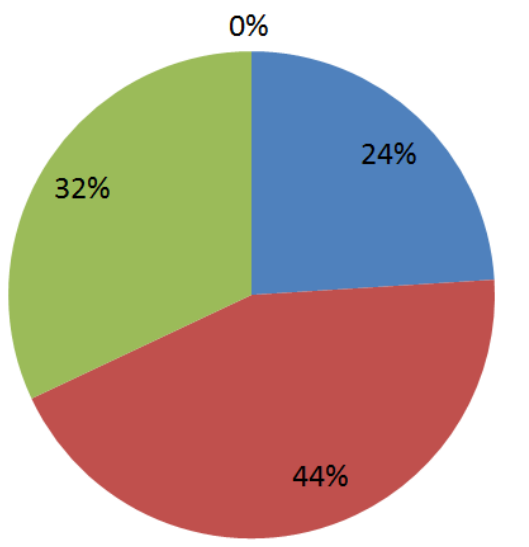

- Often

- Sometimes

Seldom

Never

(a) Highway Study

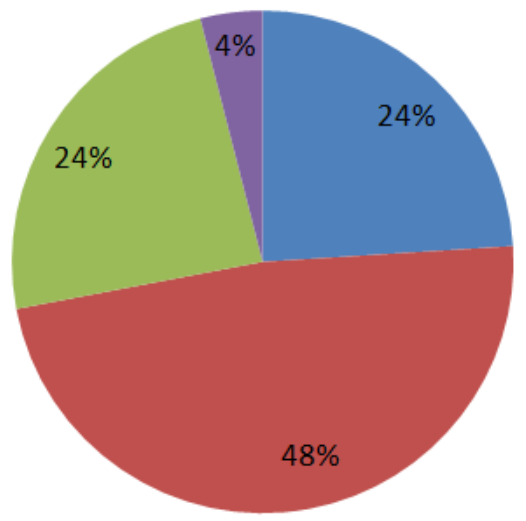

- Often

- Sometimes

- Seldom

Never

(b) City Study

Figure 4.6: How often participants drive outside their regular route 


\section{Chapter 5}

\section{Results}

In this chapter, we analyze data collected from OpenDS and SMI's eye tracking software to determine the impact unfamiliar road signs on drivers' behaviour, and its influence on driver distraction. The data includes participants' gaze fixations, verbal identification of road signs, driving speed, lane deviation, and questionnaire responses.

\subsection{Hypotheses}

As stated in section 4.2, our hypotheses are as follows:

- H1: If participants face unfamiliar road signs, their driving performance will decrease. Performance will show a decrease in driving speed, and lane keeping.

- H2: Drivers will experience a higher cognitive workload with unfamiliar road signs. A higher workload will increase the visual time needed to identify a sign, and will result in low sign recognition accuracy.

\subsection{Gaze Fixation}

We manually tagged the fixation data to identify events of interest. In both studies, we examine the longest consecutive gaze fixation time (in seconds) participants spent fixated on each individual road signs per track. Fixation points are considered consecutive when the subject stared at a road sign without looking away. Additionally, we examine the total gaze fixation time (in seconds) participants spent looking at a sign. Due to limitations of the eye tracking software, gaze data could not be reliably collected from participants wearing eyeglasses. Therefore, the remainder of the gaze fixation data is composed of 17 participants from the Highway study, and 15 from the City study. 


\begin{tabular}{|c|c|c|c|c|c|}
\hline & Max & Min & Median & Mean & Standard Deviation \\
\hline Germany & 13.76 & 0 & 3.11 & 3.44 & 2.50 \\
\hline Canada & 14.01 & 0 & 3.38 & 3.70 & 2.57 \\
\hline China & 14.13 & 0 & 3.64 & 4.12 & 2.96 \\
\hline
\end{tabular}

Table 5.1: Total gaze fixation time (seconds) statistics per sign (Highway Study)

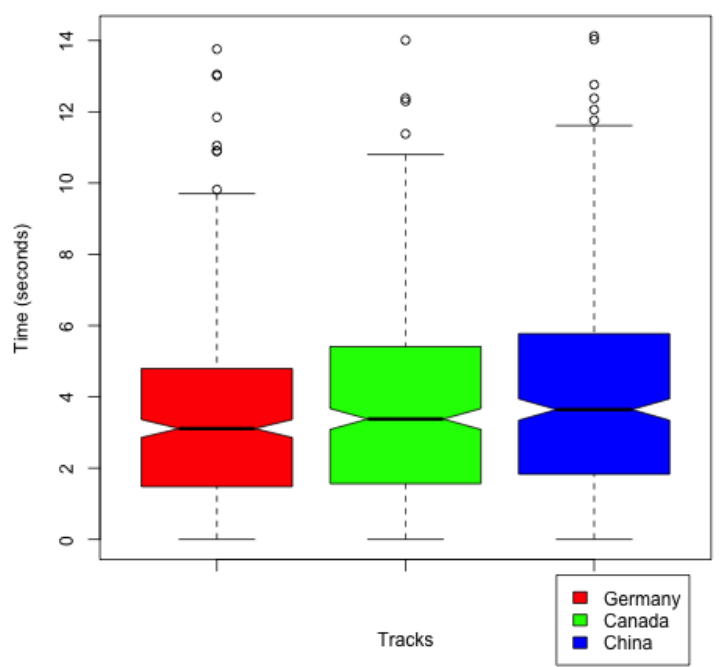

(a) Total gaze fixation time

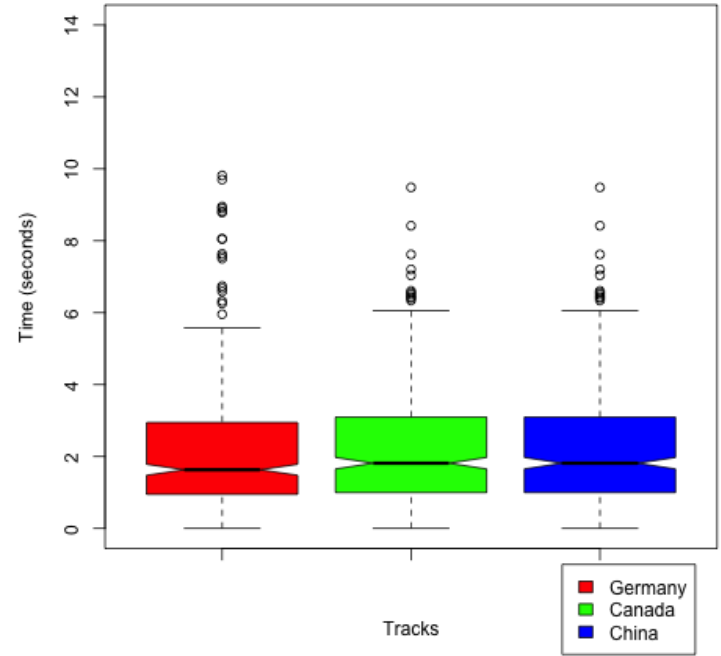

(b) Longest consecutive gaze fixation time

Figure 5.1: Gaze fixation box plots (Highway Study)

For the statistical analysis, we calculated the mean value across all road signs for each participant, giving us one data point per participant per track.

\subsubsection{Highway Study}

Figures 5.1a and 5.1b illustrate the time per Highway track participants spent looking at an individual sign, and the longest consecutive gaze for one sign, respectively. From Figure 5.1a and Table 5.1 and we can see participants spent slightly longer time in total looking at road signs on the Chinese track which could indicate that participants were most unfamiliar with road signs on this track. A Friedman test comparing the mean total gaze fixation times for each track rendered a Chi-squared value of 12.12 ( $d f$ $=2$ ) which was significant at $\mathrm{p}<0.05$. A Bonferonni adjusted pairwise comparison using Wilcoxon rank sum test shows a significant difference between Canada and 


\begin{tabular}{|c|c|c|c|c|c|}
\hline & Max & Min & Median & Mean & Standard Deviation \\
\hline Germany & 13.73 & 0 & 2.06 & 2.50 & 2.03 \\
\hline Canada & 11.46 & 0 & 2.41 & 2.85 & 2.25 \\
\hline China & 10.43 & 0 & 2.88 & 3.35 & 2.23 \\
\hline
\end{tabular}

Table 5.2: Total gaze fixation time (seconds) statistics per sign (City)

Germany, and between China and Germany.

To further examine where the difference lies, we looked at participants' longest consecutive gaze fixation. Figure $5.1 \mathrm{~b}$ shows that longest consecutive gaze fixation points remained relatively the same on all three tracks. Table B.1, B.2, and B.3 from appendix B provides further details on participants' longest consecutive gaze fixation times for each road sign.

The road signs with the two highest averages for longest consecutive gaze fixation used complex designs with more than one image to convey a message (with the exception of German Sign 14 (Bus Stop)). For example, Canadian Sign 17 (Caution possible flooding) used 2 images, one to represent the road and the second to represent flowing water. The participants who were unfamiliar with this sign mistook the image of flowing water for a bridge. One participant commented that this represented a warning for snakes crossing the road.

German Sign 14 (Bus Stop) displayed only the letter 'H'. Our observations show that participants who looked at this sign for a longer time were attempting to interpret the letter. They often mistook it to represent "hospital" by using their knowledge of local road signs to comprehend this sign. ' $\mathrm{H}$ ' is used to represent "hospital" on Canadian road signs.

On the contrary, road signs with the lowest average for longest consecutive gaze fixation used only one image. Participants glanced at the sign and came up with a meaning. This does not necessarily mean they understood the sign correctly, but rather they were able to deduce a meaning quicker.

\subsubsection{City Study}

Figures 5.2a and 5.2b illustrate the time per City track participants spent looking at a sign, and the longest consecutive gaze fixation per sign, respectively. From Figure 


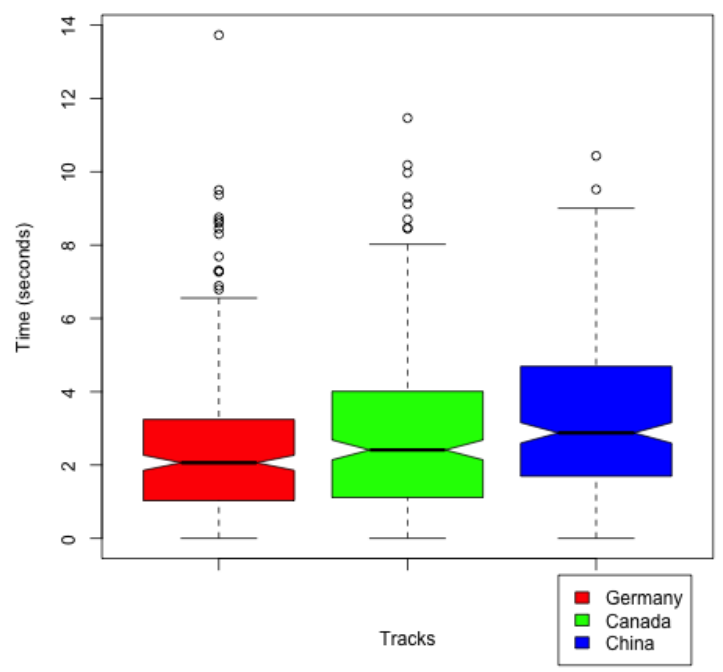

(a) Total gaze fixation time

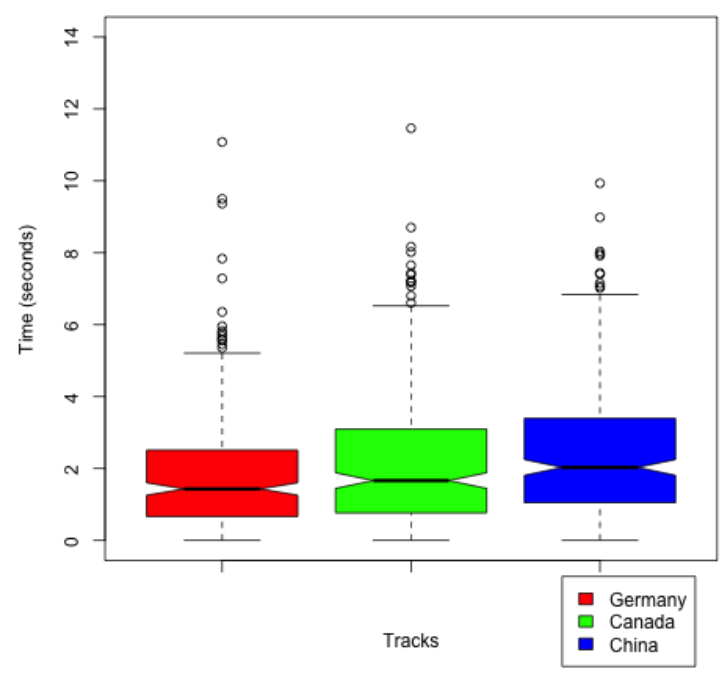

(b) Longest consecutive gaze fixation time

Figure 5.2: Gaze fixation box plots (City Study)

5.2a and Table 5.2 we see that participants spent longer looking at road signs on the Chinese track, likely because these were most unfamiliar.

A Friedman test comparing the mean total gaze fixation times for each track rendered a Chi-squared value of $14.8(d f=2)$ which was significant at $\mathrm{p}<0.05$. A post-hoc test with Bonferonni correction showed a significant difference between China and Germany ( $Z=3.29, p<0.167)$.

To further examine where the difference lies, we looked at participants' longest consecutive gaze fixation. Figure 5.2b shows longest consecutive gaze fixation points were highest on the Chinese track and lowest on the Germant track, which further supports our significance findings. Table B.4, B.5, and B.6 from appendix B provides further details on participants' consecutive gaze points for each road sign. We observed that results were similar to the Highway study. The road signs with the two highest averages for longest consecutive gaze fixation used complex images with more than one image to convey a message. Conversely, the lowest averages were associated with road signs displaying only one image. German Sign 15 (Stop) had the lowest average. Since this sign is identical to a common Canadian road sign, participants identified it quickly. 


\subsubsection{Summary of Gaze Fixations}

Our findings from both studies showed participants generally spent 2-3 seconds looking at road signs to develop an understanding of its message. Road signs with the highest gaze fixation times contained two or more images. We observed that the Canadian "caution possible flooding" sign received one of the top two highest consecutive gaze fixation averages in both studies (Sign 17 and Sign 14, respectively). Likewise, the Chinese "caution avoid collisions" road sign also received one of the top two highest consecutive gaze fixation averages in both studies (Sign 13 and Sign 15, respectively). The design of both of signs should simplified to reduce the gaze time required to analyze the sign before deciding on its meaning.

Both studies have some participants gazing at road signs for much longer than the average time. Observations during both sessions revealed some participants coming to a complete stop in order to identify a road sign. Additionally, we noticed participants would bring their face closer to the monitor if they did not comprehend a sign. On the other hand, participants who were focused on the leading vehicle, on passing a vehicle, on other track elements would miss looking at a road sign completely. These observations help to explain the outlier data identified in our graphs.

\subsection{Road Sign Identification}

Using the audio recording from the sessions, we rated participants' verbal identification of road signs for each study using the scale described in section 4.4.3. Possible scores range from -2 to +2 , with higher scores indicating better accuracy. For each study we compared scores between tracks.

\subsubsection{Highway Study}

Figure 5.3a shows the scores of participants per highway track. We observe that Canada clearly outperforms the other two countries. Participants' scores out of 50 for each track were as follows: Germany $(\mathrm{M}=27.00$, S.D $=4.29)$, Canada $(\mathrm{M}=$ 39.72 , S.D $=6.17)$, and China $(\mathrm{M}=29.50$, S.D $=4.31)$. There were 20 participants

on the German track who scored at least one -2, indicating they interpreted the 


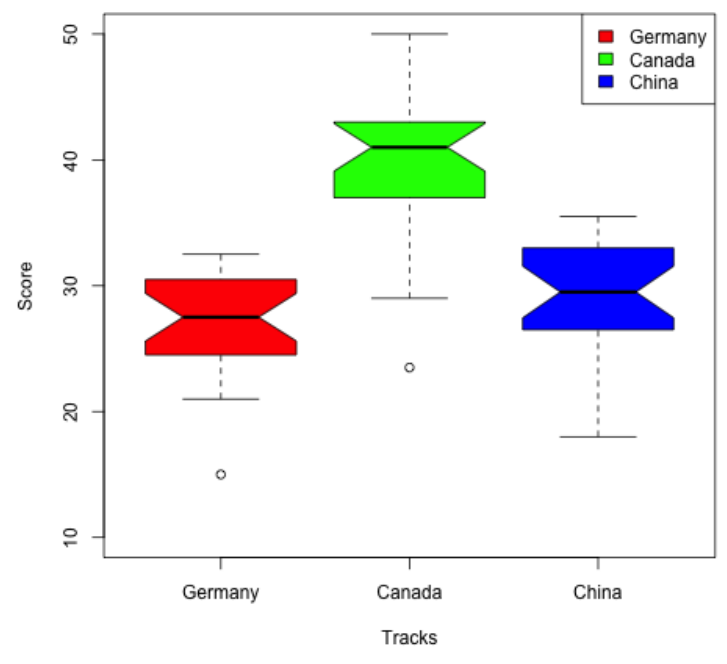

(a) Highway Study



(b) City Study

Figure 5.3: Results from verbal road sign identification by study

road sign as the opposite of their intended meaning. From this total, 19 participants misinterpreted the "end of no overtaking zone" road sign. The remaining participant misinterpreted the "no overtaking" road sign.

Although data appears normal, a Friedman test was used to compare scores between the three tracks because of the non-linear scoring scale used to evaluate participant responses. Results rendered a Chi-square value of $33.36(d f=2)$ at $\mathrm{p}<0.05$. A post-hoc Wilcoxon test with Bonferroni adjusted alpha levels of $0.0167(0.05 / 3)$, showed a significant difference between Canada and China $(Z=4.35, p<0.0167)$ and a lower but significant difference between Canada and Germany $(Z=4.35, p<$ 0.0167), with Canada outperforming both.

\subsubsection{City Study}

Figure $5.3 \mathrm{~b}$ shows the scores of participants per City track. We observe a similar pattern as the highway study, with Canada scoring much higher than China and Germany. On the German track, all but one participant scored at least one -2 value. Nineteen occurred at the "no overtaking" sign, and 5 occurred at "end of no overtaking zone" sign. Additionally, on the Chinese track, 9 participants scored at least one -2 
value. Eight occurred at the "overtaking allowed" sign, and 1 occurred at the "sharp right" turn sign. One -2 score occurred at the Canadian "passing permitted" sign.

A Friedman test comparing scores between tracks rendered a Chi-square value of $28.60(d f=2)$ with $\mathrm{p}<0.05$. A post-hoc Wilcoxon test with Bonferroni adjusted levels showed significant differences between Canada and China $(Z=4.27, p<0.05)$ and Canada and Germany $(Z=4.17, p<0.0167)$.

\subsubsection{Summary of Road Sign Identification}

We observed that the Canadian track outperformed the other two countries in both studies. Likewise, post-hoc tests revealed significant differences between the same pair of tracks (i.e., Canada and China, Canada and Germany) in both studies. Participants were able to accurately comprehend significantly more signs on the Canadian track, likely due to familiarity. German road signs "no overtaking" and "end of no overtaking zone" were interpreted as the opposite of their intended meaning in both studies. This may have occurred because typically Canadian road signs with a diagonal line through an image means the action is prohibited. On the contrary, German road signs with an open red circle indicate a prohibited action, and a diagonal line negates the original

meaning. This provides more evidence that international road sign standards are necessary. It also highlights some of the consequences of not having standardization: road signs can be interpreted as completely the opposite to their intended meaning.

\subsection{Lane Deviation}

Participants' ability to stay in their lane was measured relative to a pre-determined ideal path which ran through the middle of the lane. Deviations were calculated from the OpenDS driving logs. There were categorized into zones as described in Table 4.2, where Zone 0 indicates perfect lane keeping and Zone 4 indicates a deviation greater than $1.5 \mathrm{~m}$. Statistical comparisons were done between the proportion of distance participants spent in their proper lane (zones 0 and 1 combined) per track, and the distance spent outside of their lane (zones 2 and greater combined) per track. Controlled passes were compared separately. 


\begin{tabular}{|c|c|c|c|}
\hline \multicolumn{4}{|c|}{ Germany } \\
\hline & & Mean & Standard Deviation \\
\hline & Zone 0 & 1239.0 & 247.80 \\
\hline & Zone 1 & 330.10 & 226.62 \\
\hline & Zone 2 & 27.06 & 39.21 \\
\hline & Zone 3 & 3.45 & 8.65 \\
\hline & Zone 4 & 0.00 & 0.00 \\
\hline & $\mathrm{CP}$ & 46.94 & 45.65 \\
\hline \multicolumn{4}{|l|}{ Canada } \\
\hline & & Mean & Standard Deviation \\
\hline & Zone 0 & 1286.56 & 285.62 \\
\hline & Zone 1 & 373.52 & 274.79 \\
\hline & Zone 2 & 29.11 & 42.19 \\
\hline & Zone 3 & 3.53 & 12.99 \\
\hline & Zone 4 & 4.88 & 14.52 \\
\hline & CP & 20.30 & 71.49 \\
\hline \multicolumn{4}{|l|}{ China } \\
\hline & & Mean & Standard Deviation \\
\hline & Zone 0 & 1164.21 & 299.76 \\
\hline & Zone 1 & 352.25 & 264.31 \\
\hline & Zone 2 & 26.52 & 40.82 \\
\hline & Zone 3 & 7.39 & 16.47 \\
\hline & Zone 4 & 7.81 & 16.21 \\
\hline & $\mathrm{CP}$ & 70.81 & 62.93 \\
\hline
\end{tabular}

Table 5.3: Zone statistics for each track (Highway Study). Average distance travelled in each zone is reported in meters.

\subsubsection{Highway Study}

Table 5.3 shows the average distance $(\mathrm{m})$ travelled in each zone and during controlled passes (CP) per Highway track. We can see that most time was spent within the proper lane (zone 0 and 1). High standard deviations indicate a lot of variability between participants. They deviated the most on the Chinese track, and spent the most time in controlled passes. Figure 5.4 summarized the distances travelled within and outside the correct lane for each track.

A Friedman test on distance travelled in the correct lane per track yielded a Chisquared value of $35.52(d f=2)$ at $\mathrm{p}<0.05$. A post-hoc Wilcoxon test with Bonferonni adjusted alpha levels showed significant differences among all tracks. Canada and 


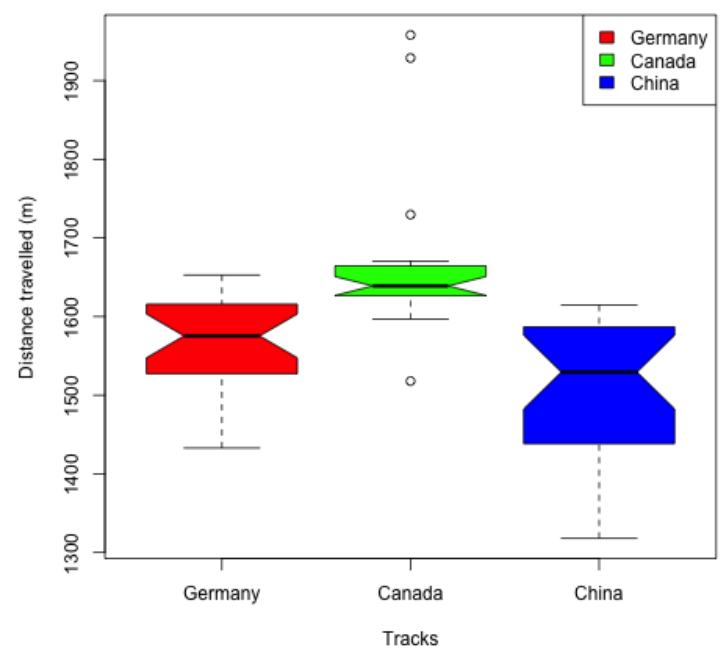

(a) Distance travelled in proper lane

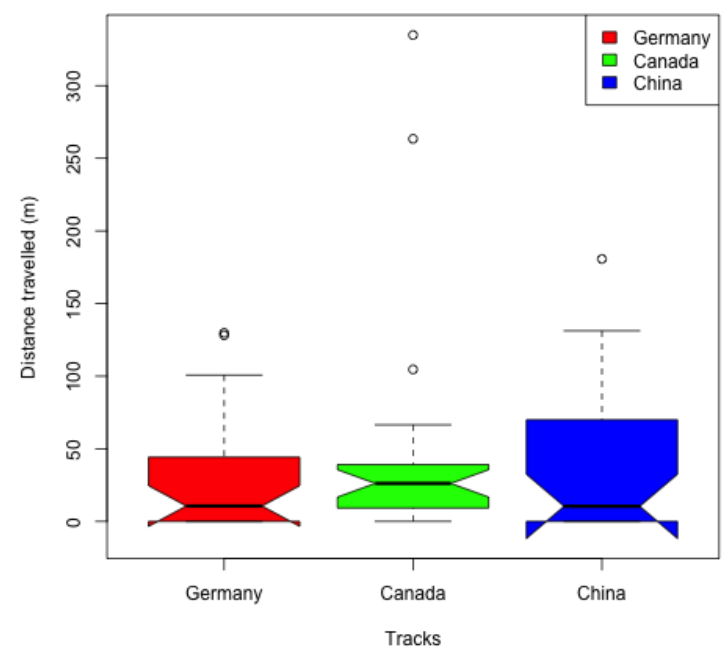

(b) Distance travelled outside of correct lane

Figure 5.4: Distribution of distance travelled inside and outside correct lane per track (Highway Study)

China $(Z=4.37, p<0.0167)$, Canada and Germany $(Z=3.915, p<0.0167)$, and China and Germany $(Z=-3.11, p<0.0167)$. These results show participants travelled further within their proper lane for Canada than the other two countries.

A Friedman test on distance travelled in the incorrect lane per track yielded a Chisquared value of $0.30(d f=2)$ at $\mathrm{p}<0.05$. A post-hoc Wilcoxon test with Bonferonni adjusted alpha levels did not reveal any significant differences among Highway tracks (due to the stricter Bonferroni $\mathrm{p}<0.0167$ threshold).

A Friedman test on Controlled Passes per track yielded a Chi-squared value of $15.65(d f=2)$ at $\mathrm{p}<0.05$. While a post-hoc Wilcoxon pairwise comparison between Canada and China revealed $\mathrm{p}<0.05$, it does not meet the threshold for the Bonferonni-adjusted p-value therefore we do not consider the difference statistically significant.

These statistical results further indicate that although participants drove mostly in zone 0 and zone 1 on all tracks, they travelled furthest in their proper lane while being least likely to undertake controlled passes on the Canadian track. 


\begin{tabular}{|c|c|c|c|}
\hline \multicolumn{4}{|c|}{ Germany } \\
\hline & & Mean & Standard Deviation \\
\hline & Zone 0 & 552.60 & 145.74 \\
\hline & Zone 1 & 402.80 & 141.96 \\
\hline & Zone 2 & 56.68 & 37.65 \\
\hline & Zone 3 & 18.71 & 9.75 \\
\hline & Zone 4 & 3.50 & 7.52 \\
\hline & $\mathrm{CP}$ & 0.58 & 2.88 \\
\hline \multicolumn{4}{|l|}{ Canada } \\
\hline & & Mean & Standard Deviation \\
\hline & Zone 0 & 516.40 & 108.46 \\
\hline & Zone 1 & 410.40 & 97.85 \\
\hline & Zone 2 & 76.98 & 51.56 \\
\hline & Zone 3 & 23.97 & 15.39 \\
\hline & Zone 4 & 10.02 & 10.54 \\
\hline & CP & 0.00 & 0.00 \\
\hline \multicolumn{4}{|l|}{ China } \\
\hline & & Mean & Standard Deviation \\
\hline & Zone 0 & 562.70 & 108.46 \\
\hline & Zone 1 & 410.40 & 97.85 \\
\hline & Zone 2 & 76.98 & 51.56 \\
\hline & Zone 3 & 23.97 & 51.56 \\
\hline & Zone 4 & 10.02 & 10.54 \\
\hline & CP & 0.00 & 0.00 \\
\hline
\end{tabular}

Table 5.4: Zone statistics for each track (City Study). Average distance travelled in each zone is reported in meters.

\subsubsection{City Study}

Table 5.4 shows the average distance $(\mathrm{m})$ travelled in each zone and during controlled passes (CP) per City track. The majority of distance was traveled in zone 0 and zone 1. The distance travelled in zone 2 was similar in all three tracks. Figure 5.5 illustrates the distance travelled within and outside their proper lane.

A Friedman test on distance travelled in the correct lane per track revealed no statistical significance.

A Friedman test on the distance travelled in the incorrect lane per track yielded a Chi-squared value of $6.48(d f=2)$ at $\mathrm{p}<0.05$. A post-hoc Wilcoxon test with Bonferonni adjusted alpha levels showed a significant difference between Canada and 


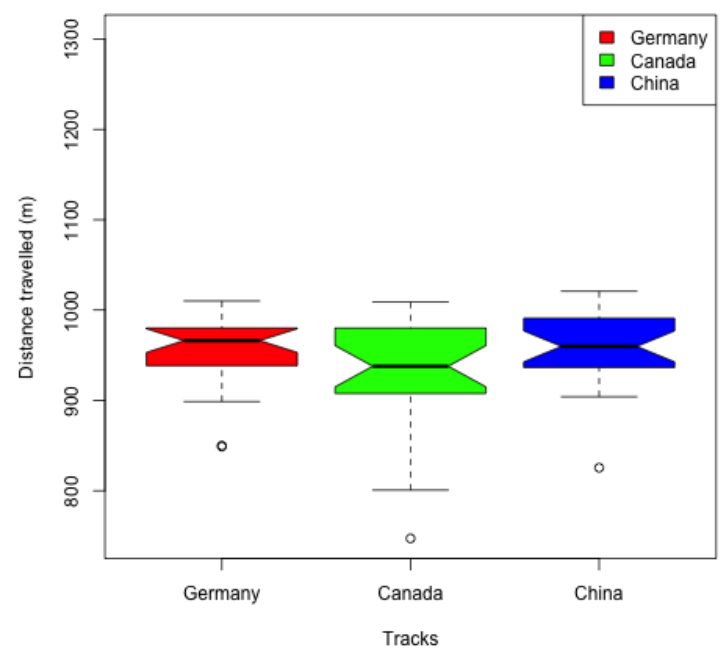

(a) Distance travelled in proper lane

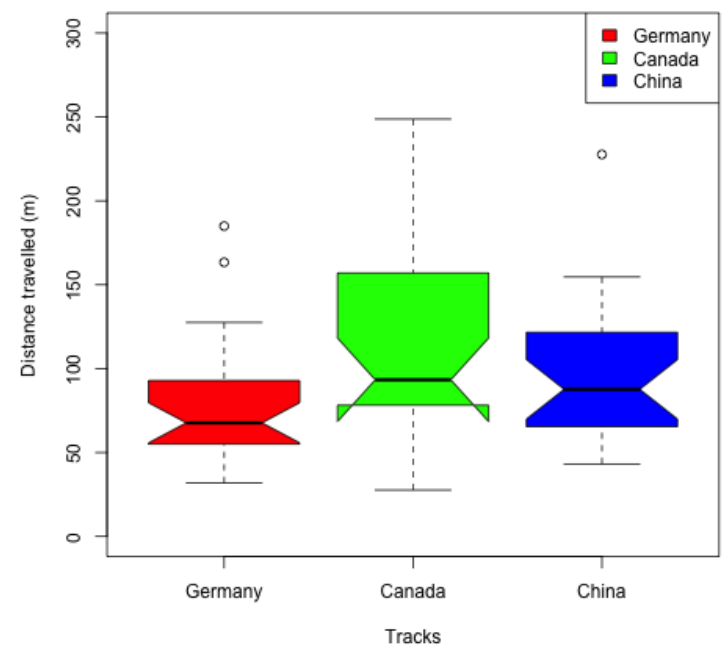

(b) Distance travelled outside of correct lane

Figure 5.5: Distribution of distance travelled inside and outside correct lane per track (City Study)

Germany $(Z=2.84, p<0.0167)$, with drivers spending longer outside of lane on the Canadian City track.

A Friedman test on controlled passes per track was not statistically significant.

These results indicate that distance travelled within the proper lane was relatively the same on all three tracks. However, participants spent more time outside of their lane on the Canadian track. This suggests that the Canadian track may have been more difficult for participants.

\subsubsection{Summary of Lane Deviation}

Participants had good lane keeping abilities in both studies. They kept within in their lane for a longer distance on the Canadian Highway track and no significant differences were found between pairs for the City track. Interestingly the city study saw more people drive outside of their lane on the Canadian track, although it is not clear why this occurred. 


\begin{tabular}{|c|c|c|c|c|c|}
\hline & Max & Min & Median & Mean & Standard Deviation \\
\hline Germany & 79.60 & 50.04 & 59.66 & 61.36 & 6.95 \\
\hline Canada & 76.70 & 46.50 & 54.31 & 57.13 & 8.62 \\
\hline China & 72.40 & 46.64 & 55.41 & 55.92 & 7.16 \\
\hline
\end{tabular}

Table 5.5: Summary of average speeds $(\mathrm{km} / \mathrm{h})$ per track (Highway Study)

\begin{tabular}{|c|c|c|c|c|c|}
\hline & Max & Min & Median & Mean & Standard Deviation \\
\hline Germany & 35.01 & 11.34 & 24.18 & 23.83 & 5.41 \\
\hline Canada & 27.25 & 10.66 & 20.00 & 20.19 & 3.87 \\
\hline China & 25.10 & 12.39 & 18.98 & 18.91 & 3.73 \\
\hline
\end{tabular}

Table 5.6: Summary of average speeds (km/h) per track (City Study)

\subsection{Speed}

Using logs collected from the OpenDS simulator, we calculated the speed of participants per track. For each participant, an average speed was calculated and used in all subsequent analysis in this section.

\subsubsection{Highway Study}

Table 5.5 shows the average speeds $(\mathrm{km} / \mathrm{h})$ on highway each track. We observe that Germany had the highest average speed over the other two countries. The minimum average speed participants drove on all three tracks, was no greater than $50.04 \mathrm{~km} / \mathrm{h}$. The speed limit varied along each track. The lowest posted speed limit was $50 \mathrm{~km} / \mathrm{h}$ and the highest was $100 \mathrm{~km} / \mathrm{h}$, with the exception of the Chinese track which reached speed of $120 \mathrm{~km} / \mathrm{h}$. A Friedman test comparing average speeds per track rendered a Chi-square value of $10.64(d f=2)$ at $\mathrm{p}<0.05$. A Bonferroni corrected posthoc comparison using Wilcoxon signed rank test with adjusted alpha level of 0.0167 $(0.05 / 3)$ found a significant difference between China and Germany $(Z=-3.30, p<$ 0.0167). This supports data from table 5.5 showing Germany had the highest speeds over China who had the lowest average speeds. 


\subsubsection{City Study}

Table 5.6 shows the average speeds $(\mathrm{km} / \mathrm{h})$ on each City track. Similar to the highway study, Germany had the highest average speed. The maximum average speed on all three tracks did not exceed $36 \mathrm{~km} / \mathrm{h}$. The posted speed limit on all three tracks was a constant $50 \mathrm{~km} / \mathrm{h}$. This means that participants on average did not meet the maximum speed limit in the city study. Data followed a normal distribution thus we tested participants' average speeds between the three tracks using a one-way repeated-measure ANOVA test. Results revealed a significant effect of track $(\mathrm{F}(2,48)$ $=28.79)$ at $\mathrm{p}<0.05$ with an $\eta^{2}$ of 0.97. A post-hoc pairwise-t test with Bonferroni adjusted levels of $0.0167(0.05 / 3)$ found significant differences between Canada and Germany, and between China and Germany, at $\mathrm{p}<0.0167$. This further supports data from table 5.6 that shows Germany had the highest average speed from the other two countries.

\subsubsection{Summary of Speed}

Drivers were generally cautious in both studies, maintaining driving speeds well below the posted speed limit. With mean speeds of approximately $20 \mathrm{~km} / \mathrm{h}$, drivers were especially cautious on the City tracks. The reduced speeds in both studies at least partially explained why drivers were mostly able to stay within their lanes.

\subsection{Perception Questionnaire}

Participants completed an online questionnaire at the end of both studies. Their responses were organized into four categories: track difficulty, perceived level of road sign distraction, perceived ability to obey road signs, perceived lane keeping. Table 5.7 and 5.8 shows the statistical analysis of the Likert scale responses from the Highway and City study respectively. Full questionnaires are available in Appendix F. 


\begin{tabular}{|c|c|c|c|}
\hline Question & Tracks & Mean, Standard Deviation & Wilcoxon Test \\
\hline Track Difficulty & $\begin{array}{l}\text { G: } \\
\text { C: } \\
\text { Ch: }\end{array}$ & $\begin{array}{l}\mathrm{M}=1.96, \mathrm{~S} . \mathrm{D}=0.61 \\
\mathrm{M}=1.28, \mathrm{~S} . \mathrm{D}=0.46 \\
\mathrm{M}=2.32, \mathrm{~S} . \mathrm{D}=0.63\end{array}$ & $\begin{array}{ll}{ }^{* *} \mathrm{C} \text { and } \mathrm{Ch}: & \mathrm{Z}=-4.12, \mathrm{p}<0.0167 \\
{ }^{* *} \mathrm{C} \text { and } \mathrm{G}: & \mathrm{Z}=-3.62, \mathrm{p}<0.0167 \\
\text { n.s. } & \end{array}$ \\
\hline $\begin{array}{l}\text { Perceived level of } \\
\text { road sign distraction }\end{array}$ & $\begin{array}{l}\text { G: } \\
\text { C: } \\
\text { Ch: }\end{array}$ & $\begin{array}{l}\mathrm{M}=2.82, \mathrm{~S} . \mathrm{D}=0.94 \\
\mathrm{M}=1.72, \mathrm{~S} . \mathrm{D}=0.89 \\
\mathrm{M}=3.48, \mathrm{~S} . \mathrm{D}=0.87\end{array}$ & $\begin{array}{ll}{ }^{* *} \mathrm{C} \text { and } \mathrm{Ch}: & \mathrm{Z}=-4.39, \mathrm{p}<0.0167 \\
{ }^{* *} \mathrm{C} \text { and } \mathrm{G}: & \mathrm{Z}=-4.20, \mathrm{p}<0.0167 \\
{ }^{* *} \mathrm{G} \text { and } \mathrm{Ch}: & \mathrm{Z}=-3.08, \mathrm{p}<0.0167\end{array}$ \\
\hline $\begin{array}{l}\text { Ability to obey } \\
\text { road signs }\end{array}$ & $\begin{array}{l}\text { G: } \\
\text { C: } \\
\text { Ch: }\end{array}$ & $\begin{array}{l}\mathrm{M}=2.04, \mathrm{~S} . \mathrm{D}=0.54 \\
\mathrm{M}=2.32, \mathrm{~S} . \mathrm{D}=0.56 \\
\mathrm{M}=1.96, \mathrm{~S} . \mathrm{D}=0.54\end{array}$ & N.A. \\
\hline $\begin{array}{l}\text { Ability to stay in } \\
\text { proper lane }\end{array}$ & $\begin{array}{l}\text { G: } \\
\text { C: } \\
\text { Ch: }\end{array}$ & $\begin{array}{l}\mathrm{M}=2.04, \mathrm{~S} . \mathrm{D}=0.45 \\
\mathrm{M}=2.28, \mathrm{~S} . \mathrm{D}=0.61 \\
\mathrm{M}=2.12, \mathrm{~S} . \mathrm{D}=0.52\end{array}$ & N.A. \\
\hline
\end{tabular}

Table 5.7: Likert scale questionnaire responses (Highway Study). ** indicates statistical significance. Tracks denoted as follows: (G)ermany, (C)anada, (Ch)ina. n.s. = not significant, N.A. = not applicable because original Friedman test not significant

\subsubsection{Highway Study}

\section{Perceived Track Difficulty}

We used a 3 -point Likert scale ( $1=$ easy, $2=$ moderate, $3=$ hard) to ask participants how difficult they found each track in terms of general driving and road sign identification. Figure 5.6 shows the distribution of responses where we can see participants thought the Canadian track was the easiest and none found it hard. Sixteen percent found the German track difficult as compared to an $8 \%$ who found the Chinese track difficult.

A Friedman test comparing the Likert scale responses per track revealed a Chisquare value of $28.41(d f=2)$ which was significant at $\mathrm{p}<0.05$. A post-hoc test using Wilcoxon with Bonferroni adjusted alpha levels of $0.0167(0.05 / 3)$, showed significant differences between Canada and China $(Z=-4.12, p<0.0167)$ and between Canada and Germany $(Z=-3.62, p<0.0167)$, reflecting the observed difference between Canada and the other countries.

\section{Perceived Level of Road Sign Distraction}

We asked participants to rate how distracting road signs were, using a 5-point Likert scale $(1=$ Not distracting and $5=$ Very distracting). Figure 5.7 shows that the German track was rated moderately distracting, with most responses falling in the middle of the scale. The Chinese track had the highest number of participants rating it very 




Figure 5.6: Likert scale responses to perceived track difficulty (Highway Study)

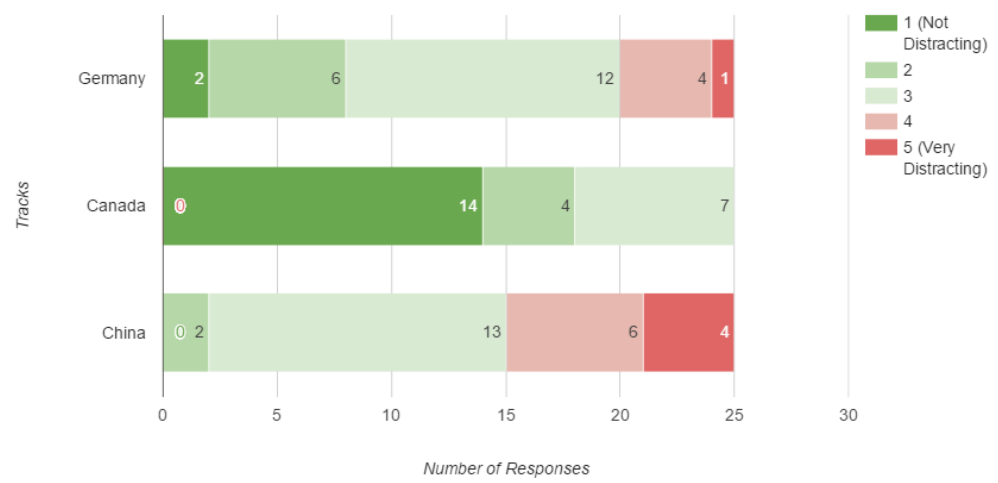

Figure 5.7: Perceived level of road sign distraction (Highway Study)

distracting (16\%). The Canadian track had highest number of participants say that the track was not distracting (56\%). A Friedman test comparing the perceived level of distraction responses per track rendered a Chi-squared value of $37.06(d f=2)$ which was significant at $\mathrm{p}<0.05$. A post-hoc using Wilcoxon with Bonferroni-corrected results showed significant differences between all three pairs: Germany - China $(Z=$ -3.08, $p<0.0167)$, Canada - China $(Z=-4.39, \mathrm{p}<0.0167)$, and Canada - Germany $(Z=-4.20, p<0.0167)$, with Canada as least distracting. 


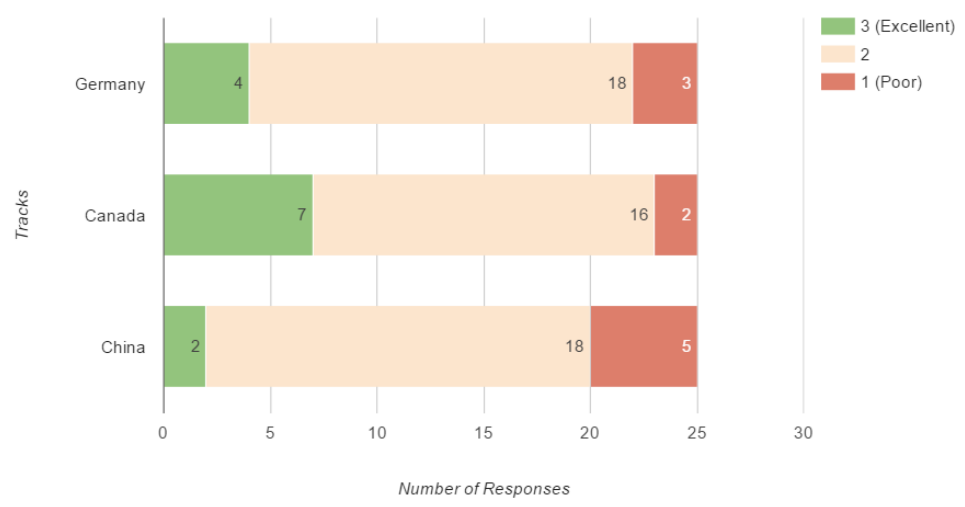

Figure 5.8: Perceived ability to obey road signs (Highway Study)

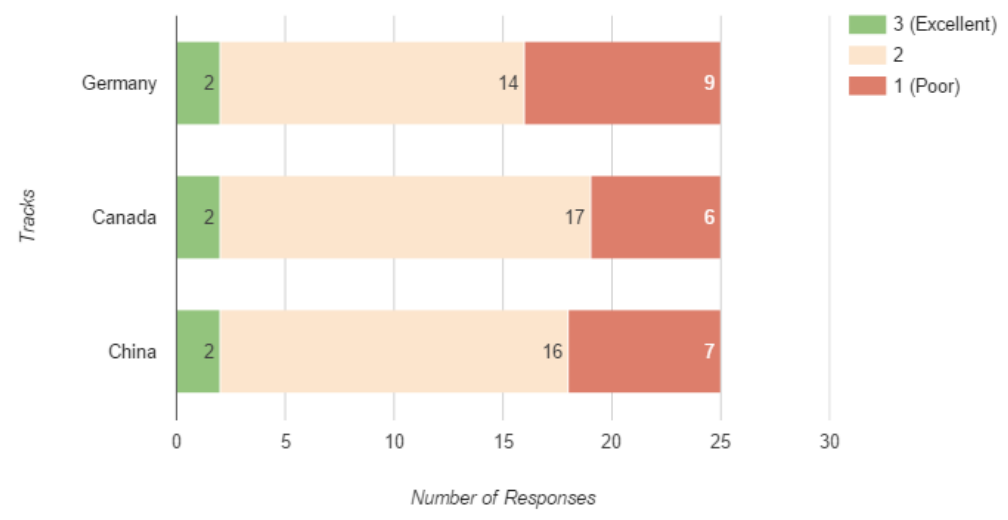

Figure 5.9: Perceived ability to stay in proper lane (Highway Study)

\section{Perceived Ability to Obey Road Signs and Stay in Proper Lane}

We used 3-point Likert scales ( $1=$ Poor and $3=$ Excellent) asking participants to rate their ability to obey road signs and stay in their lane during each track. Figure 5.8 shows the distribution of responses for ability to obey road signs. Participants felt their abilities to obey road signs were better on the Canadian track and moderate overall. A Friedman test comparing participants' responses to obeying road signs per track showed an overall significant difference between tracks but post-hoc Bonferroni adjusted Wilcoxon test could not reliably determine where the differences exists.

Figure 5.9 shows the distribution of responses when asked how well they were 


\begin{tabular}{|c|c|c|c|}
\hline Question & Tracks & Mean, Standard Deviation & Wilcoxon Test \\
\hline Track Difficulty & $\begin{array}{l}\text { G: } \\
\text { C: } \\
\text { Ch: }\end{array}$ & $\begin{array}{l}\mathrm{M}=1.96, \mathrm{~S} . \mathrm{D}=0.61 \\
\mathrm{M}=1.40, \mathrm{~S} . \mathrm{D}=0.58 \\
\mathrm{M}=2.28, \mathrm{~S} . \mathrm{D}=0.61\end{array}$ & $\begin{array}{ll}{ }^{* *} \mathrm{C} \text { and } \mathrm{Ch}: & \mathrm{Z}=-3.73, \mathrm{p}<0.0167 \\
{ }^{* *} \mathrm{C} \text { and } \mathrm{G}: & \mathrm{Z}=-3.35, \mathrm{p}<0.0167 \\
\text { n.s. } & \end{array}$ \\
\hline $\begin{array}{l}\text { Perceived level of } \\
\text { road sign distraction }\end{array}$ & $\begin{array}{l}\text { G: } \\
\text { C: } \\
\text { Ch: }\end{array}$ & $\begin{array}{l}\mathrm{M}=2.48, \mathrm{~S} . \mathrm{D}=1.00 \\
\mathrm{M}=1.12, \mathrm{~S} . \mathrm{D}=0.33 \\
\mathrm{M}=3.12, \mathrm{~S} . \mathrm{D}=1.30\end{array}$ & $\begin{array}{ll}{ }^{* *} \mathrm{C} \text { and } \mathrm{Ch}: & \mathrm{Z}=-4.21, \mathrm{p}<0.0167 \\
\text { n.s. } & - \\
\text { n.s. } & -\end{array}$ \\
\hline $\begin{array}{l}\text { Ability to obey } \\
\text { road signs }\end{array}$ & $\begin{array}{l}\text { G: } \\
\text { C: } \\
\text { Ch: }\end{array}$ & $\begin{array}{l}\mathrm{M}=2.64, \mathrm{~S} . \mathrm{D}=0.86 \\
\mathrm{M}=3.04, \mathrm{~S} . \mathrm{D}=0.84 \\
\mathrm{M}=2.20, \text { S.D }=0.87\end{array}$ & $\begin{array}{ll}{ }^{* *} \mathrm{C} \text { and } \mathrm{Ch}: & \mathrm{Z}=3.79, \mathrm{p}<0.0167 \\
{ }^{* *} \mathrm{C} \text { and } \mathrm{G}: & \mathrm{Z}=2.99, \mathrm{p}<0.0167 \\
\text { n.s. } & \end{array}$ \\
\hline $\begin{array}{l}\text { Ability to stay in } \\
\text { proper lane }\end{array}$ & $\begin{array}{l}\text { G: } \\
\text { C: } \\
\text { Ch: }\end{array}$ & $\begin{array}{l}\mathrm{M}=2.00, \mathrm{~S} . \mathrm{D}=0.96 \\
\mathrm{M}=2.12, \mathrm{~S} . \mathrm{D}=0.93 \\
\mathrm{M}=2.12, \mathrm{~S} . \mathrm{D}=0.93\end{array}$ & N.A. \\
\hline
\end{tabular}

Table 5.8: Likert scale questionnaire responses (City Study). ** indicates statistical significance. Tracks denoted as follows: (G)ermany, (C)anada, (Ch)ina. n.s. = not significant, N.A. = not applicable because original Friedman test not significant

able to keep within their lane. Participants rated themselves as mediocre on all three tracks. Nine participants rated their lane keeping as poor on the German track, suggesting that they felt this was the most difficult track. However, a Friedman test comparing participants' perceived abilities to stay in their lane showed no significant difference between tracks.

\subsubsection{City Study}

\section{Perceived Track Difficulty}

Following the same format as in the previous study, Figure 5.10 shows the 3 point Likert scale responses for the City study. The Canadian track was rated the easiest and the Chinese track was considered hardest. A Friedman test comparing perceived track difficulty responses per track revealed a Chi-squared value of 21.79 ( $d f$ $=2$ ) which was significant at $\mathrm{p}<0.05$. A post-hoc test using Wilcoxon test with Bonferroni-corrected results showed significant differences between Canada and China $(Z=-3.73, p<0.0167)$ and between Canada and Germany $(Z=-3.35, p<0.0167)$. This further reflects the data presented in the figure. 




Figure 5.10: Likert scale responses to perceived track difficulty (City Study)



Figure 5.11: Perceived level of road sign distraction (City Study)

\section{Perceived Level of Road Sign Distraction}

Figure 5.11 show that the Chinese track had the highest number of participants (3 of 25) rating it as very distracting, whereas the Canadian track had no negative ratings. A Friedman test comparing perceived sign distraction responses per track rendered a Chi-squared value of $34.13(d f=2)$ which was significant at $\mathrm{p}<0.05$. A post-hoc using Wilcoxon test with Bonferroni-corrected results showed significant differences between Canada and China $(Z=-4.21, p<0.0167)$ and Canada and Germany $(Z=$ $-4.15, p<0.0167)$, supporting that Canadian signs were considered least distracting. 




Figure 5.12: Perceived ability to obey road signs (City Study)

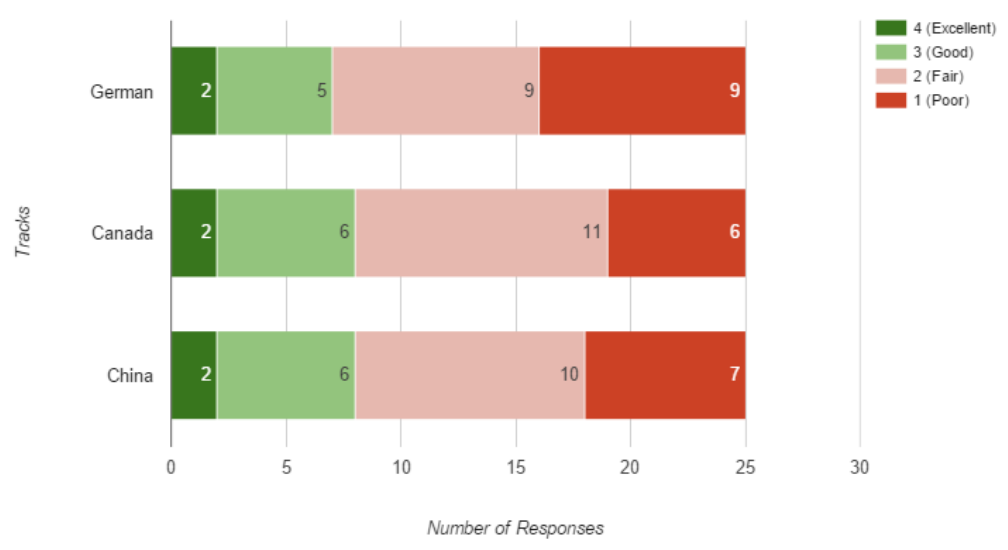

Figure 5.13: Perceived ability to stay in proper lane (City Study)

\section{Perceived Ability to Obey Road Signs and Stay in Proper Lane}

For the second study, we increased our Likert scale to 4 points ( $1=$ Poor, $2=$ Fair, $3=$ Good, $4=$ Excellent) to get a more detailed understanding of participants' reported abilities. Figure 5.12 shows participants' responses for ability to obey road signs. The majority of participants rated their ability to obey road signs as "Good" or "Excellent" on the Canadian track. Participants found it much harder to obey signs on the Chinese track with the majority rating it "Fair" or "Poor". A Friedman test comparing participants' responses to obeying road signs rendered a Chi-squared value 
of $21.85(d f=2)$ at $\mathrm{p}<0.05$. A post-hoc test found significant differences between Canada and China $(Z=3.79, p<0.0167)$, and Canada and Germany $(Z=2.99, p$ $<0.0167$ ), with a clear perception that Canadian signs were easiest to obey.

Figure 5.13 shows the distribution of responses to participants' perceived ability to stay in their lane. This figure shows similarly mixed perceptions about their lane keeping abilities across all three tracks. A Friedman test revealed no significant difference between their responses.

\subsubsection{Summary of Perception Questionnaire}

Both studies show the Canadian track was rated least distracting and least difficult over the other two countries, whereas the Chinese track was rated the opposite. This suggests that participants are more inclined to perceive a familiar environment as easier in terms of cognitive workload. Participants had mixed perceptions about their abilities to stay in the correct lane on both studies and statistical tests found no significant differences between participants lane keeping abilities per track. Additionally, while participants perceived their ability to obey road signs was easier on the Canadian Highway track, there were no statistical differences in the City study.

\subsection{Recognition and Interpretation Questionnaire}

The post-test questionnaire asked participants to say whether they recognize 5 road signs for each track they drove (15 in total). These signs are shown in Appendix A. The road signs presented had either appeared on the track or were decoys. Participants were also asked to write down the meaning of each sign. The researcher categorized participants' written interpretations of each sign as correct or incorrect. Partially correct answers were counted as correct. The number of correct answers was tabulated to give an interpretation score for each participant.

\subsubsection{Highway Study}

Figure 5.14 shows that out of 15 road signs for the Highway Study, $73.3 \%$ were accurately labelled real or decoy. Individual road sign recognition scores are found in 


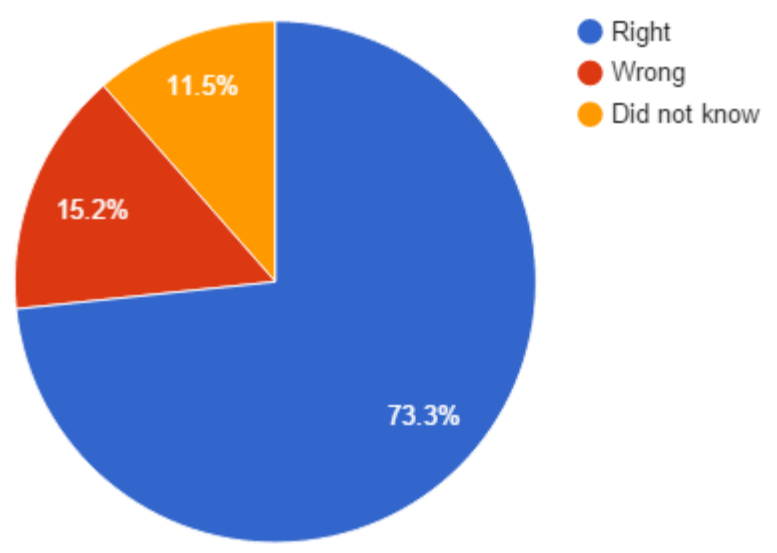

Figure 5.14: Road Sign Recognition Scores (Highway Study)

Appendix C.

Table 5.9 shows us the distribution of recognition and interpretation responses per track. The majority of participants correctly recognized if a sign appeared on the track. However, interpretation scores were much lower, with $58 \%$ correctly interpreted overall. The German "No Hazardous Goods" sign had the worst recognition to interpretation ratio with 17 of 25 participants (68\%)correctly recognizing the sign but only 1 had the correct interpretation. Additionally, the German "Bus Stop" sign was recognized by 19 participants but only 9 out of 25 participants were able to correctly interpret it.

The Canadian track had the best recognition to interpretation ratio, with the exception of the "Dangerous Goods Allowed" sign which had only 3 participants correctly interpret its meaning. Some interesting answers participants provided for interpreting this sign were: "Four way road ahead", "Stop Ahead", and "Safe to enter".

Similar to the German track, all participants were able to interpret the Chinese sign "Double Curve". This indicates a good road sign design because all participants were able to interpret the meaning of this sign. On the other hand, the Chinese sign "Stop for Inspection" and "Slow down" were not understood by any participant. 


\begin{tabular}{|c|c|c|c|c|c|c|c|c|c|}
\hline \multirow{2}{*}{ Track } & \multirow{2}{*}{ Sign } & \multirow{2}{*}{ Decoy } & \multicolumn{3}{|c|}{ Recognition } & \multicolumn{3}{|c|}{ Interpretation } & \multirow{2}{*}{$\begin{array}{l}\text { Recognition-to- } \\
\text { Interpretation Ratio }\end{array}$} \\
\hline & & & Correct & Incorrect & Unsure & Correct & Incorrect & No answer & \\
\hline \multirow{5}{*}{ Germany } & Warning Hazard & - & 23 & 2 & 0 & 21 & 4 & 0 & $23: 21$ \\
\hline & Bus Stop & - & 19 & 5 & 1 & 9 & 15 & 1 & $19: 9$ \\
\hline & Double Curve & - & 20 & 3 & 2 & 25 & 0 & 0 & $20: 25$ \\
\hline & No Hazardous Goods & - & 17 & 4 & 4 & 1 & 24 & 0 & $17: 1$ \\
\hline & Yield & - & 19 & 3 & 3 & 21 & 4 & 0 & $19: 21$ \\
\hline \multirow{6}{*}{ Canada } & Railway Crossing & $\mathrm{X}$ & 15 & 7 & 3 & 16 & 7 & 2 & $15: 16$ \\
\hline & $\begin{array}{l}\text { Trans-Canada } \\
\text { Highway Marker }\end{array}$ & - & 22 & 3 & 0 & 21 & 3 & 1 & $22: 21$ \\
\hline & Keep right of & $\mathrm{X}$ & 20 & 3 & 2 & 21 & 2 & 1 & $20 \cdot 21$ \\
\hline & traffic island & $X$ & 20 & 3 & 2 & 21 & 3 & 1 & $20: 21$ \\
\hline & Loose Gravel & - & 24 & 1 & 0 & 22 & 2 & 1 & $24: 22$ \\
\hline & Dangerous Goods Allowed & - & 20 & 3 & 2 & 3 & 14 & 8 & $20: 3$ \\
\hline \multirow{5}{*}{ China } & Stop for Inspection & - & 18 & 2 & 5 & 0 & 21 & 4 & $18: 0$ \\
\hline & Double Curve & - & 25 & 0 & 0 & 25 & 0 & 0 & $25: 25$ \\
\hline & Yield & $\mathrm{X}$ & 13 & 7 & 5 & 16 & 7 & 2 & $13: 16$ \\
\hline & T-Intersection & $\mathrm{X}$ & 18 & 0 & 7 & 17 & 6 & 2 & $18: 17$ \\
\hline & Slow Down & - & 8 & 8 & 9 & 0 & 15 & 10 & $8: 0$ \\
\hline
\end{tabular}

Table 5.9: Recognition and Identification of signs (Highway Study)

\begin{tabular}{|c|c|c|c|c|c|c|c|c|c|}
\hline \multirow{2}{*}{ Track } & \multirow{2}{*}{ Sign } & \multirow{2}{*}{ Decoy } & \multicolumn{3}{|c|}{ Recognition } & \multicolumn{3}{|c|}{ Interpretation } & \multirow{2}{*}{$\begin{array}{l}\text { Recognition-to- } \\
\text { Interpretation Ratio }\end{array}$} \\
\hline & & & Correct & Incorrect & Unsure & Correct & Incorrect & No answer & \\
\hline \multirow{5}{*}{ Germany } & Intersection Ahead & $\mathrm{X}$ & 16 & 2 & 7 & 2 & 18 & 5 & $16: 2$ \\
\hline & Bus Stop & - & 24 & 1 & 0 & 2 & 22 & 2 & $24: 2$ \\
\hline & Double Curve & $\mathrm{X}$ & 16 & 5 & 4 & 21 & 2 & 2 & $16: 21$ \\
\hline & No Hazardous Goods & - & 11 & 10 & 4 & 0 & 24 & 1 & $11: 0$ \\
\hline & Parking Prohibited & - & 17 & 1 & 7 & 3 & 16 & 6 & $17: 3$ \\
\hline \multirow{5}{*}{ Canada } & Shared Path & $\mathrm{X}$ & 23 & 2 & 0 & 22 & 2 & 1 & $23: 22$ \\
\hline & Caution possble flooding & - & 19 & 4 & 2 & 17 & 5 & 3 & $19: 17$ \\
\hline & Keep right of & $\mathrm{X}$ & 22 & 2 & 1 & 20 & 5 & 0 & $22: 20$ \\
\hline & Loose Gravel & - & 24 & 1 & 0 & 22 & 2 & 1 & $24: 22$ \\
\hline & Dangerous Goods Prohibited & - & 20 & 4 & 1 & 0 & 23 & 2 & $20: 0$ \\
\hline \multirow{5}{*}{ China } & Stop for Inspection & - & 15 & 7 & 3 & 0 & 21 & 4 & $15: 0$ \\
\hline & Sharp Turn & - & 23 & 2 & 0 & 25 & 0 & 0 & $23: 25$ \\
\hline & Yield & - & 22 & 1 & 2 & 16 & 7 & 2 & $22: 16$ \\
\hline & T-Intersection & $\mathrm{X}$ & 2 & 19 & 4 & 17 & 6 & 2 & $2: 17$ \\
\hline & Avoid Collisions & - & 21 & 2 & 2 & 6 & 15 & 4 & $8: 0$ \\
\hline
\end{tabular}

Table 5.10: Recognition and Identification of signs (City Study)

Chinese characters are included on these signs, and since none of the participants identified themselves as fluent in Chinese, we assume they were not familiar with the characters. Instead, they mapped the road signs to similar North American signs. For example, participants interpreted the "Stop for Inspection" road sign to mean "Do Not Enter". Likewise, a participant noted that the orange colour used in the "Slow Down" road sign usually relates to construction warnings. Based on participants' explanations, $36 \%$ of participants who incorrectly interpreted the sign thought this sign related to construction. 


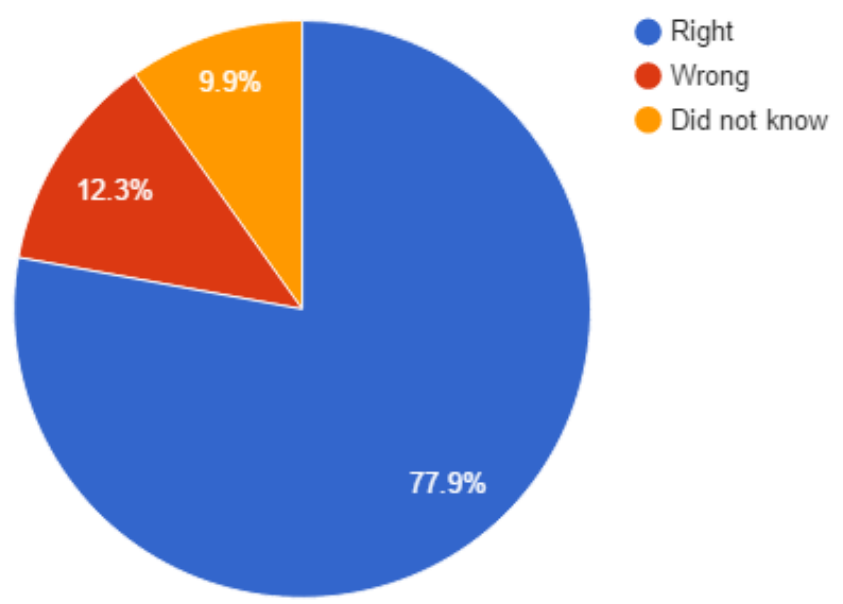

Figure 5.15: Overall Road Sign Recognition Scores (City Study)

\subsubsection{City Study}

As in the Highway study, participants were asked to say whether they recognize 5 road signs for each track they drove. Figure 5.15 shows that $77.9 \%$ of participants correctly recognized whether a road sign was present on a track. Individual road sign recognition scores are found in Appendix C. In comparison, $46 \%$ of signs were correctly interpreted.

Table 5.10 shows the distribution of recognition and interpretation responses per City track. Similar to the Highway study, the majority of participants correctly recognized if a sign appeared on the track. The German "No Hazardous Goods" sign was not correctly interpreted by any participant, a similar response rate was previously seen on the Highway track with the same sign. $72 \%$ of participants interpreted this sign to be concerned with trucks or heavy vehicles. The German "Bus Stop" sign was also easily recognized but poorly interpreted in both studies.

The Canadian "Dangerous Goods" sign was misinterpreted by all participants. On the contrary, the Canadian "Loose Gravel" road sign was properly interpreted by 22 of 25 participants.

The Chinese "Sharp Turn" sign was correctly interpreted by all participants. The 
"Avoid Collisions" road sign had mixed responses. Many participants replied that this road sign was a warning specifically for trucks and collisions, which indicates that participants literally interpreted the symbols on the road sign.

\subsubsection{Summary of Recognition and Interpretation Questionnaire}

While both studies saw a greater than $70 \%$ correct recognition scores for the 15 road signs, many participants failed to correctly interpret their meaning. It was evident in many cases (e.g., Bus Stop, Avoid collisions, No hazardous goods) that participants related road signs to ones they had previously seen. Whether this exposure was from road signs encountered during the simulation, or from real-life driving is unclear. For example, the Chinese sign "Stop for Inspection" had 56\% and 40\% (Highway and City study, respectively) of participants believing that it meant "Do not Enter", likely due to the similarities with the North American Do Not Enter road sign. Participants who correctly identified the bus stop road sign on the German track said their initial thought was that it meant "hospital", but its placement near bus shelters altered their interpretation. Participants frequently looked to their environment for clues to help understand an unfamiliar road sign.

\subsection{Effects of unfamiliar road signs on driving performance}

In this section, we take a look at participants' road sign scores and focus on participants who scored less than 1 (partially correct) on each road sign, assuming that these participants were unfamiliar with that specific sign. We measure participants' driving speed $15 \mathrm{~m}$ before the road sign and the point immediately after they pass it (i.e., the road sign is out-of-frame). Additionally, we mark their lane deviation zone at the $15 \mathrm{~m}$ mark and their zone after they pass the road sign. Controlled passes were excluded from the dataset for this analysis.

\subsubsection{Highway Study}

Appendix D includes Table D.1, D.2, and D.3, which list the number of participants who found each road sign unfamiliar per track. Additionally, the tables show how 
many of these participants decreased their speed.

On the German track, we observed 115 instances of decreased speed. The average speed decrease was $9.14 \mathrm{~km} / \mathrm{h}(\max =48.89, \min =0.5$, S.D $=24.86)$. Of these instances, $46 \%$ deviated from their initial zone, with $40 \%$ deviating by one zone, and $6 \%$ deviated by 2 or more zones. The maximum was a 5 zone deviation. The road sign "Honking Prohibited" had the highest number of participants (14 participants) deviate from their lane.

On the Canadian track, we observed 52 instances of decreased speed. The average speed decrease was $8.22 \mathrm{~km} / \mathrm{h}(\max =51.26, \min =0.04, \mathrm{~S} \cdot \mathrm{D}=11.25)$. Only $13 \%$ of instances coincided with deviation from their initial zone; all resulting in a one zone deviation. One participant was not in their proper lane before encountering the "directional" road sign, but they corrected this and were in zone 1 after passing the road sign. The "caution possible flooding" road sign had the highest number of occurrences where participants deviated from zone 0 to 1 . Moreover, five participants did not verbally identify the "stop sign" but decreased their speed to near-zero. Therefore, we can assume that these participants recognized the road sign but failed to verbalize it to the experimenter.

On the Chinese track, we observed 106 instances of speed decreases. The average speed decrease was measured at $6.48 \mathrm{~km} / \mathrm{h}(\max =37.34, \min =0.31$, S.D $=7.44)$. Of these instances, only $34 \%$ deviated from their initial zone, with $28 \%$ deviating by one zone, and $6 \%$ deviating by 2 zones. Five participants were not in their proper lane before encountering the road sign (driving in zone 2 and 3) but were either in zone 1 or 0 immediately after passing the sign. As a road sign was approaching, they intentionally drove back into their lane to see the road sign. The "Cars permitted" and "No honking" signs had the highest number of occurrences where participants deviate from zone 0 to zone 1 .

\subsubsection{City Study}

Appendix D includes Table D.4, D.5 and D.6, which show the number of participants who found each sign unfamiliar. On the German track, there were 96 instances of decreased speed. The average speed decrease was $8.35 \mathrm{~km} / \mathrm{h}(\max =45.85$, $\min =0.4$, 
S.D $=8.81)$. Of these, $34 \%$ deviated from their initial zone, with $33 \%$ deviating by one zone, and $1 \%$ deviating by 2 zones. The "No parking" sign led to the most lane deviations. Likewise, "no hazardous goods", "priority road", and "two-way traffic" signs had 4 participants each deviate from their initial zone. Although one participant failed to verbally identify a yield sign, our findings show that they decreased their speed by $10 \mathrm{~km} / \mathrm{h}$, which suggests that they did recognize the road sign but failed to verbally communicate it to the experimenter. Likewise, 2 participants did not identify the "stop sign no.2" verbally, but they slowed to a near-zero speed.

On the Canadian track, we observed that 61 instances of decreased speed. The average speed decrease was $14.52 \mathrm{~km} / \mathrm{h}(\max =53.99, \min =0.31$, S.D $=12.20)$. Of the 61 instances, $2 \%$ deviated from zone 0 to zone 2, and $30 \%$ deviated by one zone. Six participants were in zone 2 prior to passing an unfamiliar sign, and 5 of them returned to zone 1 after passing the sign. The sixth participant further deviated to zone 3 when passing the "stop" road sign.

On the Chinese track, there were 119 instances of decreased speed, with an average reduction of $12.22 \mathrm{~km} / \mathrm{h}(\max =40.90, \min =0.31, \mathrm{~S} . \mathrm{D}=8.99) .29 \%$ deviated by one zone, and $3 \%$ deviated by two or more zones ( $\max$ deviation $=4)$. The participant who deviated by 4 zones started at zone 4 and decreased to zone 0 at the road sign.

\subsubsection{Summary of Effects of unfamiliar road signs on driving performance}

From these results, we can see that while participants encountered unfamiliar signs, they largely maintained their lane position in both studies. When a deviation occurred, it was usually only by one zone. We did find, however that many showed speed decreases, and this occurred approximately twice as often in the foreign tracks as on the Canadian track. It appears that drivers needed to compensate less for the effects of unfamiliar signs when in a familiar environment.

\subsection{Effects of unfamiliar road signs on gaze fixation}

In this section, we examine the unfamiliar road signs identified in Appendix D, to determine if participants gazed at these sign longer than the average total gaze time. 
Unfamiliar signs are those where participants scored less than 1 in the verbal identification of the sign while driving. Due to limitations of the eye tracking software only 17 participants from the Highway study, and 15 from the City study were considered during this analysis.

\subsubsection{Highway Study}

Appendix E includes Table E.1, E.2, and E.3 which list the unfamiliar road signs for the highway study. There were 20 unfamiliar signs identified on the German track, from which 8 road signs had over $50 \%$ of participants exceed the average gaze time. The "Intersection Ahead" sign had 13 out of 14 participants exceed the average gaze time. Additionally, this sign scored a 11 out of 50 on our road sign identification scale. The lowest identification score was for the "end of highway" road sign (4\%). From table E.1, we notice that only $25 \%$ of participants exceeded the average total gaze time for this sign. Observations made in the session showed that some participants would bring their face closer to the monitor in an attempt to comprehend the signs, indicating that their focus was placed on the unfamiliar signs themselves rather than on the road ahead at that point in time.

On the Canadian track, 14 road signs were marked as unfamiliar. Five of these road signs had over $50 \%$ of participants exceed the average total gaze time. The "dangerous goods prohibited" had $80 \%$ of participants exceed total average. It also received the lowest identification score with $12 \%$.

On the Chinese track, 20 signs were unfamiliar. Eleven of these signs had over $50 \%$ of participants exceed the average gaze time. All 17 participants scored a zero on the identification scale for the "stop for inspection" road sign. 53\% of participants exceeded average total gaze time for this sign. Likewise, no participant could explain the meaning of this sign on the post-test questionnaire (Section 5.6.1). Even with additional time, participants were unable to correctly or partially guess the meaning of the sign. 


\subsubsection{City Study}

Tables E.4, E.5, and E.6 of Appendix E list the road signs unfamiliar to participants in the City study. There were 15 unfamiliar road signs on the German track. Six signs were unfamiliar to only one person; 3 of these signs exceeded the average total gaze time. The "Bus Stop" and "No Parking" signs each had 5 participants exceed the average total gaze time. These road signs scored $32 \%$ and $25 \%$, respectively, on the identification scale.

On the Canadian track, 14 road signs were marked as unfamiliar; four exceeded average total gaze time. In particular, the "dangerous goods prohibited" road sign had 8 out of 15 participants exceed the average. This sign not only also had a low identification score, but none of the participants were able to correctly identify this road sign during the post-test questionnaire.

On the Chinese track, 14 road signs were marked as unfamiliar. Six of these exceeded average total gaze time. In particular, the "Intersection Ahead" sign had a $60 \%$ of participants exceeding the total gaze time. An identification score of $50 \%$ further indicates that participants had trouble comprehending this sign. Likewise, the "caution avoid collisions" sign had $57 \%$ of users exceeding total gaze time, and a road sign identification score of $46 \%$.

\subsubsection{Summary of Effects of unfamiliar road signs on gaze fixation}

There is no clear pattern of gaze fixations when faced with unfamiliar road signs. In both studies, some unfamiliar signs had long fixations while others did not. Other characteristics of the sign, such as complexity or the presence of text may have a larger impact on gaze fixation but this has not been closely explored.

\subsection{Support for Hypotheses}

In this section, we summarize our hypothesis and whether our findings offered support for each. We provide an explanation for each.

H1 (Partially Supported): If participants face unfamiliar road signs, their driving performance will decrease. Performance will show a decrease 


\section{in driving speed, and lane keeping.}

This hypotheses is partially supported. Participants stayed within their proper lane for a longer distance on the Canadian Highway track, but no significant differences were found between city tracks. They generally drove much slower than expected on all tracks, but surprisingly, the fastest track was Germany, not, Canada. We also looked at what happened specifically when participants could not identify a sign. Our findings for both studies indicate participants mostly drove in the correct lane (zone 0 and zone 1) when encountering unfamiliar signs regardless of which track. However, speed decreases occurred approximately twice as often on the foreign tracks than on the Canadian track. With respect to perception, participants were significantly more confident in their abilities on the Canadian tracks.

H2 (Partially Supported): Drivers will experience a higher cognitive workload with unfamiliar road signs. A higher workload will increase the visual time needed to identify a sign, and will result in low sign recognition accuracy.

This hypothesis is partially supported. Longer gaze duration times and longer consecutive gaze duration times reflected poor road sign identification scores and incorrect interpretation scores. This finding, however, is not consistent since low identification and interpretation scores sometimes show short gaze fixation times, due to participants glancing at a road sign and misinterpreting the sign, or quickly deciding that they do not comprehend the sign at all. 


\section{Chapter 6}

\section{Discussion and Conclusion}

The main goal of this thesis was to examine drivers' behaviour when they encounter unfamiliar road signs. This was addressed using the OpenDS driving simulator and SMI's eye tracking software. In this chapter, we provide a summary of results from our user studies, interpret our findings and position them within the literature, discuss our recommendations, address the limitations of our studies, and discuss future work.

\subsection{Summary of Results}

In general, participants required about 2-3 seconds to look at a road sign and verbally identify its meaning. On both the Highway and City track, we noticed that the road signs requiring the most visual time were those which contained two or more images. In driving, speed of response is critical, which means reducing the complexity of a road sign design should be made a priority in interface design [48]. One participant on our highway track commented that she was so focused on trying to identify the Chinese character on the road sign that it wasn't until she noticed the shape and colour of the road sign that she was able to identify it as a stop sign. Our session observations noted that some participants would come to a complete stop in order to identify a road sign. Although, behaviour on a simulator is less precise than actual driving $[9,49]$, it does suggest that some participants will reduce their speed substantially to spend more time looking at a sign. This behaviour can lead to collisions due to fast approaching vehicles on highways, or closely following vehicles in cities. Thus, complex road signs may increase the probability of car accidents because they hold drivers' visual attention for longer.

While some participants' gaze fixation times were short, their verbal identification

of road signs were incorrect. Duration of gaze alone is not reflective of road sign comprehension, which is why we also considered verbal identification of road signs. 
Our findings show Canada outperformed the other two countries for comprehension, which means participants were unsurprisingly better at identifying local road signs. This aligns with findings from previous studies which demonstrate that drivers are better able to comprehend local road signs over foreign ones [19]. Additionally, the explanations for some of the road signs demonstrated that participants tried to relate an unfamiliar road sign with a visually similar local road sign. This supports previous studies $[6,10]$ which state that drivers have a tendency to use previous experiences and local practices in unfamiliar situations (e.g., a different country). This can cause a misinterpretation of traffic rules, increasing drivers' susceptibility to risk [67]. We observed this in our findings, where some road signs were mistaken for the opposite of their actual meaning. It can result in drivers making incorrect decisions (e.g., passing a vehicle, entering a prohibited street), subsequently making them more susceptible to risk.

To better assess driver distraction, we measured participants' lane deviation. Our findings show that, for the most part, participants did not deviate from their proper lane. Micro deviations were not considered hazardous so long as drivers maintained within their proper lane. To test for small deviations, the zone parameters would need to be finer-grained. We also compared the amount of deviation that occurred before and after an unfamiliar road sign was encountered; however, results were inconsistent. To our knowledge, our study was the first to measure lane deviation with unfamiliar road signs using a driving simulator. The majority of papers that examine driver distraction do so with static images or videos $[42,73]$. From our results we cannot claim that unfamiliar road signs result in distraction based on lane performance. Lane deviations that did occur were a result of controlled passes or participants' steering abilities. Participants did, however, drive much more slowly than expected, which likely helped them control their lane deviation. In real-life, driving at half the posted speed limit could also be very dangerous.

Data collected from the post-test questionnaire gave us participants' opinions of each track. For both studies, Canada scored the best overall in terms of difficulty, perceived road sign distraction, lane keeping abilities, and ability to obey road signs. Some of these perceptions agreed with our statistical findings; Canada received the 
highest road identification score, and participants stayed in their lane $96.6 \%$ and 89.3\% (Highway study and City study, respectively) of the time. However, participants required more time to look at signs on the Canadian track compared to the German track potentially because drivers quickly dismissed the German road signs as unknown whereas they felt that they should understand the Canadian signs and expended more effort. The Chinese track faired worst in terms of perceived track difficulty, perceived road sign distraction, and ability to obey road signs. Our statistical findings match participants' opinions, with the exception that China scored higher than Germany for road sign identification on the Highway study. Although participants indicated that Chinese road signs were the most distracting, our lane deviation data and the number of reported unfamiliar signs did not support this perception. Rather, perceived distraction relates to a higher cognitive workload as seen by duration of gaze fixation on unfamiliar road signs (as identified by road identification scores). A comment made by participant 22 during our Highway study summarizes this relationship well: "I was more familiar with Canadian signs therefore I was able to be more attentive to my speed, I could remember what prior road signs said, and knew what my driving restrictions were. On the other countries, I was unfamiliar with the signs therefore, I did not pay attention to my speed limit, or to traffic in front of $m e "$.

Participants were able to correctly recognize whether a sign appeared on one of the tracks within more than $70 \%$ accuracy. However, they had a harder time describing the meaning of road signs. In particular, the most confusing signs also had the longest gaze fixations. This further supports our initial comments about the necessity of simple road sign designs.

From the findings discussed, we direct our focus to how we can apply this understanding to enhancing in-vehicle systems. Our findings can be a starting point to designing in-vehicle systems that help reduce external driving distraction. In our case, we focus on unfamiliar road signs. Since our findings show that participants fixate longer on complex road signs, complex signs may increase the risk of collisions. Likewise, they may incorrectly interpret the meaning of a road sign which can lead them to make errors in judgement while driving. Studies describe implementing systems 
that alert drivers to dangers on the road $[43,59]$ (e.g., following too closely), in the attempt to reduce hazardous and distracted driving. We propose that it maybe possible to further reduce these risks by designing an in-vehicle system which presents drivers with road sign information when drivers are in an unfamiliar location. This information could be retrieved using context-aware systems [2]. Additionally, context-aware systems would have knowledge about drivers' behaviour [36,51] and could theoretically know about drivers' movements and geo-location. Therefore, systems could warn drivers when they attempt to do something against traffic policies.

Studies show that current image processing systems still require extensive work before they can provide an accurate and reliable method for dynamically identifying objects in real-time [28]. We suggest an alternative is to use web-based services such as Google Maps ${ }^{1}$ Street View feature to asynchronously identify road signs present along routes. Translation or interpretation details could be retrieved in real-time by the car using geo-location. These road signs could be processed and potentially stored by in-vehicle systems such that when a driver encounters an unfamiliar sign or attempts to contradict local traffic signs, the system could present the driver with information about the road sign. Different modalities could be used for in-vehicle interfaces such that drivers could communicate via speech or touch if they want more information about the sign. Such a system would be particularly helpful for new or temporary drivers in foreign environments, or even as a driving aid to new drivers in their local environment.

We recognize that re-evaluating road sign designs will take a long time and significant cost efforts, which is why we believe designing in-vehicle systems may be the key to helping drivers with road signs. The methods discussed for in-vehicle systems require further exploration; our findings merely reveal that a problem exists and we suggest a potential solution. Additionally, our findings can be used as a starting point for further in-vehicle tools to reduce the external distraction currently present in driving.

\footnotetext{
${ }^{1}$ http://maps.google.ca/maps
} 


\subsection{Recommendations}

Based on our observations and findings, we propose four recommendations. We believe these will improve driver safety, and minimize distraction. We divide our recommendations into two categories: those relating to road signs, and those relating to the design of in-vehicle systems.

\subsubsection{Design of Road signs}

\section{R1: Design of road signs should be simplistic}

Road signs should not use complex symbols to convey their meaning but rather should follow ergonomic design principles: Spatial compatibility, Conceptual compatibility, Physical representation, Frequency, Singular functionality, and Visibility.

Our findings show participants had trouble recognizing complex designs both while driving in our simulation and during the post-test questionnaire. This supports previous ergonomic studies such as Ng and Chin [16] and Shinar [63], which indicate that road signs with high comprehension scores adhere closer with ergonomic principles. We emphasis the importance of using this design approach. However, design of a road sign should not compromise meaningfulness for simplicity. This is in-line with semantic symbol design approach proposed by Viaganò and Rovida [71].

\section{R2: Road signs should be internationally standardized}

Road sign symbols that convey warning, caution, prohibited actions, and permitted actions should be standardized and used internationally.

Variation between countries' road signs were apparent in both of our studies. Participants would often use previous knowledge of local traffic signs to comprehend signs from different countries. In some cases, they would mistakenly interpret a road sign to mean the opposite of its intended message. Previous studies [10,67] have shown that drivers' comprehension is influenced by previous driving practices. By using a set of road sign designs internationally, we can promote cross cultural comprehension. This would reduce driving hazards that occur because of misinterpretation of traffic signs. Additionally, our recommendation complements findings by Shinar et al. [63] and Ward et al. [72] which show that a lack of standardization exists between countries, and many road sign designs do not meet standards already in place. 


\subsubsection{Design of In-vehicle Systems}

\section{R3: In-vehicle systems should be used as context-aware interpreters}

In-vehicle systems should be context-aware in order to convey the meaning of road signs to drivers. From our studies, we specifically believe that geographical context would be beneficial.

In both of our studies, Canadian road signs had the highest sign identification scores, and were perceived least distracting compared to the other two countries. While participants were able to comprehend local signs, they had more trouble when driving in an unfamiliar country. We can use this knowledge to develop in-vehicle systems that are capable of assisting drivers in an unfamiliar place. They can act as interpreters to help drivers understand foreign traffic signs and policies. The systems could relate current signs with ones equivalent to the driver's local traffic signs or policies. This familiarity can be used as leverage so a driver can potentially respond to driving situations correctly, thus reducing driving risks.

Context-aware systems might also use other contextual information to customize their output. For example, sensors might determine a driver's level of stress or fatigue, and external input such as weather or traffic conditions could also influence the invehicle system. Further research would be needed to determine the best combinations.

\section{R4: In-vehicle systems should leverage web mapping services}

In-vehicle systems should leverage web mapping services like Google Maps to present drivers with road sign information such as upcoming signs and/or road sign rules. This would differ from traditional turn-by-turn directions found on navigational systems. Instead, it would present drivers with information about warnings, prohibited/permitted actions, and cautions that they may encounter along their route in a familiar language.

This recommendation is made as an alternative to using dynamic image processing methods. Additionally, this design should selectively alert drivers about traffic sign policies if they attempt to drive in an illegal manner (e.g., passing vehicles), to prevent overwhelming drivers with notifications and causing further distraction. As discussed in the literature $[20,43]$, overwhelming users can affect user acceptance and usability. 


\subsection{Limitations}

Although it provided useful results, our study had some limitations. The eye tracking glasses were not able to register the eye movements of participants who wore eyeglasses. Additionally, in the City study, the eye tracker was not properly positioned on two participants which resulted in gaze fixation not being captured. As a result, we were not able to include them as part of our eye tracking analysis. This may have had an impact on our gaze fixation results and our comparison between unfamiliar signs and gaze duration, however, we were still able to analyze gaze data from over $60 \%$ of the participants. Data from all 50 participants was used in the analysis not requiring gaze data.

While the majority of our data was collected and parsed using Python scripts, gaze points had to be collected manually because the SMI software did not support defining regions of interest on video from a non-static source. This might have caused slight discrepancies in the time participants spent looking at a sign. Creating a separate

program to read video and raw gaze data from the eye tracking software which could identify road signs and mark them as areas of interest is a complex image processing problem that eye-tracking experts have yet to solve. This is clearly outside the scope of this thesis.

Some participants had more trouble controlling the steering wheel than others which may have made it more difficult for them to stay in their lane. This may be due to the sensitivity of the steering wheel, or participants' unfamiliar with gaming "wheels". In an attempt to balance this, we gave all participants a practice run on a test track so they can familiarize themselves with the controls and sensitivity.

If we were to run this study again, we would restrict recruitment to participants who do not need corrective eye glasses (contact lenses worked properly). Additionally, we could give participants more time to drive on a practice track before introducing them to the real tracks. Likewise, if our interface was identical in size to a real vehicle (i.e., size of steering wheel and pedals), participants might have more control of their vehicle. 


\subsection{Future Work}

Future work on driver distraction and unfamiliar road signs should build upon our findings to develop in-vehicle interface systems that inform drivers when they encounter unfamiliar signs. Our studies used a single monitor to display the simulator. We could improve the simulation by providing a more realistic driving environment. This could be done by running the simulator over multiple monitors so drivers can have a larger frame of view (e.g., check blind spots, side mirrors). Additionally, we could use a Controller Area Network (CAN-bus) to connect a real vehicle to the simulator.

In our work, we compared road signs between Germany, Canada, and China. We could test participants with road signs from other countries to determine whether findings were similar. Likewise, we could more precisely compare signs with various characteristics (e.g., text-only signs versus symbol-only signs).

\subsection{Conclusion}

The U.S National Highway Traffic Safety Administration (NHTSA) [53] reported that in 2013 alone, 3154 people were killed in distracted driving accidents. Studies have shown that distraction is not just limited to in-car activities [66,68], but also encompass external distractions. In this thesis, our main research question is concerned with how unfamiliar road signs affect drivers' behaviour. Our findings show that participants fixate on road signs with a complex design and those that are unfamiliar for longer. This may increase their risk of collisions. Likewise, misinterpretation of signs occurred due to the influence of previous driving experience and local driving practices. This may lead drivers to make errors in judgement, putting them further at risk for accidents. Results also demonstrated that participants had the tendency to stay in their lane even when they encountered unfamiliar road signs, although many drivers drove at reduced speeds throughout the track to compensate for the anticipated cognitive load.

To aid drivers in understanding unfamiliar road signs, we suggest using this thesis as a starting point for developing in-vehicle systems that are context-aware, and can 
use web mapping services to present drivers with road signage information. This information should be presented in an unobtrusive way to promote user acceptance and reduce the chances of further distraction. More research is necessary in this area to determine the optimal approach for reducing driving risk. 


\section{Bibliography}

[1] Hashim Al-Madani and Abdul Rahman Al-Janahi. Role of drivers personal characteristics in understanding traffic sign symbols. Accident analysis $\&$ prevention, 34(2):185-196, 2002.

[2] Wael Alghamdi, Elhadi Shakshuki, and Tarek R Sheltami. Context-aware driver assistance system. Procedia Computer Science, 10:785-794, 2012.

[3] Canadian Automobile Association. CAA distracted driving - distractions. http://distracteddriving.caa.ca/education/index.php. [Online; accessed August-2015].

[4] Canadian Automobile Association. CAA distracted driving - statistics. http:// distracteddriving.caa.ca/education/index.php. [Online; accessed August2015].

[5] Mohamed A. Aty and A. Essam Radwan. Demographic factors and traffic crashes: Part I-descriptive statistics and models. Technical report, Florida Department of Transportation, 1998.

[6] Mary Bazire and Charles Tijus. Understanding road signs. Safety science, 47(9):1232-1240, 2009.

[7] Francesco Bellotti, Riccardo Berta, and Alessandro De Gloria. A social serious game concept for green, fluid and collaborative driving. In Applications in Electronics Pervading Industry, Environment and Society, pages 163-170. Springer, 2014 .

[8] Tamar Ben-Bassat and David Shinar. Ergonomic guidelines for traffic sign design increase sign comprehension. Human Factors: The Journal of the Human Factors and Ergonomics Society, 48(1):182-195, 2006.

[9] Gerard J Blaauw. Driving experience and task demands in simulator and instrumented car: a validation study. Human Factors: The Journal of the Human Factors and Ergonomics Society, 24(4):473-486, 1982.

[10] Avinoam Borowsky, David Shinar, and Yisrael Parmet. Sign location, sign recognition, and driver expectancies. Transportation research part F: traffic psychology and behaviour, 11(6):459-465, 2008.

[11] Curt C Braun and N Clayton Silver. Interaction of warning label features: determining the contributions of three warning characteristics. In Proceedings of the Human Factors and Ergonomics Society Annual Meeting, volume 39, pages 984-988. SAGE Publications, 1995. 
[12] Patrick Brézillon, Brigitte Cambon De Lavalette, Charles Tijus, Sébastien Poitrenaud, Christine Leproux, Alexandre Lacaste, and Mary Bazire. External and internal representations of road pictographic signs. Computing and Philosophy. L. Magnani (eds), Associated International Academic Publishers, 2004.

[13] Karel A Brookhuis, Dick De Waard, and Wiel H Janssen. Behavioural impacts of advanced driver assistance systems-an overview. European Journal of Transport and Infrastructure Research, 1(3):245-253, 2001.

[14] Chad A Brooks and Andry Rakotonirainy. In-vehicle technologies, advanced driver assistance systems and driver distraction: Research challenges. Proceedings from the International Conference on Driver Distraction, 2005.

[15] Ty Burr. Do you speak Canadian road sign? http://www.bostonglobe.com/ arts/2015/07/02/tycolumn/D39RVUckYXCyJRNTOd0sQP/story.html. [Online; accessed July-2015].

[16] Alan HS Chan and Annie WY Ng. Investigation of guessability of industrial safety signs: effects of prospective-user factors and cognitive sign features. International Journal of Industrial Ergonomics, 40(6):689-697, 2010.

[17] Samuel G Charlton and Nicola J Starkey. Driving on familiar roads: Automaticity and inattention blindness. Transportation research part F: traffic psychology and behaviour, 19:121-133, 2013.

[18] Robert Dewar. Warning: Hazardous road signs ahead. Ergonomics in Design: The Quarterly of Human Factors Applications, 1(3):26-31, 1993.

[19] Sunanda Dissanayake and Jian John Lu. Traffic control device comprehension: Differences between domestic and international drivers in usa. IATSS research, 25(2):80-87, 2001.

[20] Birsen Donmez, Linda Boyle, and John D Lee. Designing feedback to mitigate distraction. In Driver Distraction: Theory, Effects, and Mitigation, pages 519531. CRC Press, 2009.

[21] Tania Dukic, Christer Ahlstrom, Christopher Patten, Carmen Kettwich, and Katja Kircher. Effects of electronic billboards on driver distraction. Traffic injury prevention, 14(5):469-476, 2013.

[22] Jerry G Ells and Robert E Dewar. Rapid comprehension of verbal and symbolic traffic sign messages. Human Factors: The Journal of the Human Factors and Ergonomics Society, 21:161-168, 1979.

[23] Mica R Endsley. Designing for situation awareness: An approach to user-centered design. CRC Press, 2011. 
[24] Mica R Endsley and Daniel J Garland. Pilot situation awareness training in general aviation. In Proceedings of the Human Factors and Ergonomics Society Annual Meeting, volume 44, pages 357-360. SAGE Publications, 2000.

[25] Human Factors and Ergonomics Society. What is human factors/ergonomics. https://www.hfes.org/web/AboutHFES/about.html, 2002. [Online; accessed August-2015].

[26] Economic Commission for Europe: Inland Transport Committee. Convention on road signs and signals. In (E/CONF.56/17/Rev.1/Amend.1). Vienna: United Nations Economic and Social Council, 1968.

[27] Adam Galpin, Geoffrey Underwood, and David Crundall. Change blindness in driving scenes. Transportation research part F: traffic psychology and behaviour, 12(2):179-185, 2009.

[28] David Geronimo, Antonio M Lopez, Angel D Sappa, and Thorsten Graf. Survey of pedestrian detection for advanced driver assistance systems. Pattern Analysis and Machine Intelligence, IEEE Transactions on, 32(7):1239-1258, 2010.

[29] Richard D Gilson, Lloyd Hitchcock, Richard A Pew, Mica R Endsley, Kip Smith, RM Taylor, Eugene C Adam, and Nadine B Sarter. Situational awareness in complex systems. Technical report, DTIC Document, 1994.

[30] Paul A. Green, Heejin Jeong, and Te-Ping Kang. Using an OpenDS driving simulator for car following: A first attempt. In Adjunct Proceedings of the 6th International Conference on Automotive User Interfaces and Interactive Vehicular Applications, AutomotiveUI '14, pages 1-6, New York, NY, USA, 2014. ACM.

[31] Milton Harmelink and Rodney Edwards. Introduction to the Ontario Traffic Manual: Appendix B - Sign Design Principles. Ministry of Transportation, Ontario, 32005.

[32] Jochen Heinzman and Alexander Zelinsky. Automotive safety solutions through technology and human-factors innovation. In Experimental Robotics, pages 137147. Springer, 2014.

[33] Kevin G Hooper and Hugh W McGee. Driver perception-reaction time: Are revisions to current specification values in order? Technical report, National Transportation Research Board, 1983.

[34] American National Standards Institute. Product safety signs and labels. https://www.nema.org/Standards/ComplimentaryDocuments/ Z535-4-Contents-and-Scope.pdf, 1991. [Online; accessed August-2015]. 
[35] SensoMotoric Instruments. SMI eye tracking glasses. http://www.smivision. com/en/gaze-and-eye-tracking-systems/products/overview.html, 2015. [Online; accessed August-2015].

[36] Casey Kennington, Spyros Kousidis, Timo Baumann, Hendrik Buschmeier, Stefan Kopp, and David Schlangen. Better driving and recall when in-car information presentation uses situationally-aware incremental speech output generation. In Proceedings of the 6th International Conference on Automotive User Interfaces and Interactive Vehicular Applications, pages 1-7. ACM, 2014.

[37] Casey Kennington, Spyros Kousidis, Timo Baumann, Hendrik Buschmeier, Stefan Kopp, and David Schlangen. Better driving and recall when in-car information presentation uses situationally-aware incremental speech output generation. In Proceedings of the 6th International Conference on Automotive User Interfaces and Interactive Vehicular Applications, AutomotiveUI '14, pages 7:1-7:7, New York, NY, USA, 2014. ACM.

[38] Spyros Kousidis, Casey Kennington, Timo Baumann, Hendrik Buschmeier, Stefan Kopp, and David Schlangen. A multimodal in-car dialogue system that tracks the driver's attention. In Proceedings of the 16th International Conference on Multimodal Interaction, pages 26-33. ACM, 2014.

[39] Arnaud Koustanaï, Pierre Van Elslande, and Claude Bastien. Use of change blindness to measure different abilities to detect relevant changes in natural driving scenes. Transportation research part F: traffic psychology and behaviour, 15(3):233-242, 2012.

[40] John D Lee, Brent Caven, Steven Haake, and Timothy L Brown. Speech-based interaction with in-vehicle computers: The effect of speech-based e-mail on drivers' attention to the roadway. Human Factors: The Journal of the Human Factors and Ergonomics Society, 43(4):631-640, 2001.

[41] S David Leonard. Does color of warnings affect risk perception? International Journal of Industrial Ergonomics, 23(5):499-504, 1999.

[42] Arien Mack and Irvin Rock. Inattentional blindness. MIT press Cambridge, MA, 1998.

[43] Masha Maltz and David Shinar. Imperfect in-vehicle collision avoidance warning systems can aid drivers. Human Factors: The Journal of the Human Factors and Ergonomics Society, 46(2):357-366, 2004.

[44] Gabriela Mancero, William Wong, and Paola Amaldi. Looking but not seeing: implications for HCI. In Proceedings of the 14th European conference on Cognitive ergonomics: invent! explore!, pages 167-174. ACM, 2007. 
[45] Rafael Math, Angela Mahr, Mohammad M Moniri, and Christian Müller. OpenDS: A new open-source driving simulator for research. GMM-FachberichtAmE 2013, 2013.

[46] Bernhard Maurer, Sandra Trösterer, Magdalena Gärtner, Martin Wuchse, Axel Baumgartner, Alexander Meschtscherjakov, David Wilfinger, and Manfred Tscheligi. Shared gaze in the car: Towards a better driver-passenger collaboration. In Adjunct Proceedings of the 6th International Conference on Automotive User Interfaces and Interactive Vehicular Applications, AutomotiveUI '14, pages 1-6, New York, NY, USA, 2014. ACM.

[47] Keenan R May, Thomas M Gable, and Bruce N Walker. A multimodal air gesture interface for in vehicle menu navigation. In Proceedings of the 6th International Conference on Automotive User Interfaces and Interactive Vehicular Applications, pages 1-6. ACM, 2014.

[48] Sin J. P. McDougall, Oscar de Bruijn, and Martin B. Curry. Exploring the effects of icon characteristics on user performance: The role of icon concreteness, complexity, and distinctiveness. Journal of Experimental Psychology: Applied, 6:291-306, 2000.

[49] Robert C McLane and Walter W Wierwille. The influence of motion and audio cues on driver performance in an automobile simulator. Human Factors: The Journal of the Human Factors and Ergonomics Society, 17(5):488-501, 1975.

[50] Barbara Metz and Hans-Peter Krüger. Do supplementary signs distract the driver? Transportation research part F: traffic psychology and behaviour, 23:1$14,2014$.

[51] Daniel Münter, Anna Kötteritzsch, Tobias Islinger, Thorsten Köhler, Christian Wolff, and Jürgen Ziegler. Improving navigation support by taking care of drivers' situational needs. In Proceedings of the 4th International Conference on Automotive User Interfaces and Interactive Vehicular Applications, pages 131138. ACM, 2012.

[52] Annie WY Ng and Alan HS Chan. Visual and cognitive features on icon effectiveness. In Proceedings of the international multiconference of engineers and computer scientists, volume 2, pages 19-21. Citeseer, 2008.

[53] U.S. Department of Transportion National Highway Traffic Safety Administration. Distracted Driving 2013. http://www.distraction.gov/downloads/ pdfs/Distracted_Driving_2013_Research_note.pdf, 2015. [Online; accessed August-2015].

[54] United Nations World Tourism Organization. UNWTO Annual Report 2014. http://www2 . unwto.org/annualreport2014, 2014. [Online; accessed August2015]. 
[55] United Nations World Tourism Organization. UNWTO Tourism Highlights 2014 Edition. http://mkt.unwto.org/publication/ unwto-tourism-highlights-2014-edition, 2014. [Online; accessed August2015].

[56] Jeffrey F Paniati. Redesign and evaluation of selected work zone sign symbols. Transportation Research Record, 1989.

[57] Panos Papadimitratos, A La Fortelle, Knut Evenssen, Roberto Brignolo, and Stefano Cosenza. Vehicular communication systems: Enabling technologies, applications, and future outlook on intelligent transportation. Communications Magazine, IEEE, 47(11):84-95, 2009.

[58] Eleni Petridou, H Askitopoulou, Dimitris Vourvahakis, Y Skalkidis, and Dimitrios Trichopoulos. Epidemiology of road traffic accidents during pleasure travelling: the evidence from the island of crete. Accident Analysis 85 Prevention, 29(5):687-693, 1997.

[59] Ioannis Politis, Stephen Brewster, and Frank Pollick. Evaluating multimodal driver displays of varying urgency. In Proceedings of the 5th International Conference on Automotive User Interfaces and Interactive Vehicular Applications, pages 92-99. ACM, 2013.

[60] Ronald A Rensink, J Kevin O'Regan, and James J Clark. To see or not to see: The need for attention to perceive changes in scenes. Psychological science, 8(5):368-373, 1997.

[61] Andreas Riener and Hannes Thaller. Subliminal visual information to enhance driver awareness and induce behavior change. In Proceedings of the 6th International Conference on Automotive User Interfaces and Interactive Vehicular Applications, AutomotiveUI '14, pages 6:1-6:9, New York, NY, USA, 2014. ACM.

[62] GetHomeSafe: Extended Multimodal Search and Communication Systems for Safe In-Car Application. Current state of development. http: //www.gethomesafe-fp7.eu/index.php/menu-opends/99-cat-opends/ cat-opends-about/100-state, 2015. [Online; accessed August-2015].

[63] David Shinar, Robert E Dewar, Heikki Summala, and Lidia Zakowska. Traffic sign symbol comprehension: a cross-cultural study. Ergonomics, 46(15):1549$1565,2003$.

[64] David Shinar and Margreet Vogelzang. Comprehension of traffic signs with symbolic versus text displays. Transportation research part F: traffic psychology and behaviour, 18:72-82, 2013.

[65] David L Strayer and Frank A Drews. Cell-phone-induced driver distraction. Current Directions in Psychological Science, 16(3):128-131, 2007. 
[66] Jane Stutts, John Feaganes, Eric Rodgman, Charles Hamlett, Donald Reinfurt, Kenneth Gish, Michael Mercadante, and Loren Staplin. The causes and consequences of distraction in everyday driving. In Annual Proceedings/Association for the Advancement of Automotive Medicine, volume 47, page 235. Association for the Advancement of Automotive Medicine, 2003.

[67] Heikki Summala. American drivers in europe: Different signing policy may cause safety problems at uncontrolled intersections. Accident Analysis \&3 Prevention, 30(2):285-289, 1998.

[68] Kirsteen Titchener and Ides Y Wong. Driver distractions: Characteristics underlying drivers risk perceptions. Journal of Risk Research, 13(6):771-780, 2010.

[69] Traffic and Electrical Section Engineering Branch. Manual of Standard Traffic Signs and Pavement Markings. Ministry of Transportation, British Colombia, 9 2000 .

[70] Sergej Truschin, Michael Schermann, Suparna Goswami, and Helmut Krcmar. Designing interfaces for multiple-goal environments: Experimental insights from in-vehicle speech interfaces. ACM Transactions on Computer-Human Interaction (TOCHI), 21(1):7, 2014.

[71] Roberto Viganò and Edoardo Rovida. A proposed method about the design of road signs. Journal of Transportation Safety 85 Security, 7(1):56-75, 2015.

[72] Shanna J Ward, Michael S Wogalter, and Andrew W Mercer. Comprehension and training of international road signs. In Proceedings of the Human Factors and Ergonomics Society Annual Meeting, volume 48, pages 2104-2108. SAGE Publications, 2004.

[73] Christopher D Wickens and William J Horrey. Models of attention, distraction, and highway hazard avoidance. Driver distraction. Theory, effects and mitigation, pages 249-279, 2008.

[74] Yu Zhang, Elizabeth Harris, Meghan Rogers, David Kaber, Joseph Hummer, William Rasdorf, and Jia Hu. Driver distraction and performance effects of highway logo sign design. Applied ergonomics, 44(3):472-479, 2013. 
Appendix A

Road Signs used for Highway and City studies 


\begin{tabular}{|c|c|c|c|}
\hline German Signs & Description & Highway Track & City Track \\
\hline & $\begin{array}{c}\text { Dangerous curve to } \\
\text { the right }\end{array}$ & $\checkmark$ & \\
\hline & Double Curve & $\checkmark$ & \\
\hline & $\begin{array}{c}\text { Maximum Speed } \\
\text { Limit }\end{array}$ & $\checkmark$ & \\
\hline & No Hazardous Goods & $\checkmark$ & $\checkmark$ \\
\hline & & & \\
\hline & & & \\
\hline
\end{tabular}




\begin{tabular}{|c|c|c|c|}
\hline German Signs & Description & Highway Track & City Track \\
\hline & Buses Warning & $\checkmark$ & \\
\hline & Pedestrian Zone & $\checkmark$ & \\
\hline & Bus Stop & $\checkmark$ & \\
\hline & End of Pedestrian & & \\
\hline & & & \\
\hline & & & \\
\hline & & & \\
\hline
\end{tabular}




\begin{tabular}{|c|c|c|c|}
\hline German Signs & Description & Highway Track & City Track \\
\hline & No Parking & $\checkmark$ & $\checkmark$ \\
\hline & No Cars & $\checkmark$ & \\
\hline & Do Not Enter & & \\
\hline & & & \\
\hline & Roundabout & & $\checkmark$ \\
\hline & & & \\
\hline & & & \\
\hline & & & \\
\hline
\end{tabular}




\begin{tabular}{|c|c|c|c|}
\hline German Signs & Description & Highway Track & City Track \\
\hline & Two Way Traffic & $\checkmark$ & $\checkmark$ \\
\hline$\uparrow$ & & & \\
\hline
\end{tabular}






\begin{tabular}{|c|c|c|c|}
\hline Canadian Signs & Description & Highway Track & City Track \\
\hline & No Parking & $\checkmark$ & $\checkmark$ \\
\hline & $\begin{array}{l}\text { Speed Limit Changes } \\
\text { Ahead }\end{array}$ & $\checkmark$ & \\
\hline & Yield at Roundabout & & $\checkmark$ \\
\hline & Overtaking Permitted & $\checkmark$ & $\checkmark$ \\
\hline & $\begin{array}{l}\text { Overtaking Not } \\
\text { Permitted }\end{array}$ & $\checkmark$ & \\
\hline & Stop & $\sqrt{ }$ & $\checkmark$ \\
\hline & $\begin{array}{l}\text { Dangerous Goods } \\
\text { Prohibited }\end{array}$ & $\checkmark$ & $\checkmark$ \\
\hline & $\begin{array}{l}\text { Dangerous Goods } \\
\text { Permitted }\end{array}$ & $\checkmark$ & $\checkmark$ \\
\hline & No Littering & & $\checkmark$ \\
\hline & $\begin{array}{l}\text { Pedestrians } \\
\text { Prohibited }\end{array}$ & $\checkmark$ & $\checkmark$ \\
\hline
\end{tabular}




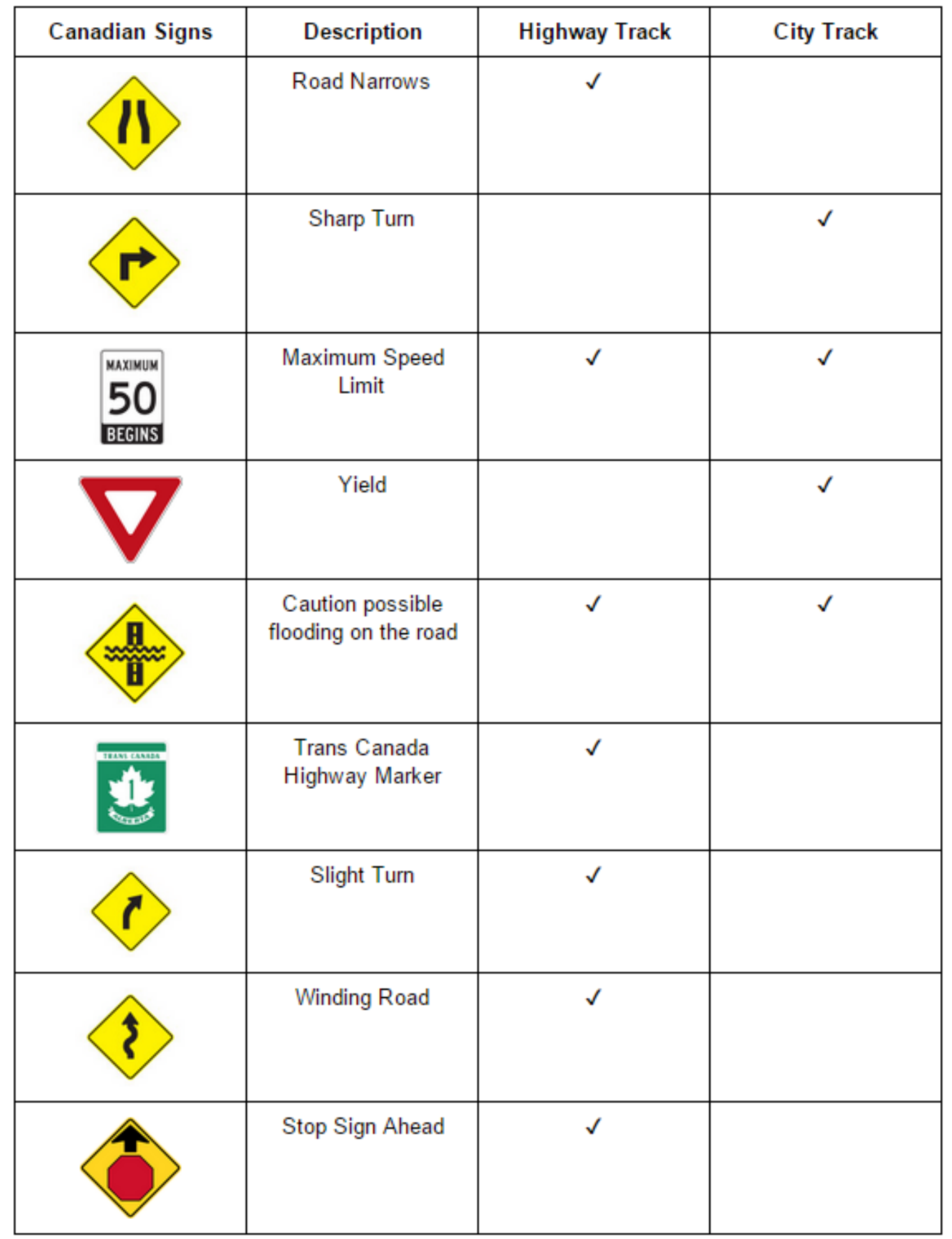




\begin{tabular}{|c|c|c|c|}
\hline Chinese Signs & Description & Highway Track & City Track \\
\hline & Stop for Inspection & $\checkmark$ & $\checkmark$ \\
\hline & Cars Permitted & $\checkmark$ & \\
\hline & & & \\
\hline & Honking Permitted & $\checkmark$ & \\
\hline & & & \\
\hline & & & \\
\hline & & & \\
\hline
\end{tabular}




\begin{tabular}{|c|c|c|c|}
\hline Chinese Signs & Description & Highway Track & City Track \\
\hline & Mandatory Turn & & $\checkmark$ \\
\hline & $\begin{array}{l}\text { Maximum Speed } \\
\text { Limit }\end{array}$ & $\checkmark$ & $\checkmark$ \\
\hline & Intersection Ahead & & $\checkmark$ \\
\hline & Pedestrian Crossing & & $\checkmark$ \\
\hline & Turn out & $\checkmark$ & \\
\hline & Stop & $\checkmark$ & $\checkmark$ \\
\hline & $\begin{array}{l}\text { Caution Avoid } \\
\text { Collisions }\end{array}$ & $\checkmark$ & $\checkmark$ \\
\hline & Intersection & & $\checkmark$ \\
\hline & Downwards Incline & $\checkmark$ & \\
\hline
\end{tabular}




\begin{tabular}{|l|c|c|c|}
\hline Chinese Signs & Description & Highway Track & City Track \\
\hline & Cliff & $\checkmark$ & \\
\hline & Watch for Children & $\checkmark$ & \\
\hline & $\begin{array}{c}\text { Caution Possible } \\
\text { Flooding on the Road }\end{array}$ & $\checkmark$ & \\
\hline & Fork in the Road & & \\
\hline & Ahead & $\checkmark$ & \\
\hline & Bumpy Road & & \\
\hline & Slippery Road & & \\
\hline & & & \\
\hline
\end{tabular}




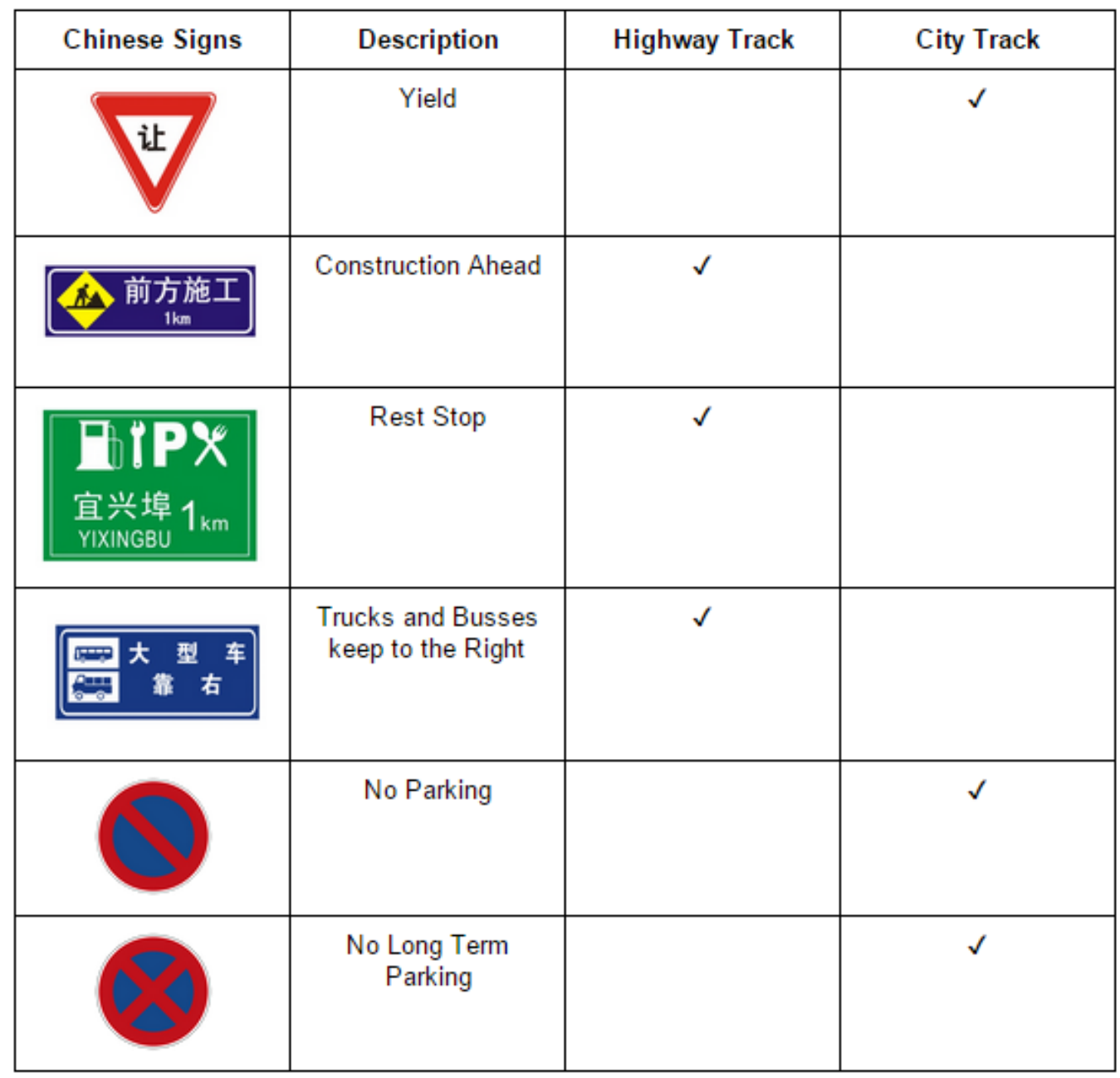




\section{Appendix B}

\section{Longest Consecutive Gaze Fixation Time Per Sign}

The following is a list of tables showing statistics for the longest consecutive gaze

fixation time per sign. It is organized based on study. 


\begin{tabular}{|c|c|c|c|c|c|}
\hline \multicolumn{6}{|c|}{ Longest Consecutive Gaze Fixation Time (German Track) - Highway } \\
\hline Signs & $\operatorname{Max}$ & Min & Median & Mean & Standard Deviation \\
\hline S1 - Caution Sharp Right Turn & 8.95 & 0 & 3.29 & 3.24 & 2.25 \\
\hline S2 - Maximum Speed Limit 100 & 9.82 & 0.63 & 3.59 & 3.62 & 2.46 \\
\hline S3 - Hazardous Goods Prohibited & 7.64 & 0 & 3.82 & 3.71 & 1.95 \\
\hline S4 - Slippery Road & 8.05 & 0.40 & 1.21 & 2.02 & 1.96 \\
\hline S5 - Caution Sharp Left Turn & 3.36 & 0.38 & 1.03 & 1.17 & 0.80 \\
\hline S6 - Loose Gravel & 5.00 & 0.38 & 3.01 & 2.76 & 1.37 \\
\hline S7 - General Caution & 4.54 & 0 & 2.15 & 2.18 & 1.28 \\
\hline S8 - Overtaking Prohibited & 5.34 & 163 & 2.22 & 2.68 & 1.02 \\
\hline S9 - Two-way Traffic & 2.84 & 0.23 & 1.11 & 1.22 & 0.73 \\
\hline S10 - Emergency Phone & 6.25 & 0 & 3.58 & 3.22 & 1.91 \\
\hline S11 - Maximum Speed Limit 80 & 3.09 & 0.22 & 1.15 & 1.18 & 0.74 \\
\hline S12 - Caution Buses & 8.90 & 0 & 2.06 & 2.31 & 2.10 \\
\hline S13 - Pedestrian Zone & 8.78 & 0 & 2.13 & 2.61 & 2.20 \\
\hline S14 - Bus Stop & 3.56 & 0 & 10.31 & 11.35 & 0.87 \\
\hline S15 - End of Pedestrian Zone & 9.70 & 0.86 & 3.64 & 4.09 & 2.67 \\
\hline S16 - Double Curve & 6.67 & 0.53 & 1.16 & 1.63 & 1.43 \\
\hline S17 - End of No Overtaking & 3.46 & 0 & 0.78 & 1.02 & 0.90 \\
\hline S18 - Upwards Incline & 3.74 & 0.22 & 1.48 & 1.75 & 1.02 \\
\hline S19 - Intersection Ahead & 4.45 & 0 & 173 & 2.02 & 1.33 \\
\hline S20 - End of Highway & 8.81 & 0.71 & 2.62 & 2.90 & 1.90 \\
\hline S21 - Yield & 3.49 & 0 & 1.33 & 1.44 & 0.85 \\
\hline S22 - Animal Crossing & 2.16 & 0.17 & 5.99 & 0.86 & 0.58 \\
\hline S23 - No Parking & 4.42 & 0 & 1.99 & 2.11 & 1.25 \\
\hline S24 - No Cars & 4.89 & 0 & 1.16 & 1.75 & 1.42 \\
\hline S25 - Do Not Enter & 3.74 & 0 & 0.70 & 0.99 & 0.91 \\
\hline
\end{tabular}

Table B.1: Longest Consecutive Gaze Fixation Time per sign (German Track)

\begin{tabular}{|c|c|c|c|c|c|}
\hline Signs & Max & Min & Median & Mean & Standard Deviation \\
\hline S1 - Maximum Speed Limit 50 & 3.84 & 0.10 & 1.19 & 1.55 & 0.96 \\
\hline S2 - Dangerous Goods Prohibited & 6.44 & 0.50 & 3.56 & 3.37 & 1.76 \\
\hline S3 - Directional Sign & 5.46 & 0.60 & 2.78 & 2.75 & 1.28 \\
\hline S4 - Stop Ahead & 3.95 & 0 & 1.16 & 1.42 & 0.10 \\
\hline S5 - Stop & 3.32 & 0 & 0.85 & 1.12 & 0.99 \\
\hline S6 - Hidden Road & 7.03 & 0 & 1.16 & 1.58 & 1.85 \\
\hline S7 - Road Narrows & 1.63 & 0.20 & 0.98 & 0.93 & 0.39 \\
\hline S8 - Trans-Canada Highway Marker & 6.55 & 0.61 & 4.37 & 3.76 & 1.70 \\
\hline S9 - Slight Right Curve & 5.36 & 0 & 1.80 & 2.07 & 1.55 \\
\hline S10 - Overtaking Prohibited & 3.59 & 0 & 1.53 & 1.82 & 1.01 \\
\hline S11 - Loose Gravel & 5.21 & 0.10 & 2.79 & 2.90 & 1.20 \\
\hline S12 - Maximum Speed Limit 80 & 3.73 & 0 & 1.41 & 1.69 & 1.07 \\
\hline S13 - Pedestrians Prohibited & 7.20 & 0 & 2.26 & 2.97 & 2.07 \\
\hline S14 - Dangerous Goods Permitted & 5.41 & 0.33 & 2.99 & 2.92 & 1.53 \\
\hline S15 - Overtaking Permitted & 3.84 & 0.18 & 1.93 & 1.91 & 1.10 \\
\hline S16 - Slippery Road & 9.48 & 0.46 & 4.12 & 4.50 & 2.34 \\
\hline S17 - Caution Possible Flooding & 8.42 & 1.21 & 4.08 & 3.90 & 1.71 \\
\hline S18 - 50 Speed Limit Begins Ahead & 3.74 & 0.37 & 1.06 & 1.38 & 1.07 \\
\hline S19 - Maximum Speed Limit 50 & 5.45 & 0.01 & 1.53 & 1.82 & 1.19 \\
\hline S20 - No Stopping & 6.40 & 0.22 & 1.60 & 2.33 & 1.71 \\
\hline S21 - No Parking & 4.59 & 0.33 & 1.81 & 1.78 & 1.14 \\
\hline S22 - Maximum Speed Limit 100 & 3.41 & 0 & 1.70 & 1.62 & 0.84 \\
\hline S23 - Winding Road & 4.03 & 0.08 & 1.25 & 1.57 & 1.22 \\
\hline S24 - Airport Route & 3.72 & 0.17 & 1.56 & 1.44 & 0.93 \\
\hline S25 - Do Not Enter & 3.61 & 0.30 & 0.96 & 1.48 & \\
\hline
\end{tabular}

Table B.2: Longest Consecutive Gaze Fixation Time per sign (Canadian Track) 


\begin{tabular}{|c|c|c|c|c|c|}
\hline Signs & $\operatorname{Max}$ & Min & Median & Mean & Standard Deviation \\
\hline S1 - Maximum Speed Limit 50 & 4.24 & 0.18 & 1.33 & 1.26 & 0.97 \\
\hline S2 - Fork Ahead & 4.13 & 0.65 & 1.80 & 1.97 & 1.02 \\
\hline S3 - Slow Down & 8.17 & 0.27 & 3.06 & 3.25 & 2.10 \\
\hline S4 - Stop & 4.96 & 0.08 & 0.46 & 0.89 & 1.12 \\
\hline S5 - No Cars & 1.10 & 0 & 0.38 & 0.37 & 0.37 \\
\hline S6 - Downwards Incline & 4.51 & 0.33 & 1.56 & 1.79 & 1.09 \\
\hline S7 - Cliff on Right & 8.05 & 1.11 & 3.38 & 4.00 & 2.14 \\
\hline S8 - Double Curve & 9.11 & 0.58 & 2.16 & 3.08 & 2.22 \\
\hline S9 - Cars Allowed & 5.42 & 0.20 & 2.39 & 2.44 & 1.56 \\
\hline S10 - Maximum Speed Limit 50 & 3.31 & 0.37 & 0.85 & 0.45 & 1.73 \\
\hline S11 - Watch for Children & 5.61 & 0.85 & 2.49 & 2.47 & 1.28 \\
\hline S12 - Turn Out on Right & 3.78 & 0.45 & 1.53 & 1.81 & 0.98 \\
\hline S13 - Caution Avoid Collisions & 9.92 & 1.73 & 4.61 & 4.64 & 2.04 \\
\hline S14 - Trucks and Buses Stay on Right & 1.19 & 0.07 & 6.39 & 6.07 & 3.09 \\
\hline S15 - Maximum Speed Limit 120 & 4.04 & 0.25 & 1.78 & 1.78 & 0.97 \\
\hline S16 - Rest Stop Ahead & 9.58 & 0 & 2.89 & 3.15 & 2.39 \\
\hline S17 - Honking Prohibited & 7.87 & 0 & 3.16 & 3.05 & 1.93 \\
\hline S18 - Honking Permitted & 6.99 & 0 & 1.70 & 2.13 & 1.93 \\
\hline S19 - Construction Ahead & 8.65 & 0 & 2.76 & 3.40 & 2.24 \\
\hline S20 - Bumps Ahead & 4.85 & 0.27 & 2.01 & 2.09 & 1.54 \\
\hline S21 - Slippery Road & 5.04 & 0.43 & 1.56 & 1.91 & 1.25 \\
\hline S22 - Maximum Speed Limit 80 & 2.26 & 0 & 1.20 & 1.12 & 0.63 \\
\hline S23 - Caution Possible Flooding & 1.02 & 0.06 & 0.37 & 0.38 & 2.67 \\
\hline S24 - Stop for Inspection & 6.35 & 0.15 & 2.79 & 3.36 & 1.89 \\
\hline S25 - Yield to Oncoming Traffic & 5.04 & 0.85 & 2.13 & 2.34 & \\
\hline
\end{tabular}

Table B.3: Longest Consecutive Gaze Fixation Time per sign (Chinese Track)

\begin{tabular}{|c|c|c|c|c|c|}
\hline Longest Consecutive Gaze Fixation Time (German Track) - City & Max & Min & Median & Mean & Standard Deviation \\
\hline Signs & 2.74 & 0 & 0.83 & 0.82 & 0.68 \\
\hline S1 - Maximum Speed Limit 50 & 4.28 & 0 & 1.43 & 1.41 & 1.16 \\
\hline S2 - Bus Stop & 3.01 & 0.66 & 1.31 & 1.49 & 0.67 \\
\hline S3 - Roundabout & 1.55 & 0.23 & 0.70 & 0.77 & 0.46 \\
\hline S4 - Yield & 2.48 & 0.25 & 0.61 & 0.81 & 0.63 \\
\hline S5 - Stop Sign & 5.96 & 1.18 & 3.93 & 3.83 & 1.47 \\
\hline S6 - No Parking & 3.29 & 0.27 & 1.93 & 1.77 & 0.96 \\
\hline S7 - Sharp Right Turn & 4.46 & 0.45 & 2.06 & 2.20 & 1.28 \\
\hline S8 - Overtaking Prohibited & 3.89 & 0.99 & 2.15 & 2.29 & 0.94 \\
\hline S9 - Two-way Traffic & 7.29 & 0.22 & 2.15 & 2.32 & 1.73 \\
\hline S10 - Loose Gravel & 11.08 & 0.48 & 3.76 & 4.37 & 2.94 \\
\hline S11 - No Hazardous Goods & 9.50 & 0.65 & 2.56 & 3.20 & 2.31 \\
\hline S12 - Slippery Road & 4.32 & 0.13 & 0.98 & 1.27 & 1.11 \\
\hline S13 - Stop Sign & 4.84 & 0.26 & 1.60 & 2.26 & 1.57 \\
\hline S14 - Pedestrian Crossing & 2.10 & 0.23 & 0.58 & 0.74 & 0.51 \\
\hline S15 - Stop Sign & 2.75 & 0 & 1.11 & 1.08 & 0.87 \\
\hline S16 - End of No Overtaking & 7.84 & 0.65 & 2.51 & 3.07 & 2.03 \\
\hline S17 - Priority Road & 2.45 & 0.37 & 1.16 & 1.15 & 0.59 \\
\hline S19 - Yield & 2.46 & 0.35 & 1.06 & 1.08 & 0.57 \\
\hline
\end{tabular}

Table B.4: Longest Consecutive Gaze Fixation Time per sign (German Track) 


\begin{tabular}{|c|c|c|c|c|c|}
\hline \multicolumn{6}{|c|}{ Longest Consecutive Gaze Fixation Time (Canadian Track) - City } \\
\hline Signs & Max & Min & Median & Mean & Standard Deviation \\
\hline S1 - Maximum Speed Limit 50 & 1.90 & 0 & 0.51 & 0.66 & 0.62 \\
\hline S2 - Stop & 1.65 & 0 & 0.50 & 0.59 & 0.42 \\
\hline S3 - Pedestrians Prohibited & 5.34 & 0 & 1.95 & 2.38 & 1.97 \\
\hline S4 - Sharp Right Turn & 2.37 & 0 & 1.28 & 1.21 & 0.72 \\
\hline S5 - Dangerous Goods Prohibited & 1.14 & 0 & 0.34 & 0.41 & 2.94 \\
\hline S6 - Stop & 2.03 & 0 & 0.53 & 0.70 & 0.56 \\
\hline S7 - Slippery Road & 8.70 & 0 & 3.19 & 3.48 & 2.41 \\
\hline S8 - Yield & 2.79 & 0 & 0.55 & 0.82 & 0.86 \\
\hline S9 - Roundabout & 6.16 & 0 & 1.01 & 1.47 & 1.49 \\
\hline S10 - Yield & 3.44 & 0 & 1.81 & 1.78 & 0.88 \\
\hline S11 - No Parking & 4.61 & 0 & 1.98 & 2.01 & 1.21 \\
\hline S12 - No Stopping & 6.15 & 0 & 2.64 & 2.46 & 1.75 \\
\hline S13 - Overtaking Permitted & 4.59 & 0.25 & 2.28 & 2.16 & 1.35 \\
\hline S14 - Caution Possible Flooding & 7.44 & 0.18 & 4.21 & 4.07 & 2.06 \\
\hline S15 - Hidden Road & 7.22 & 0.66 & 1.80 & 2.29 & 1.58 \\
\hline S16 - Airport Route & 4.62 & 0.37 & 1.33 & 1.67 & 1.07 \\
\hline S17 - Loose Gravel & 6.60 & 0.58 & 2.48 & 2.59 & 1.65 \\
\hline S18 - No Littering & 8.17 & 0.86 & 1.90 & 3.74 & 2.87 \\
\hline S19 - Dangerous Goods Permitted & 7.19 & 1.30 & 2.79 & 3.35 & 1.84 \\
\hline
\end{tabular}

Table B.5: Longest Consecutive Gaze Fixation Time per sign (Canadian Track)

\begin{tabular}{|c|c|c|c|c|c|}
\hline Longest Consecutive Gaze Fixation Time (Chinese Track) - City & Max & Min & Median & Mean & Standard Deviation \\
\hline Signs & 4.71 & 0 & 0.91 & 1.10 & 1.18 \\
\hline S1 - Maximum Speed Limit 50 & 6.84 & 0.50 & 2.67 & 2.76 & 1.51 \\
\hline S2 - Sharp Right Turn & 3.68 & 0 & 1.41 & 1.46 & 0.94 \\
\hline S3 - T-Intersection & 6.02 & 0.63 & 1.73 & 2.10 & 1.41 \\
\hline S4 - Stop & 6.47 & 0.13 & 3.96 & 3.70 & 1.76 \\
\hline S5 - No Parking & 5.67 & 0.12 & 1.88 & 2.01 & 1.49 \\
\hline S6 - Yield & 3.18 & 0.08 & 1.23 & 1.41 & 0.85 \\
\hline S7 - Pedestrian Crossing & 1.96 & 0.07 & 0.95 & 0.96 & 0.54 \\
\hline S8 - Roundabout & 4.12 & 0.25 & 1.63 & 1.82 & 1.26 \\
\hline S9 - Attention for Pedestrians & 3.99 & 0.27 & 0.96 & 1.58 & 1.20 \\
\hline S10 - No Long Term Parking & 7.97 & 1.48 & 3.89 & 4.29 & 2.01 \\
\hline S11 - Overtaking Permitted & 7.43 & 0.96 & 3.41 & 3.53 & 2.18 \\
\hline S12 - Honking Prohibited & 5.06 & 0.61 & 2.03 & 2.04 & 1.09 \\
\hline S13 - Slippery Road & 5.96 & 0.10 & 2.74 & 3.00 & 1.64 \\
\hline S14 - Intersection Ahead & 7.92 & 0.96 & 4.66 & 4.30 & 2.63 \\
\hline S15 - Caution Avoid Collisions - Mandatory Right Turn & 6.14 & 0.27 & 1.21 & 1.66 & 1.51 \\
\hline S17 - No Cars & 5.44 & 0.63 & 2.16 & 2.26 & 1.44 \\
\hline S18 - Caution Possible Flooding & 8.98 & 0.43 & 3.54 & 3.76 & 2.15 \\
\hline S19 - Stop for Inspection & 9.93 & 0.68 & 3.14 & 3.73 & 2.59 \\
\hline
\end{tabular}

Table B.6: Longest Consecutive Gaze Fixation Time per sign (Chinese Track) 


\title{
Appendix C
}

\section{Road Sign Recognition Scores}

The following graphs represent post-test questionnaire recognition scores per track.

\author{
C.1 Highway Study \\ C.2 City Study
}





(a) German Track
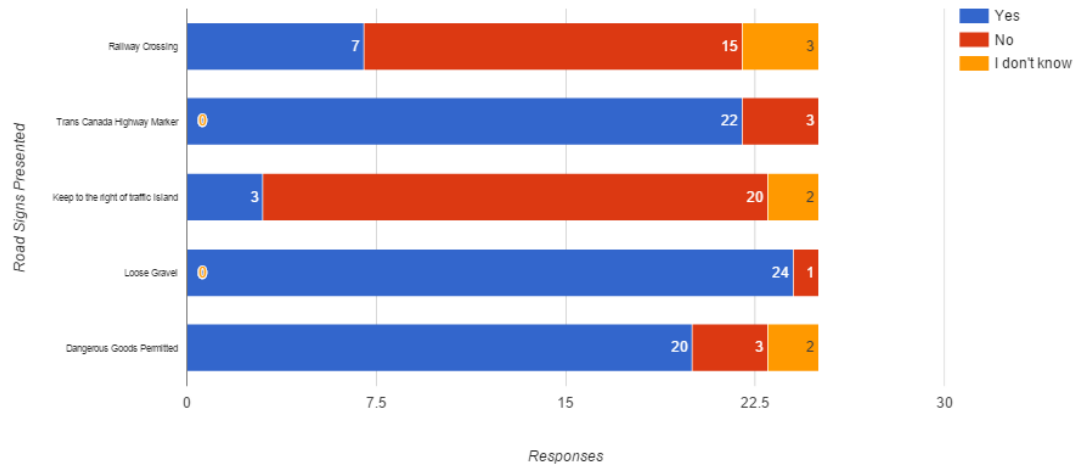

(b) Canadian Track

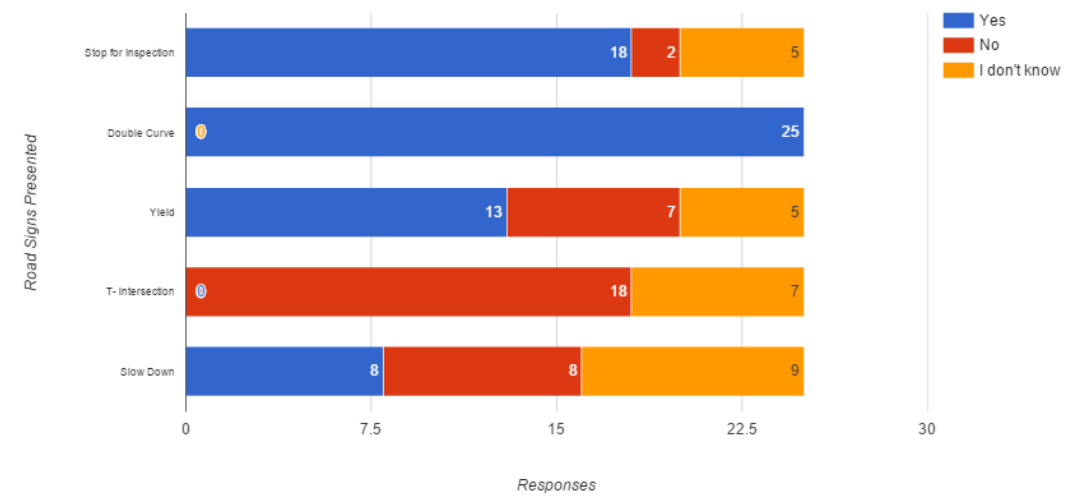

(c) Chinese Track

Figure C.1: Individual Recognition Scores per track (Highway Study) 




(a) German Track

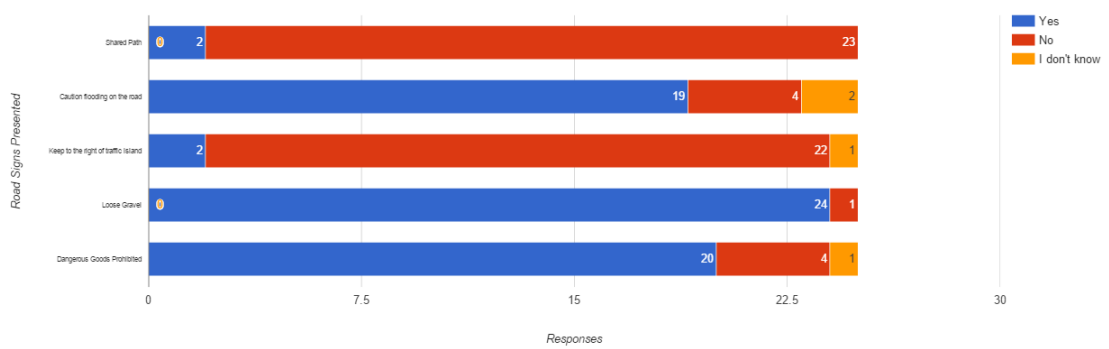

(b) Canadian Track



(c) Chinese Track

Figure C.2: Individual Recognition Scores per track (City Study) 


\section{Appendix D}

\section{Effects of Unfamiliar road signs on speed - Tables}

The following tables describe the number of participants who found each road sign

unfamiliar for each track. 


\begin{tabular}{|c|c|c|c|}
\hline Track & Unfamiliar Road Sign & Number of Participants & $\begin{array}{l}\text { Number who reduced } \\
\text { their speed }\end{array}$ \\
\hline \multirow{22}{*}{ Germany } & No Hazardous Goods & 25 & 11 \\
\hline & End of highway & 24 & 22 \\
\hline & End of No Overtaking & 24 & 19 \\
\hline & No Cars & 23 & 5 \\
\hline & No Parking & 23 & 2 \\
\hline & Intersection Ahead & 19 & 8 \\
\hline & Bus Stop & 17 & 10 \\
\hline & Loose Gravel & 16 & 12 \\
\hline & No Overtaking & 12 & 6 \\
\hline & Do not enter & 12 & 4 \\
\hline & Yield & 10 & 5 \\
\hline & Slippery Road & 7 & 7 \\
\hline & Pedestrian Zone & 4 & 1 \\
\hline & Dangerous Curve Right & 4 & 0 \\
\hline & Caution Buses & 3 & 3 \\
\hline & End of Pedestrian Zone & 3 & 1 \\
\hline & Emergency Phone & 3 & 1 \\
\hline & Two-way Traffic & 3 & 0 \\
\hline & Maximum speed limit & 1 & 0 \\
\hline & Dangerous Curve Left & 1 & 0 \\
\hline & Maximum speed limit no. 2 & 1 & 0 \\
\hline & Upwards Incline & 1 & 0 \\
\hline
\end{tabular}

Table D.1: Number of participants unfamiliar with German road signs (Highway Study) 


\begin{tabular}{|c|c|c|c|}
\hline Track & Unfamiliar Road Sign & Number of Participants & $\begin{array}{l}\text { Number who reduced } \\
\text { their speed }\end{array}$ \\
\hline \multirow{19}{*}{ Canada } & Dangerous Good Permitted & 22 & 6 \\
\hline & Dangerous Goods Prohibited & 22 & 6 \\
\hline & Caution possible flooding & 17 & 11 \\
\hline & Hidden Road Ahead & 7 & 1 \\
\hline & Loose Gravel & 6 & 5 \\
\hline & Do not enter & 6 & 4 \\
\hline & Stop & 5 & 5 \\
\hline & Maximum 50 speed limit & 5 & 5 \\
\hline & $\begin{array}{l}\text { Trans- Canada } \\
\text { Highway Marker }\end{array}$ & 5 & 1 \\
\hline & Slippery Road & 2 & 2 \\
\hline & No Stopping & 2 & 2 \\
\hline & Directional Sign & 2 & 1 \\
\hline & Slight Curve & 2 & 1 \\
\hline & Road Narrows & 2 & 0 \\
\hline & Airport Route & 2 & 0 \\
\hline & No Parking & 1 & 1 \\
\hline & Winding Road & 1 & 1 \\
\hline & Overtaking not permitted & 1 & 0 \\
\hline & Overtaking Permitted & 1 & 0 \\
\hline
\end{tabular}

Table D.2: Number of participants unfamiliar with Canadian road signs (Highway Study) 


\begin{tabular}{|c|c|c|c|}
\hline Track & Unfamiliar Road Sign & Number of Participants & $\begin{array}{l}\text { Number who reduced } \\
\text { their speed }\end{array}$ \\
\hline \multirow{21}{*}{ China } & Stop for Inspection & 25 & 18 \\
\hline & Slow Down & 20 & 17 \\
\hline & Yield to Oncoming Traffic & 19 & 14 \\
\hline & Caution possible flooding & 17 & 8 \\
\hline & Cars Permitted & 16 & 15 \\
\hline & Turn out & 12 & 3 \\
\hline & Cliff on right & 11 & 0 \\
\hline & Trucks and Buses keep right & 10 & 5 \\
\hline & Honking Prohibited & 10 & 4 \\
\hline & Caution avoid collisions & 9 & 8 \\
\hline & Honking Permitted & 9 & 6 \\
\hline & Fork Ahead & 5 & 1 \\
\hline & Construction Ahead & 4 & 1 \\
\hline & Rest Stop & 4 & 0 \\
\hline & Stop & 3 & 3 \\
\hline & Slippery Road & 3 & 2 \\
\hline & Maximum 50 speed limit & 2 & 1 \\
\hline & Watch for Children & 2 & 1 \\
\hline & Bumps Ahead & 2 & 0 \\
\hline & Maximum 80 speed limt & 2 & 0 \\
\hline & Double Curve & 1 & 0 \\
\hline
\end{tabular}

Table D.3: Number of participants unfamiliar with Chinese road signs (Highway Study) 


\begin{tabular}{|l|l|r|r|}
\hline Track & Unfamiliar Road Sign & Number of Participants & $\begin{array}{l}\text { Number who reduced } \\
\text { their speed }\end{array}$ \\
\hline \multirow{7}{*}{} & No Hazardous Goods & 25 & 17 \\
\cline { 2 - 4 } & Priority Road & 25 & 12 \\
\cline { 2 - 4 } & Overtaking Permitted & 22 & 8 \\
\cline { 2 - 4 } & Bus Stop & 21 & 7 \\
\cline { 2 - 4 } & Loose Gravel & 18 & 17 \\
\cline { 2 - 4 } & No Parking & 18 & 15 \\
\cline { 2 - 4 } & End of No Overtaking & 12 & 9 \\
\cline { 2 - 4 } & Two-way traffic & 7 & 4 \\
\cline { 2 - 4 } & Sharp Turn & 3 & 2 \\
\cline { 2 - 4 } & Stop no 3 & 2 & 3 \\
\cline { 2 - 4 } & Slippery Road & 2 & 1 \\
\cline { 2 - 4 } & Yield & 1 & 1 \\
\cline { 2 - 4 } & Stop no 2 & 1 & 1 \\
\cline { 2 - 4 } & Pedestrian Crossing & 1 & 1 \\
\cline { 2 - 4 } & Maximum speed limit & 1 & 0 \\
\cline { 2 - 4 } & Roundabout & 1 & 0 \\
\cline { 2 - 4 } & Stop & 1 & \\
\hline
\end{tabular}

Table D.4: Number of participants unfamiliar with German road signs (City Study)

\begin{tabular}{|c|c|c|c|}
\hline Track & Unfamiliar Road Sign & Number of Participants & $\begin{array}{l}\text { Number who reduced } \\
\text { their speed }\end{array}$ \\
\hline \multirow{17}{*}{ Canada } & Dangerous Goods Prohibited & 25 & 12 \\
\hline & Dangerous Goods Permitted & 24 & 19 \\
\hline & Caution possible flooding & 14 & 13 \\
\hline & Slippery Road & 9 & 7 \\
\hline & Maximum speed limit & 5 & 0 \\
\hline & Pedestrians Prohibited & 4 & 0 \\
\hline & Overtaking Permitted & 3 & 2 \\
\hline & Loose Gravel & 3 & 2 \\
\hline & Stop & 2 & 2 \\
\hline & Hidden Road Ahead & 2 & 1 \\
\hline & No Littering & 2 & 0 \\
\hline & No Stopping & 2 & 0 \\
\hline & Yield & 1 & 1 \\
\hline & Yield no 2 & 1 & 1 \\
\hline & Stop no 2 & 1 & 1 \\
\hline & Sharp Turn & 1 & 0 \\
\hline & Airport Route & 1 & 0 \\
\hline
\end{tabular}

Table D.5: Number of participants unfamiliar with Canadian road signs (City Study) 


\begin{tabular}{|l|l|r|r|}
\hline Track & Unfamiliar Road Sign & Number of Participants & $\begin{array}{l}\text { Number who reduced } \\
\text { their speed }\end{array}$ \\
\hline \multirow{7}{*}{} & Stop for Inspection & 25 & 21 \\
\cline { 2 - 4 } & No Cars & 25 & 8 \\
\cline { 2 - 4 } & Overtaking Permitted & 24 & 18 \\
\cline { 2 - 4 } & No Parking & 23 & 22 \\
\cline { 2 - 4 } & Intersection Ahead & 20 & 12 \\
\cline { 2 - 4 } & No Long Term Parking & 19 & 13 \\
\cline { 2 - 4 } & Caution possible flooding & 17 & 5 \\
\cline { 2 - 4 } & Caution Avoid Collisions & 10 & 9 \\
\cline { 2 - 4 } & Honking Prohibited & 9 & 6 \\
\cline { 2 - 4 } & Yield & 2 & 2 \\
\cline { 2 - 4 } & Slippery Road & 2 & 1 \\
\cline { 2 - 4 } & Speed Limit & 2 & 1 \\
\cline { 2 - 4 } & Pedestrian Crossing & 1 & 0 \\
\cline { 2 - 4 } & Sharp Right Turn & 1 & 0 \\
\cline { 2 - 4 } & Intersection & 1 & 0 \\
\cline { 2 - 4 } & Roundabout & 1 & 1 \\
\cline { 2 - 4 } & Attention for pedestrians & 1 & 0 \\
\hline
\end{tabular}

Table D.6: Number of participants unfamiliar with Chinese road signs (City Study) 


\section{Appendix E}

\section{Effects of Unfamiliar road signs on gaze - Tables}

The following tables identify the road signs that were unfamiliar to participants for all tracks. Tables are organized by study. 


\begin{tabular}{|c|c|c|c|}
\hline \multicolumn{4}{|l|}{ Germany } \\
\hline Sign & $\begin{array}{l}\text { Average Total } \\
\text { Gaze Duration (seconds) }\end{array}$ & $\begin{array}{l}\text { Participants who } \\
\text { Exceeded Average }\end{array}$ & Total Participants \\
\hline Dangerous Curve right & 6.09 & 0 & 1 \\
\hline No Hazardous Goods & 5.16 & 8 & 17 \\
\hline Slippery Road & 3.52 & 1 & 4 \\
\hline Dangerous Curve left & 2.06 & 1 & 1 \\
\hline Loose Gravel & 4.33 & 1 & 5 \\
\hline Overtaking Prohibited & 4.99 & 3 & 9 \\
\hline Two-way traffic & 2.61 & 0 & 2 \\
\hline Emergency Phone & 4.49 & 1 & 2 \\
\hline Caution Buses & 3.57 & 2 & 3 \\
\hline Pedestrian Zone & 3.21 & 2 & 2 \\
\hline Bus Stop & 2.13 & 4 & 11 \\
\hline End of Pedestrian Zone & 5.76 & 2 & 3 \\
\hline End of no Overtaking & 1.62 & 7 & 16 \\
\hline Upwards Incline & 2.93 & 0 & 1 \\
\hline Intersection Ahead & 0.49 & 13 & 14 \\
\hline End of Highway & 4.43 & 4 & 16 \\
\hline Yield & 2.21 & 2 & 6 \\
\hline No Parking & 3.68 & 9 & 15 \\
\hline No Cars & 2.33 & 7 & 15 \\
\hline Do not Enter & 2.42 & 4 & 7 \\
\hline
\end{tabular}

Table E.1: Average gazing time for German road signs identified as unfamiliar (Highway Study)

\begin{tabular}{|c|c|c|c|}
\hline \multicolumn{4}{|l|}{ Canada } \\
\hline Sign & $\begin{array}{l}\text { Average Total } \\
\text { Gaze Duration(seconds) }\end{array}$ & $\begin{array}{l}\text { Participants who } \\
\text { Exceeded Average }\end{array}$ & Total Participants \\
\hline Dangerous Goods Prohibited & 2.83 & 12 & 15 \\
\hline Directional Sign & 3.88 & 0 & 1 \\
\hline Stop & 2.01 & 0 & 4 \\
\hline Hidden Road & 2.57 & 1 & 4 \\
\hline $\begin{array}{l}\text { Trans-Canada Highway } \\
\text { Marker }\end{array}$ & 6.96 & 2 & 4 \\
\hline Overtaking Prohibited & 3.59 & 0 & 1 \\
\hline Loose Gravel & 6.29 & 1 & 3 \\
\hline Dangerous Goods Permitted & 5.12 & 9 & 15 \\
\hline Overtaking Permitted & 3.05 & 0 & 1 \\
\hline Slippery Road & 6.55 & 1 & 2 \\
\hline Caution Possible Flooding & 5.88 & 4 & 11 \\
\hline Maximum speed limit & 3.74 & 1 & 4 \\
\hline No Stopping & 3.55 & 1 & 1 \\
\hline Do not Enter & 2.42 & 0 & 3 \\
\hline
\end{tabular}

Table E.2: Average gazing time for Canadian road signs identified as unfamiliar (Highway Study) 


\begin{tabular}{|c|c|c|c|}
\hline \multicolumn{4}{|l|}{ China } \\
\hline Sign & $\begin{array}{l}\text { Average Total } \\
\text { Gaze Duration (seconds) }\end{array}$ & $\begin{array}{l}\text { Participants who } \\
\text { Exceeded Average }\end{array}$ & Total Participants \\
\hline Maximum speed limit & 2.37 & 0 & 1 \\
\hline Fork Ahead & 4.27 & 0 & 1 \\
\hline Slow Down & 5.12 & 4 & 17 \\
\hline Stop & 1.55 & 0 & 2 \\
\hline Cliff on right & 7.45 & 4 & 6 \\
\hline Double Curve & 4.84 & 0 & 1 \\
\hline Cars Permitted & 3.46 & 5 & 12 \\
\hline Watch for Children & 4.98 & 1 & 1 \\
\hline Turn out & 3.48 & 2 & 7 \\
\hline Caution Avoid Collisions & 7.19 & 5 & 5 \\
\hline $\begin{array}{l}\text { Trucks and Buses } \\
\text { keep right }\end{array}$ & 9.16 & 3 & 4 \\
\hline Rest Stop & 5.02 & 1 & 2 \\
\hline Honking Prohibited & 4.73 & 3 & 5 \\
\hline Honking Permitted & 2.90 & 3 & 6 \\
\hline Construction Ahead & 4.84 & 1 & 2 \\
\hline Bumps Ahead & 3.14 & 0 & 1 \\
\hline Slippery Road & 3.72 & 1 & 2 \\
\hline $\begin{array}{l}\text { Caution Possible } \\
\text { Flooding }\end{array}$ & 5.43 & 0 & 1 \\
\hline Stop for Inspection & 4.07 & 9 & 17 \\
\hline $\begin{array}{l}\text { Yield to oncoming } \\
\text { traffic }\end{array}$ & 4.06 & 7 & 14 \\
\hline
\end{tabular}

Table E.3: Average gazing time for Chinese road signs identified as unfamiliar (Highway Study) 


\begin{tabular}{|l|r|r|r|}
\hline Germany & \multicolumn{3}{|c|}{$\begin{array}{l}\text { Average Total } \\
\text { Gaze Duration }\end{array}$} \\
\hline Sign & 1.05 & $\begin{array}{l}\text { Participants who } \\
\text { Exceeded Average }\end{array}$ & Total Participants \\
\hline Maximum speed limit & 2.30 & 1 & 1 \\
\hline Bus Stop & 1.84 & 5 & 11 \\
\hline Roundabout & 1.26 & 1 & 1 \\
\hline Yield & 4.62 & 5 & 1 \\
\hline Stop & 1.93 & 1 & 2 \\
\hline No Parking & 2.69 & 2 & 6 \\
\hline Sharp Turn & 2.46 & 2 & 9 \\
\hline Two-way Traffic & 2.48 & 4 & 9 \\
\hline Loose Gravel & 4.92 & 7 & 15 \\
\hline No Hazardous Goods & 2.12 & 0 & 1 \\
\hline Stop no.2 & 3.64 & 0 & 1 \\
\hline Pedestrian Crossing & 0.91 & 0 & 1 \\
\hline Stop no.3 & 1.50 & 5 & 12 \\
\hline End of no Overtaking & 4.54 & 6 & 15 \\
\hline Priority Road & & & \\
\hline
\end{tabular}

Table E.4: Average gazing time for German road signs identified as unfamiliar (City Study)

\begin{tabular}{|l|r|r|r|}
\hline Canada & $\begin{array}{l}\text { Average Total } \\
\text { Gaze Duration (seconds) }\end{array}$ & $\begin{array}{l}\text { Participants who } \\
\text { Exceeded Average }\end{array}$ & Total Participants \\
\hline Maximum speed limit & 0.75 & 0 & 4 \\
\hline Stop & 0.87 & 0 & 1 \\
\hline Pedestrians Prohibited & 3.03 & 0 & 2 \\
\hline Sharp Turn & 1.96 & 0 & 1 \\
\hline Dangerous Goods & 5.20 & 8 & 1 \\
Permitted & 0.81 & 0 & 3 \\
\hline Stop no. & 4.64 & 0 & 1 \\
\hline Slippery Road & 1.01 & 0 & 1 \\
\hline Yield & 2.81 & 0 & 2 \\
\hline No Stopping & 2.61 & 0 & 8 \\
\hline Overtaking Permitted & 5.49 & 4 & 2 \\
\hline Caution possible & 3.02 & 1 & 2 \\
Flooding & 3.26 & 1 & 15 \\
\hline Hidden Road & 5.07 & 7 & \\
\hline Loose Gravel & & & \\
\hline Dangerous Goods & & & \\
Permitted & & & \\
\hline
\end{tabular}

Table E.5: Average gazing time for Canadian road signs identified as unfamiliar (City Study) 


\begin{tabular}{|l|r|r|r|}
\hline China & $\begin{array}{l}\text { Average Total } \\
\text { Gaze Duration }\end{array}$ (seconds) & $\begin{array}{l}\text { Participants who } \\
\text { Exceeded Average }\end{array}$ & Total Participants \\
\hline Maximum speed limit & 1.61 & 0 & 1 \\
\hline No Parking & 4.96 & 7 & 14 \\
\hline Yield & 2.81 & 1 & 2 \\
\hline Pedestrian Crossing & 1.77 & 0 & 1 \\
\hline Roundabout & 1.16 & 0 & 1 \\
\hline Attention for Pedestrians & 2.47 & 0 & 13 \\
\hline No Long Term Parking & 2.42 & 6 & 14 \\
\hline Overtaking Permitted & 5.22 & 6 & 4 \\
\hline Honking Prohibited & 4.30 & 2 & 10 \\
\hline Intersection Ahead & 3.75 & 6 & 7 \\
\hline Caution Avoid Collisions & 5.22 & 4 & 15 \\
\hline No Cars & 3.36 & 7 & 7 \\
\hline Caution Possible & 4.26 & 4 & 15 \\
Flooding & 5.49 & 6 & \\
\hline Stop for Inspection & & & \\
\hline
\end{tabular}

Table E.6: Average gazing time for Chinese road signs identified as unfamiliar (City Study) 


\section{Appendix F}

\section{Questionnaires}

F.1 Pre-test questionnaire 


\section{Pre-test Questionnaire}

Data from this questionnaire is stored on U.S servers and thus subject to U.S law

${ }^{*}$ Required

1. Age *

In Years

2. Sex *

Mark only one oval.

Male

Female

Prefer not to disclose

3. What is your current driving license level? *

Mark only one oval.

I don't have a license

G1,M1 (i.e., Learners permit)

G2,M2

$\bigcirc$ G,M (i.e., Full license)

$\bigcirc$ Other:

4. Do you hold or have you ever held a drivers license issued by another country? * If yes, specify the country in the text field below Mark only one oval.

$\bigcirc$ Yes

$\bigcirc$ No

5. Country:

\section{Driving Experience *}

In years 
7. Do you have experience driving a car in a foreign country? * Mark only one oval.

Yes After the last question in this section, skip to question 13.

No After the last question in this section, stop filling out this form.

8. Approximately how many hours a week do you spend driving? * Mark only one oval.

0-2 hours

3-5 hours

6-8 hours

9-11 hours

$12+$ hours

9. Select the area where you drive most often *

Mark only one oval.

Highway

City

10. When I drive, it is usually for

select the option that best applies

Check all that apply.

Commuting to work/school

Distances greater than $120 \mathrm{~km}$ (e.g. road trips)

Distances shorter than $15 \mathrm{~km}$ (e.g. running errands)

Other:

11. How often do drive outside of your regular routes? *

Mark only one oval.

Often

Sometimes

Seldom

$\Longrightarrow$ Never

12. Have you ever had any at-fault car accidents? *

Mark only one oval.

Yes

No

Prefer not to answer 


\section{Pre-test Questionnaire Part 2}

13. List the country/countries where you have previously driven *

Powered by

E Google Forms 


\section{F.2 Post-test questionnaire}

\section{F.2.1 Highway Study}




\section{Post-test Questionnaire}

Data from this questionnaire is stored on U.S servers and thus subject to U.S law

* Required

\section{Section 1}

Reflection questions

1. Rate the tracks in terms of difficulty *

Mark only one oval per row.

Hard Moderate Easy
Canadian Track
Chinese Track

2. Select the languages you are fluent in *

Check all that apply.

$\square$ English

- German

Chinese

$\square$ None of the above

\section{German Track}

3. How distracting were the German road signs? *

Did it take focus away from driving

Mark only one oval.




4. If you found the German road signs distracting, please explain how/why

5. For the German track, rate your ability to... *

Mark only one oval per row.

Obey posted speed signs
Stay in your lane

Some of these road signs may have been present during the track you drove. Please explain the meaning of each of the road signs presented.

1)

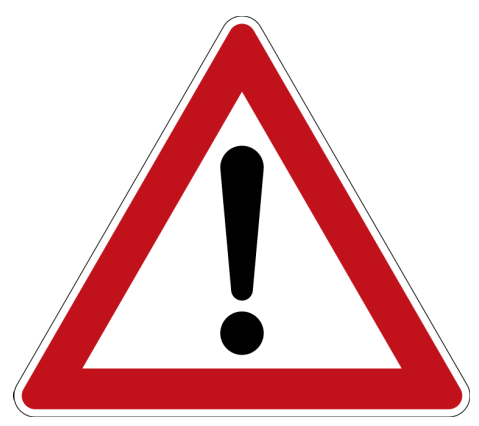

6. 1b) Appeared on German track? *

Mark only one oval.

Yes

No

I don't know

7. 1c) Rule conveyed by German road sign * 
2)

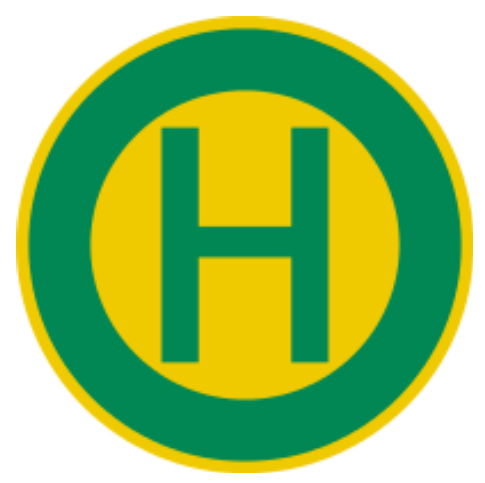

8. 2b) Appeared on German track? *

Mark only one oval.

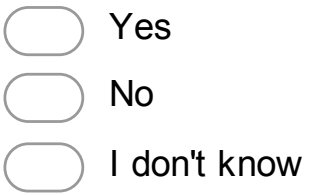

9. 2c) Rule conveyed by German road sign *

3)

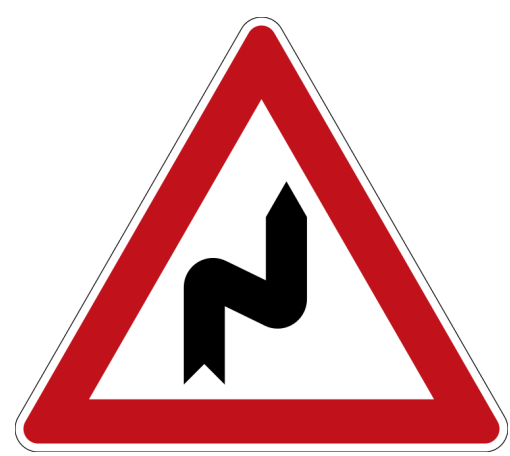

10. 3b) Appeared on German track? *

Mark only one oval.

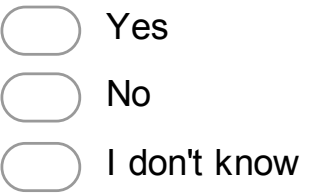


11. 3c) Rule conveyed by German road sign *

4)

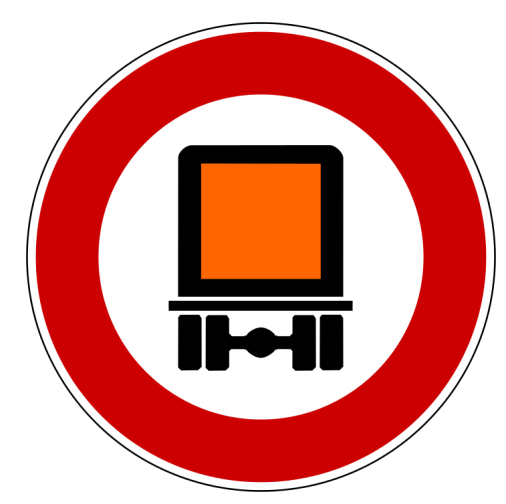

12. 4b) Appeared on German track? *

Mark only one oval.

$C_{\text {No }}$ Yes
I don't know

13. 4c) Rule conveyed by German road sign *

5)




14. 5b) Appeared on German track? *

Mark only one oval.

Yes No
I don't know

15. 5c) Rule conveyed by German road sign *

\section{Canadian Track}

16. How distracting were the Canadian road signs? *

Did it take focus away from driving

Mark only one oval.

$\begin{array}{lllll}1 & 2 & 3 & 4 & 5\end{array}$

Not Distracting $\square \longrightarrow \square$ Very Distracting

17. If you found the Canadian road signs distracting, please explain how/why

18. For the Canadian track, rate your ability to... *

Mark only one oval per row.

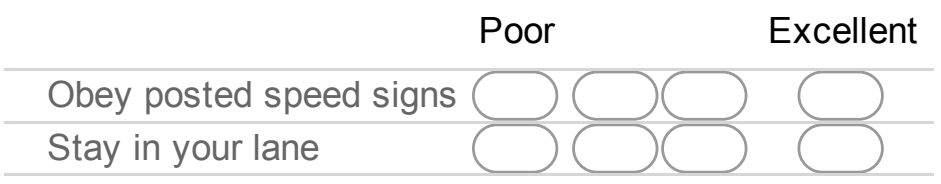

Some of these road signs may have been present during the track you drove. Please explain the meaning of each of the road signs presented. 
6)

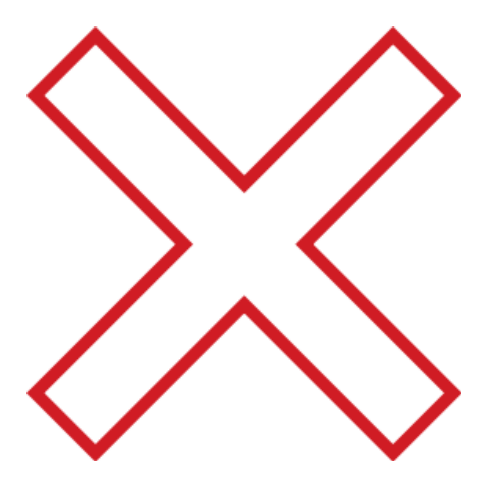

19. 6b) Appeared on Canadian track? *

Mark only one oval.

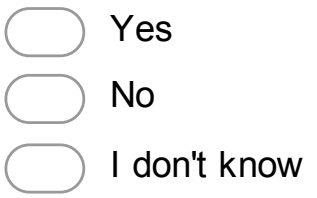

20. 6c) Rule conveyed by Canadian road sign *

7)



21. 7b) Appeared on Canadian track? *

Mark only one oval.
Yes
$\int \mathrm{No}$
I don't know 
22. 7c) Rule conveyed by Canadian road sign *

8)

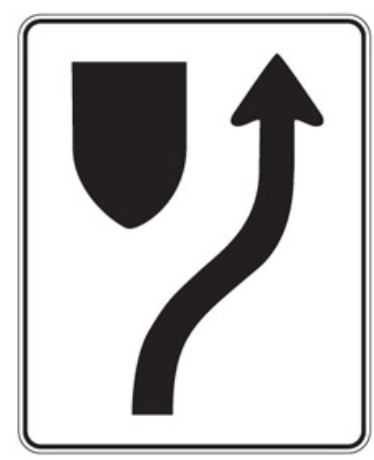

23. 8b) Appeared on Canadian track? *

Mark only one oval.

Yes

No

I don't know

24. 8c) Rule conveyed by Canadian road sign *

9) 


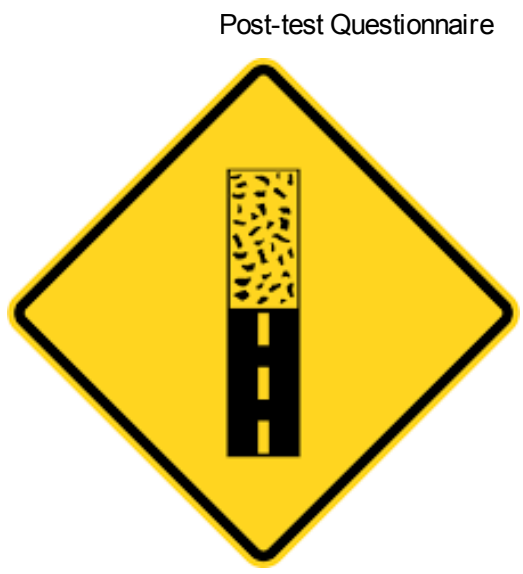

25. 9b) Appeared on Canadian track? *

Mark only one oval.

Yes $^{\mathrm{No}}$
$\mathrm{I}_{\mathrm{I}}$ don't know

26. 9c) Rule conveyed by Canadian road sign *

10)

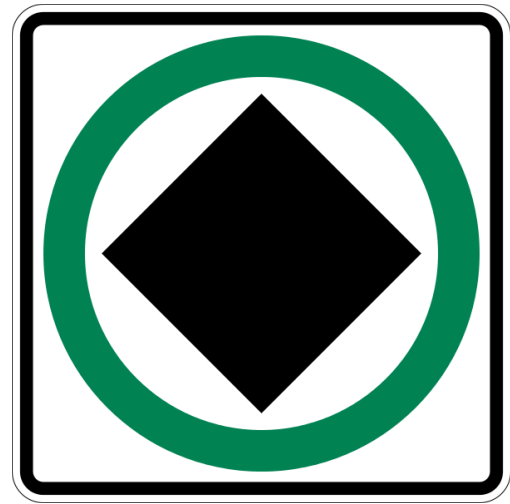

27. 10b) Appeared on Canadian track? *

Mark only one oval.

Yes No
$\square$ I don't know


28. 10c) Rule conveyed by Canadian road sign *

\section{Chinese Track}

29. How distracting were the Chinese road signs? *

Did it take focus away from driving

Mark only one oval.

$\begin{array}{lllll}1 & 2 & 3 & 4 & 5\end{array}$

Not Distracting

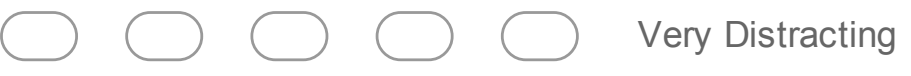

30. If you found the Chinese road signs distracting, please explain how/why

31. For the Chinese track, rate your ability to... *

Mark only one oval per row.

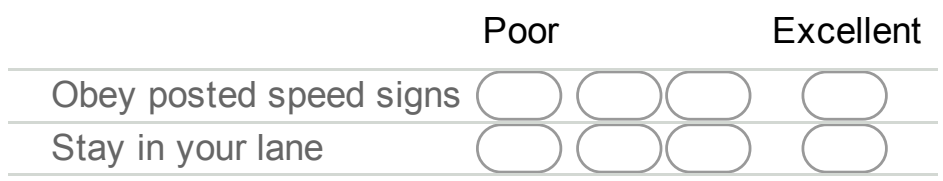

Some of these road signs may have been present during the track you drove. Please explain the meaning of each of the road signs presented.

\section{1)}




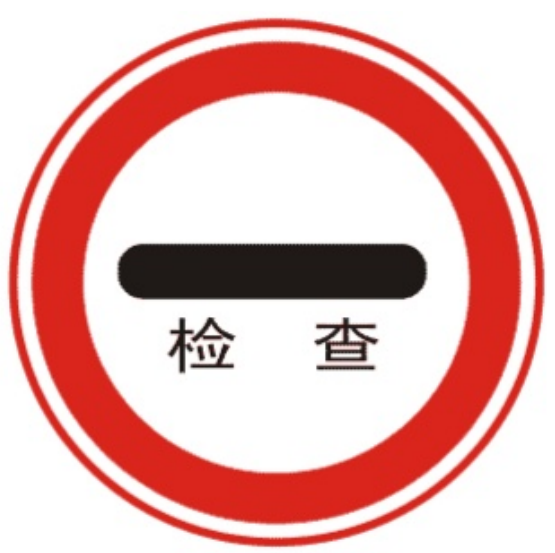

32. 11b) Appeared on Chinese track? *

Mark only one oval.

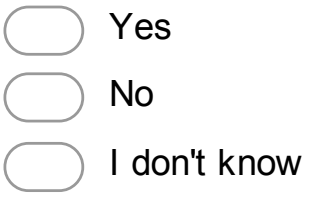

33. 11c) Rule conveyed by Chinese road sign *

12)



34. 12b) Appeared on Chinese track? *

Mark only one oval.

Yes

$\bigcirc$ No

I don't know 
35. 12c) Rule conveyed by Chinese road sign *

13)

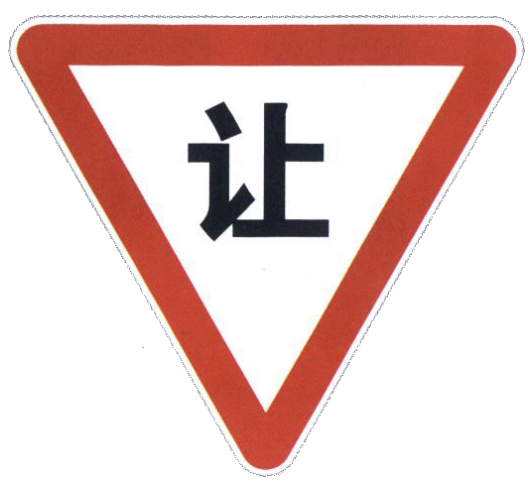

36. 13b) Appeared on Chinese track? *

Mark only one oval.

$\bigcirc$ Yes

No

I don't know

37. 13c) Rule conveyed by Chinese road sign *

14)

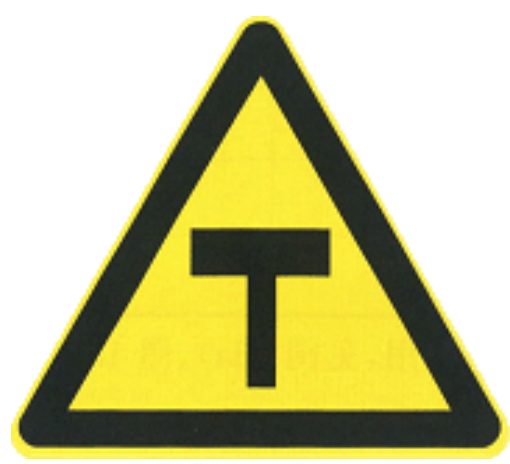


38. 14b) Appeared on Chinese track? *

Mark only one oval.
Yes
No
$\bigcirc$ I don't know

39. 14c) Rule conveyed by Chinese road sign *

15)

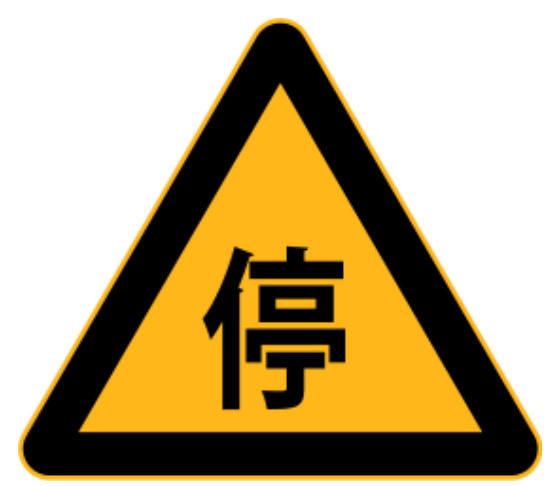

40. 15b) Appeared on Chinese track? *

Mark only one oval.
$\bigcirc$ Yes
No
$\bigcirc$ I don't know

41. 15c) Rule conveyed by Chinese road sign *

\section{Section 3}




\section{Additional comments/feedback}

Please provide any additional comments about the driving simulator, road signs, study session etc.

Powered by

\# Google Forms 


\section{F.2.2 City Study}




\section{Post-test Questionnaire}

Data from this questionnaire is stored on U.S servers and thus subject to U.S law

* Required

\section{Section 1}

Reflection questions

1. Rate the tracks in terms of difficulty *

Mark only one oval per row.

Hard Moderate Easy
Canadian Track
Chinese Track

2. Select the languages you are fluent in *

Check all that apply.

$\square$ English

- German

Chinese

$\square$ None of the above

\section{German Track}

3. How distracting were the German road signs? *

Did it take focus away from driving

Mark only one oval.

$\begin{array}{llllll} & 1 & 2 & 3 & 4 & 5 \\ \text { Not Distracting } & \longrightarrow & \longrightarrow & \end{array}$


4. If you found the German road signs distracting, please explain how/why

5. For the German track, rate your ability to... *

Mark only one oval per row.

\section{Poor Fair Good Excellent}

Obey posted speed signs
Stay in your lane

Some of these road signs may have been present during the track you drove. Please explain the meaning of each of the road signs presented.

1)

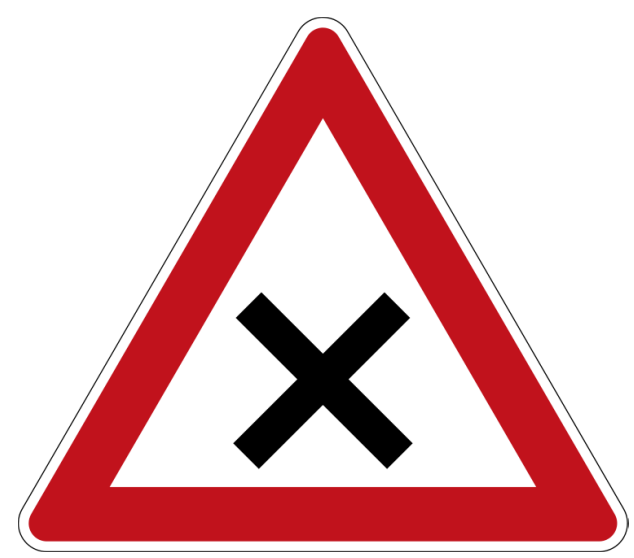

6. 1b) Appeared on German track? *

Mark only one oval.

Yes

$\bigcirc$ No

I don't know 
7. 1c) Rule conveyed by German road sign *

2)



8. 2b) Appeared on German track? *

Mark only one oval.
Yes
$\Longrightarrow$ No
$\bigcirc$ I don't know

9. 2c) Rule conveyed by German road sign *

3)

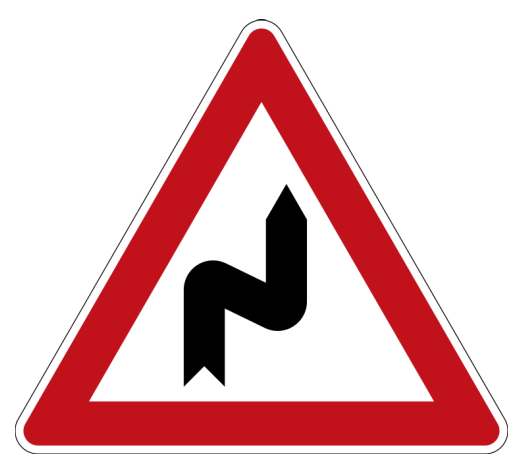


10. 3b) Appeared on German track? *

Mark only one oval.

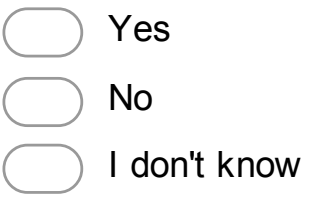

11. 3c) Rule conveyed by German road sign *

4)

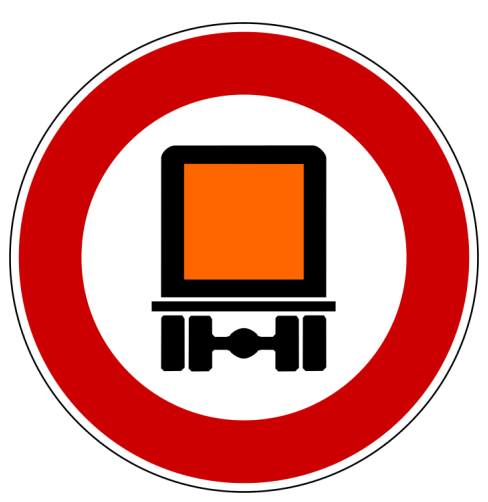

12. 4b) Appeared on German track? *

Mark only one oval.

$\square_{\text {Nes }}$
I don't know

13. 4c) Rule conveyed by German road sign *

5) 


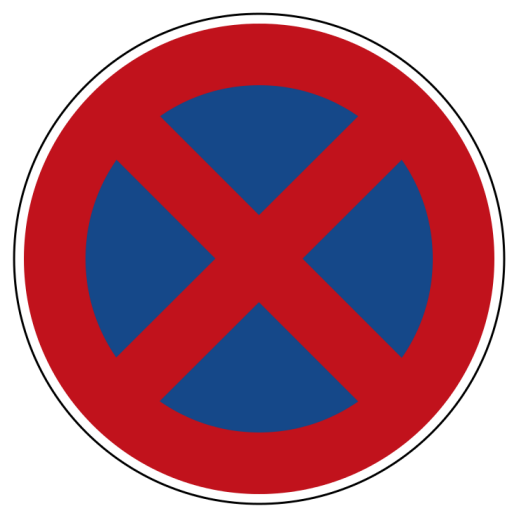

14. 5b) Appeared on German track? *

Mark only one oval.
Yes
No
I don't know

15. 5c) Rule conveyed by German road sign *

\section{Canadian Track}

16. How distracting were the Canadian road signs? *

Did it take focus away from driving

Mark only one oval.

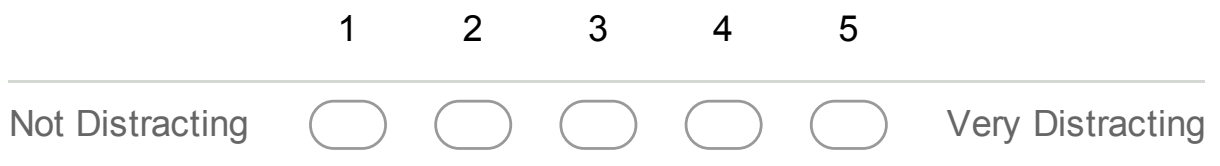

17. If you found the Canadian road signs distracting, please explain how/why 
18. For the Canadian track, rate your ability to... *

Mark only one oval per row.

\section{Poor Fair Good Excellent}

Obey posted speed signs

Stay in your lane

Some of these road signs may have been present during the track you drove. Please explain the meaning of each of the road signs presented.

6)

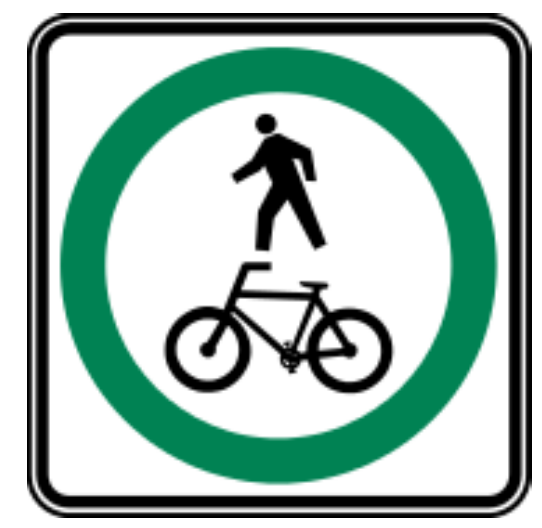

19. 6b) Appeared on Canadian track? *

Mark only one oval.
$\bigcirc$ Yes
No
I don't know

20. 6c) Rule conveyed by Canadian road sign *

7) 


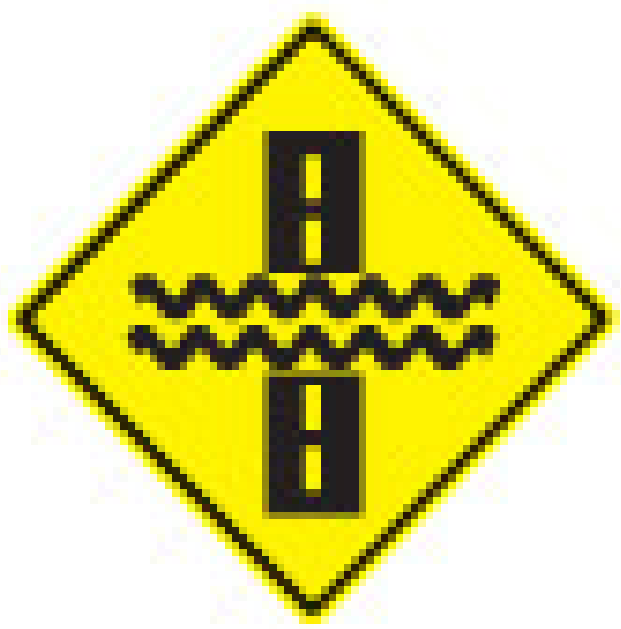

21. 7b) Appeared on Canadian track? *

Mark only one oval.

Yes No
$\square_{\text {I don't know }}$

22. 7c) Rule conveyed by Canadian road sign *

8)

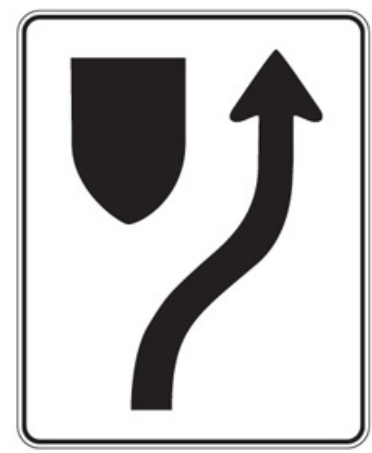


23. 8b) Appeared on Canadian track? *

Mark only one oval.

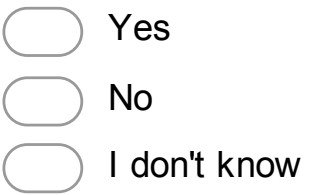

24. 8c) Rule conveyed by Canadian road sign *

9)

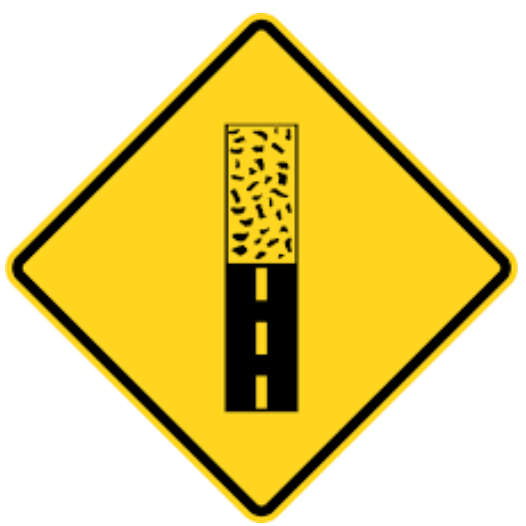

25. 9b) Appeared on Canadian track? *

Mark only one oval.

Yes
No
I don't know

26. 9c) Rule conveyed by Canadian road sign *

10) 


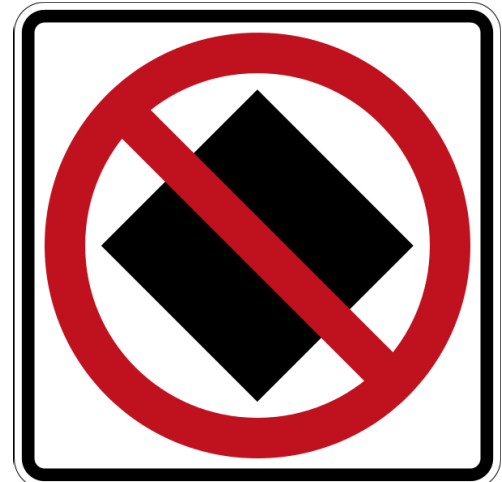

27. 10b) Appeared on Canadian track? *

Mark only one oval.

Yes

No

I don't know

28. 10c) Rule conveyed by Canadian road sign *

\section{Chinese Track}

29. How distracting were the Chinese road signs? *

Did it take focus away from driving

Mark only one oval.

$\begin{array}{lllll} & 1 & 2 & 3 & 4\end{array}$

30. If you found the Chinese road signs distracting, please explain how/why 
31. For the Chinese track, rate your ability to... *

Mark only one oval per row.

\section{Poor Fair Good Excellent}

Obey posted speed signs
Stay in your lane

Some of these road signs may have been present during the track you drove. Please explain the meaning of each of the road signs presented.

\section{1)}

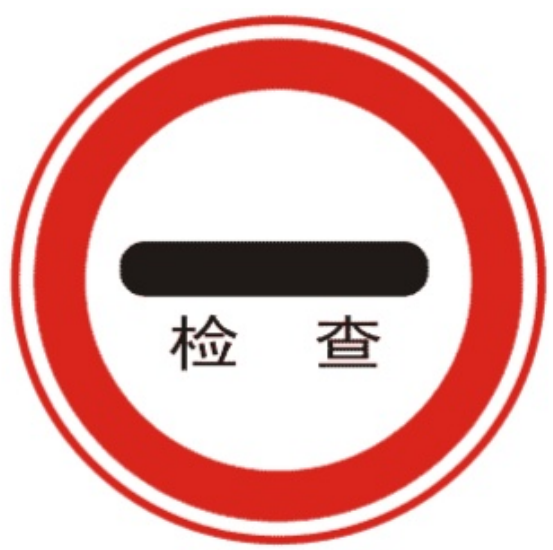

32. 11b) Appeared on Chinese track? *

Mark only one oval.
Yes
No
I don't know

33. 11c) Rule conveyed by Chinese road sign *

12) 


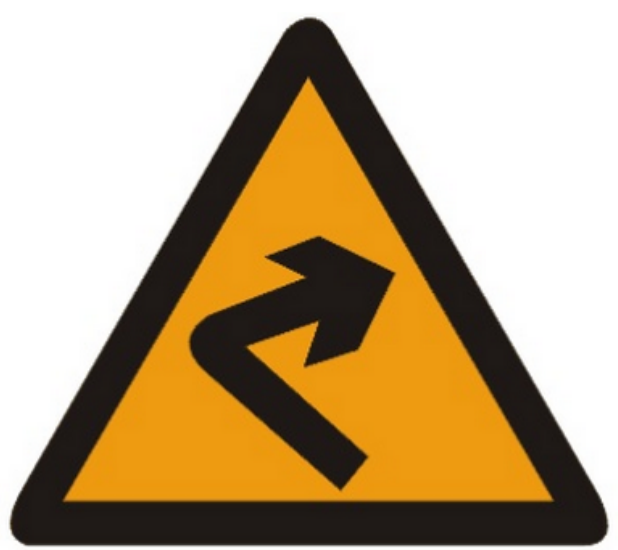

34. 12b) Appeared on Chinese track? *

Mark only one oval.

Yes No
I don't know

35. 12c) Rule conveyed by Chinese road sign *

13)

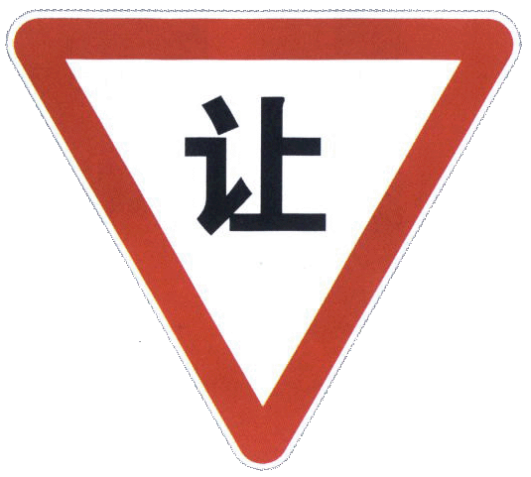

36. 13b) Appeared on Chinese track? *

Mark only one oval.
Yes
No
I don't know 
$7 / 14 / 2015$

Post-test Questionnaire

37. 13c) Rule conveyed by Chinese road sign *

14)

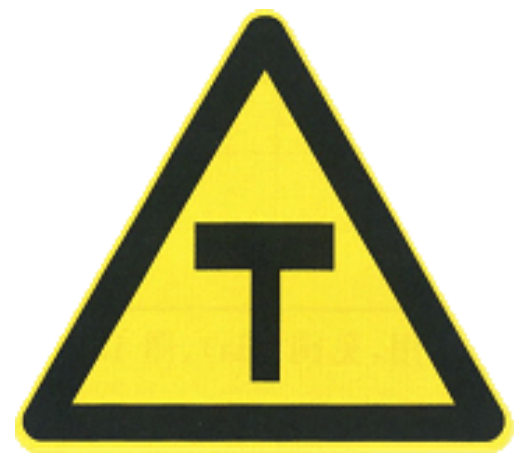

38. 14b) Appeared on Chinese track? *

Mark only one oval.

Yes

No

I don't know

39. 14c) Rule conveyed by Chinese road sign *

15)

https://docs.google.com/forms/d/17S7ZegYrfMVMZcHe-IJppswVLOtEP1CtajtrNEVJ7us/printform

$12 / 13$ 


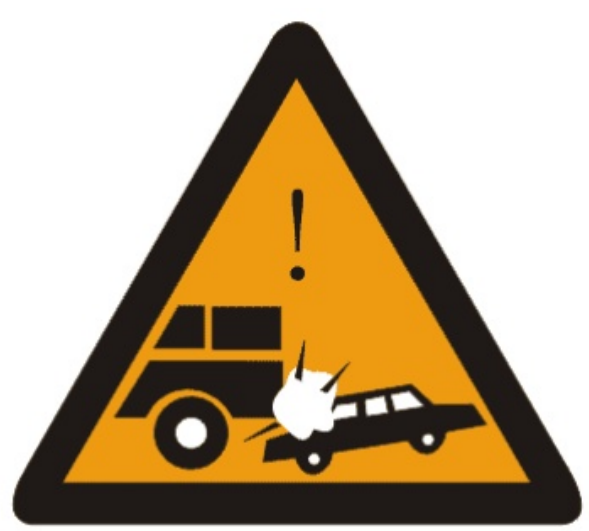

40. 15b) Appeared on Chinese track? *

Mark only one oval.

Yes $^{\text {No }}$
I I don't know $^{2}$

41. 15c) Rule conveyed by Chinese road sign *

\section{Section 3}

\section{Additional comments/feedback}

Please provide any additional comments about the driving simulator, road signs, study session etc.

Powered by

\# Google Forms 